Aus dem Institut für Auditorische Neurowissenschaften

(Prof. Dr. med. T. Moser)

der Medizinischen Fakultät der Universität Göttingen

\title{
Hörphysiologische Charakterisierung zweier Mausmodelle mit Schwerhörigkeit
}

\author{
INAUGURAL-DISSERTATION \\ zur Erlangung des Doktorgrades \\ der Medizinischen Fakultät der \\ Georg-August-Universität zu Göttingen \\ vorgelegt von \\ Anna Ihler, geb. Gehrt \\ aus \\ Göttingen
}

Göttingen 2020 
Dekan:

Referent:

Ko-Referent:

Drittreferent/in:

Datum der mündlichen Prüfung:
Prof. Dr. med. W. Brück

Prof. Dr. med. T. Moser

Prof. Dr. S. Rizzoli, Ph.D.

17.11.2021 
Hiermit erkläre ich, die Dissertation mit dem Titel „Hörphysiologische Charakterisierung zweier Mausmodelle mit Schwerhörigkeit" eigenständig angefertigt und keine anderen als die von mir angegebenen Quellen und Hilfsmittel verwendet zu haben.

Göttingen, den

(Unterschrift) 
Die Daten, auf denen die vorliegende Arbeit basiert, wurden teilweise publiziert:

Neef J, Gehrt A, Bulankina AV, Meyer AC, Riedel D, Gregg RG, Strenzke N, Moser T (2009): The $\mathrm{Ca} 2+$ channel subunit beta2 regulates $\mathrm{Ca} 2+$ channel abundance and function in inner hair cells and is required for hearing. J Neurosci 29, 10730-10740

Schütz M, Auth T, Gehrt A, Bosen F, Körber I, Strenzke N, Moser T, Willecke K (2011): The connexin26 S17F mouse mutant represents a model for the human hereditary keratitis-ichthyosis-deafness syndrome. Hum Mol Genet 20, 28-39 


\section{Inhaltsverzeichnis}

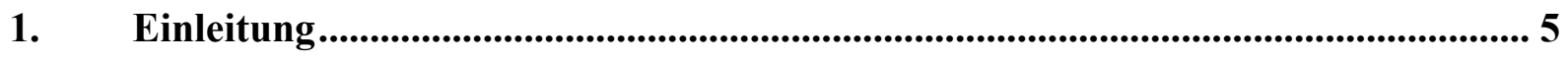

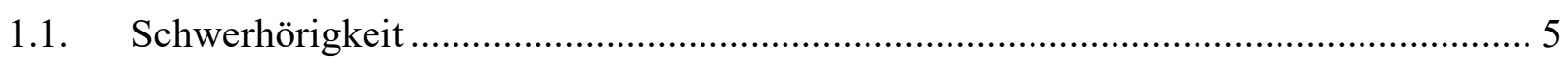

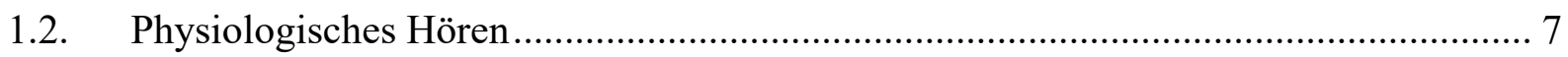

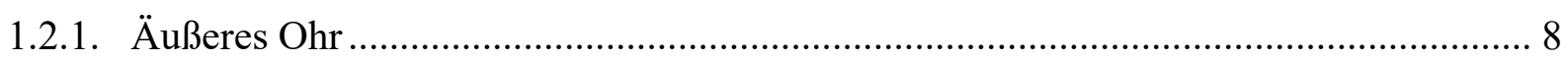

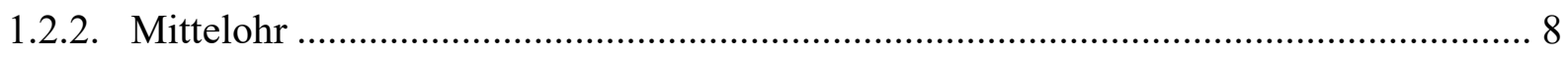

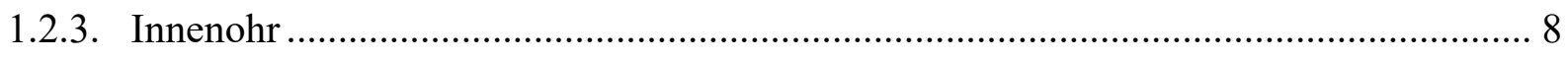

1.3. Das endocochleäre Potenzial und die Stria vascularis ............................................. 12

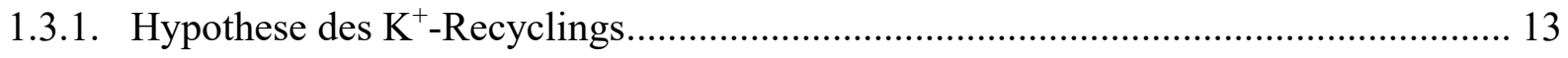

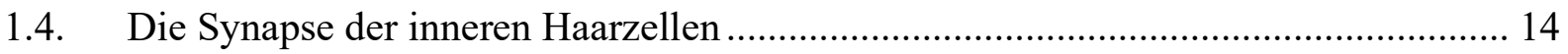

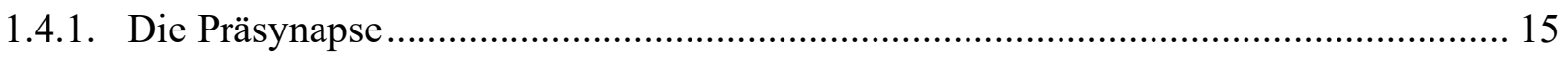

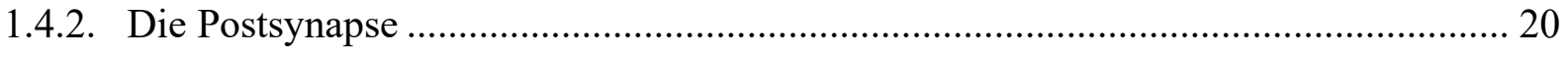

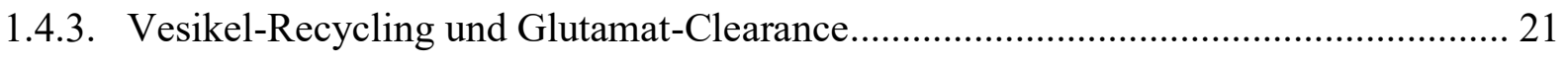

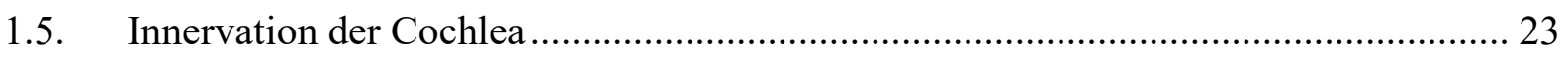

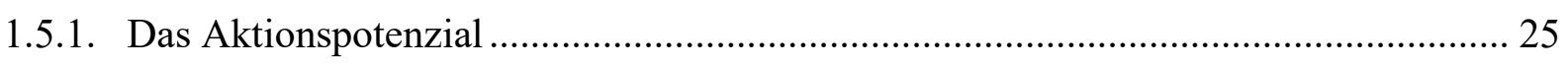



1.6. Interzelluläre Kommunikation in der Cochlea und Connexin26 ............................... 28

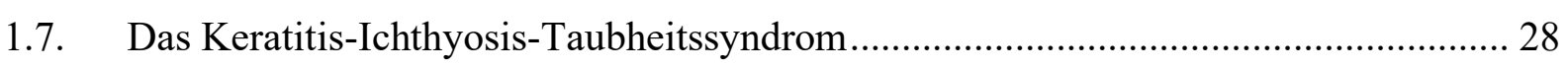

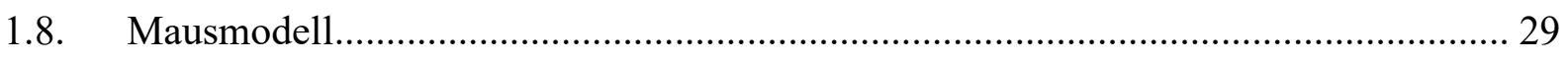

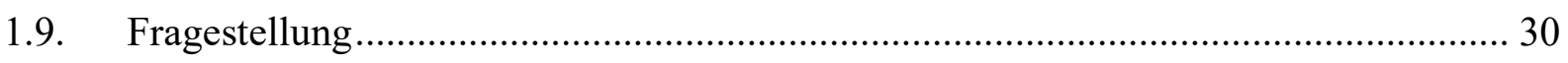

2. Material und Methoden................................................................................ 31

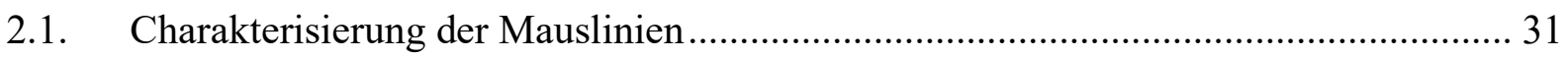

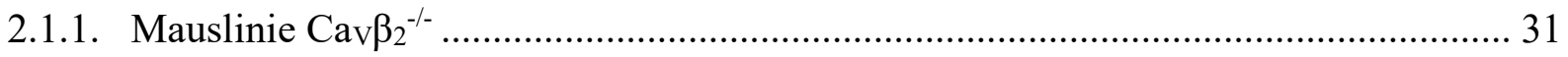

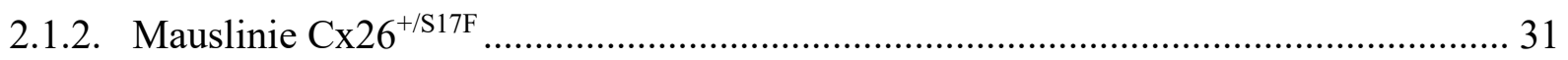

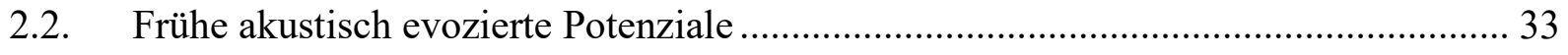

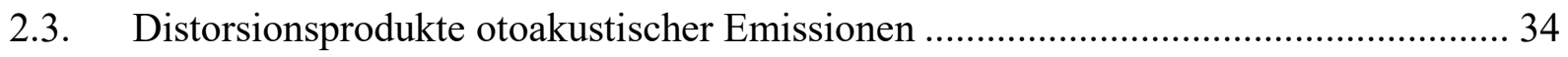

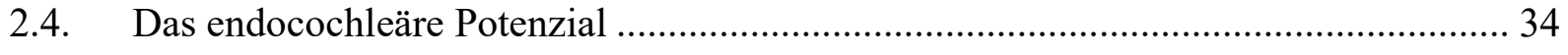

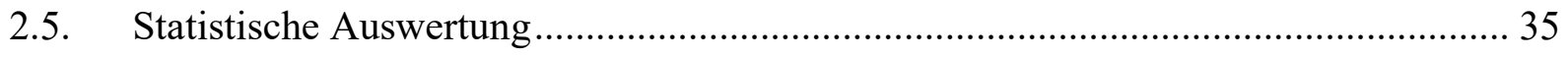

2.6. Extrazelluläre Mikroelektroden-Ableitungen von einzelnen Hörnervenfasern ............ 35

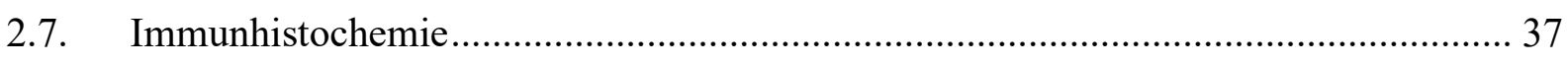

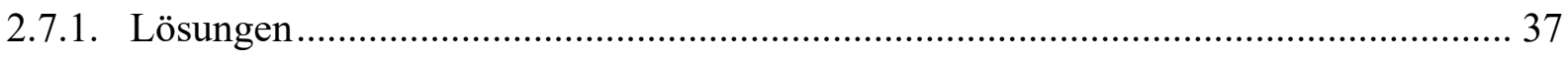

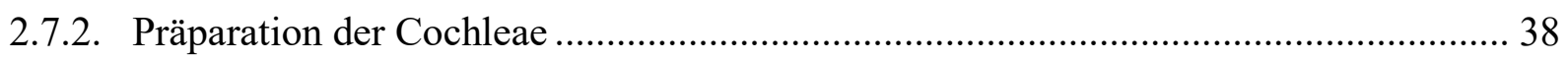

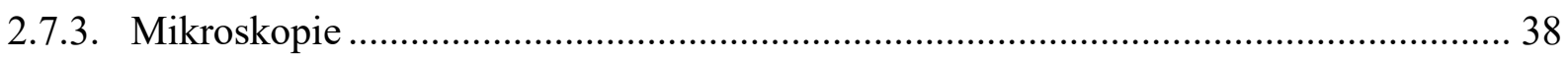




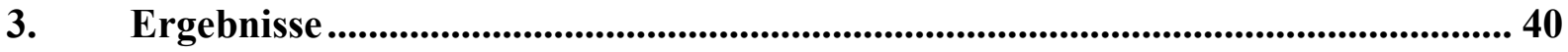

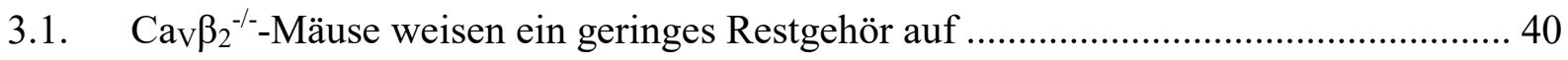

3.1.1. Frühe akustisch evozierte Potenziale und DPOAE ................................................ 40

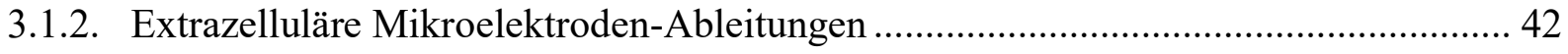

3.1.3. Die Immunhistochemie zeigt keine Auffälligkeiten .............................................. 52

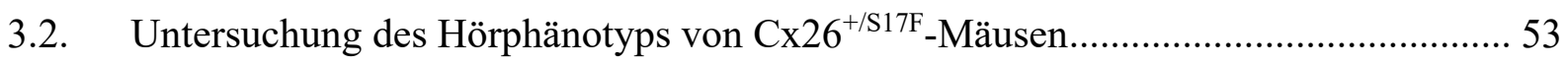

3.2.1. Die Funktion der äußeren Haarzellen ist erloschen ................................................ 53

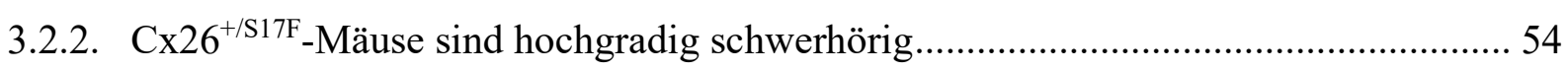

3.2.3. Das endocochleäre Potenzial ist reduziert und korreliert mit der Hörschwelle........... 55

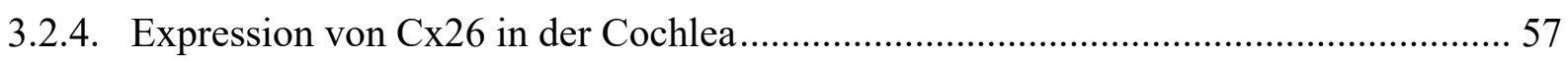

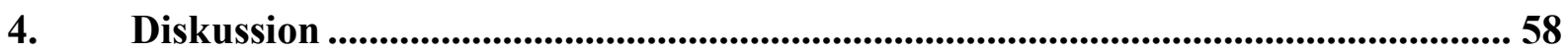

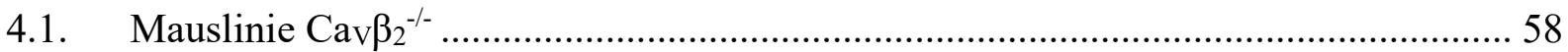

4.1.1. Warum zeigt die Immunohistochemie keine Zelldegeneration? ................................. 59

4.1.2. Haben die hohen Stimulationspegel einen Einfluss auf die Messergebnisse?............ 61

4.1.3. Warum sind die Aktionspotenzialraten $\operatorname{der} \mathrm{Cav}_{v} \beta_{2}^{-/-}$-Spiralganglionneurone niedrig? 63

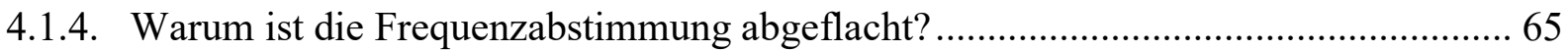

4.1.5. Wieso erscheint der dynamische Bereich der Schallkodierung breit? ........................ 67

4.1.6. Wie kann die Reduktion der Aktionspotenzialraten erklärt werden? ......................... 68

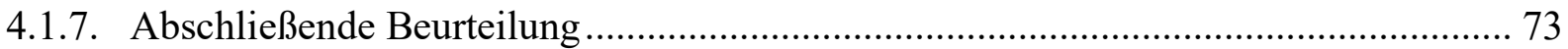

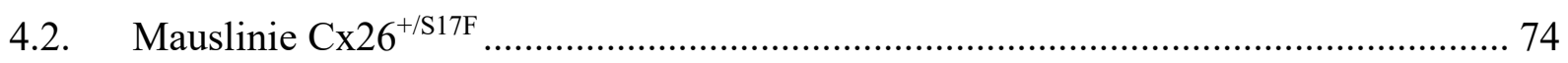

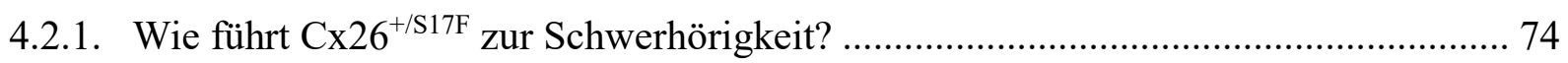

4.2.2. Welchen Effekt hat die Mutation Cx26S17F auf zellulärer Ebene? .......................... 76

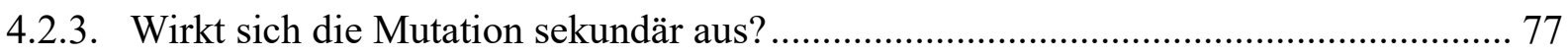

4.2.4. Kann die Dysfunktion von Cx26S17F teilkompensiert werden? ............................... 78

4.2.5. Wie wirkt sich der genetische Maushintergrund aus? .............................................. 79

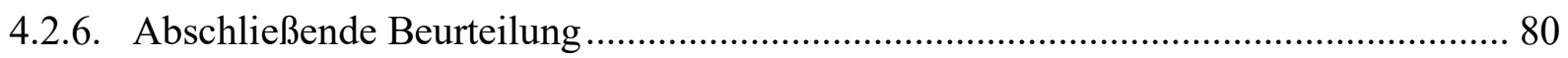

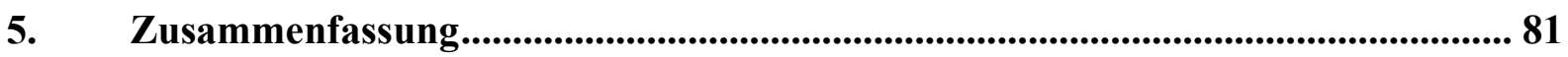

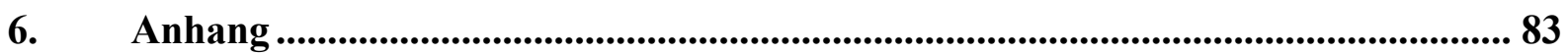

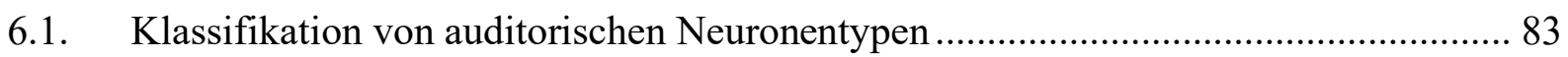

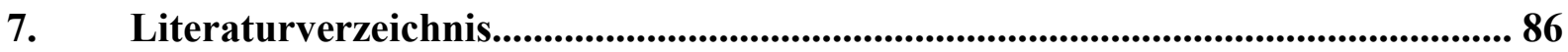




\section{Abkürzungen}

\begin{tabular}{|c|c|}
\hline ÄHZ & äußere Haarzelle(n) \\
\hline AMPA & $\alpha$-Amino-3-hydroxy-5-methyl-4-isoxazol-Propionsäure \\
\hline AP & Aktionspotenzial(e) \\
\hline ATP & Adenosintriphosphat \\
\hline BDNF & brain derived neurotrophic factor \\
\hline $\mathrm{CaBP}$ & Calciumbindende(s) Protein(e) \\
\hline CDI & $\mathrm{Ca}^{2+}$-dependend inactivation $\left(\mathrm{Ca}^{2+}\right.$-abhängige Inaktivierung) \\
\hline $\mathrm{CF}$ & charakteristische Frequenz(en) \\
\hline cAMP & cyclisches Adenosinmonophosphat \\
\hline cGMP & cyclisches Guanosinmonophosphat \\
\hline C-Terminus & Carboxyl-Terminus \\
\hline $\mathrm{Cx}$ & Connexin \\
\hline DPOAE & Distorsionsprodukt otoakustischer Emissionen \\
\hline EDTA & Ethylendiamintetraacetat \\
\hline EP & endocochleäres Potenzial \\
\hline EPSP & exzitatorisches postsynaptisches Potenzial \\
\hline FA & Formaldehyd \\
\hline FAEP & frühe akustisch evozierte Potenziale / Hirnstammaudiometrie \\
\hline G-Protein & Guaninnucleotid-bindendes Protein \\
\hline GSDB & goat serum dilution buffer (Ziegenserumverdünnungspuffer) \\
\hline GTP & Guanosintriphosphat \\
\hline HEK-Zellen & human embryonic kidney-Zellen \\
\hline IHZ & innere Haarzelle(n) \\
\hline $\mathrm{IP}_{3}$ & Inositoltrisphosphat \\
\hline IPSP & inhibitorisches postsynaptisches Potenzial \\
\hline KCNQ1/KCNE1 & für $\alpha$-/ $\beta$-Untereinheit des Kaliumkanals kodierendes Gen \\
\hline KIT & Keratitis-Ichthyosis-Taubheitssyndrom \\
\hline MAP-Kinase & mitogen-activated protein-Kinase \\
\hline mRNA & messenger RNA (Boten-Ribonukleinsäure) \\
\hline NMDA & N-Methyl-D-Asparaginsäure \\
\hline NT-3 & Neutrophin 3 \\
\hline N-Terminus & Amino-Terminus \\
\hline
\end{tabular}




\begin{tabular}{|l|l|}
\hline PB & phosphate buffer (Phosphatpuffer) \\
\hline PBS & phosphate buffered saline \\
\hline PST & $\begin{array}{l}\text { post-stimulus-time-histogram } \\
\text { Post-Stimulus-Zeit-Histogramm(e)) }\end{array}$ \\
\hline RLF & rate-level-function (Raten-Pegel-Funktion) \\
\hline SGN & Spiralganglionneuron(e) \\
\hline SH3 & Src homology 3 \\
\hline SPL [dB] & sound pressure level (Schalldruckpegel in Dezibel) \\
\hline SR & Spontanaktivitätsrate(n) \\
\hline VDI & spannungsabhängige Inaktivierung \\
\hline
\end{tabular}




\section{Einleitung}

\subsection{Schwerhörigkeit}

Der Begriff Schwerhörigkeit bezeichnet eine Minderung des Hörvermögens, wobei diese von einer leichten Beeinträchtigung bis hin zur Gehörlosigkeit reichen kann. Eine eindeutige Definition existiert nicht. Nach den Kriterien der World Health Organization (WHO) liegt bei Erwachsenen eine Schwerhörigkeit vor, wenn auf dem besser hörenden Ohr bei den Frequenzen 0,5, 1, 2 und $4 \mathrm{kHz}$ im Mittel ein Hörverlust von mindestens $26 \mathrm{~dB}$ besteht (Tabelle 1.1-1 Stadieneinteilung der Schwerhörigkeit).

\begin{tabular}{|lcc}
$\begin{array}{c}\text { Grad der } \\
\text { Schwerhörigkeit }\end{array}$ & $\begin{array}{c}\text { Hörschwelle [dB] } \\
\text { WHO 2001 }\end{array}$ & $\begin{array}{c}\text { Hörschwelle [dB] } \\
\text { Europ. Kommission 1996 }\end{array}$ \\
\hline leichtgradig & $26-40$ & $21-39$ \\
mittelgradig & $41-60$ & $40-69$ \\
hochgradig & $61-80$ & $70-94$ \\
profund inkl. Taubheit & $>80$ & $>94$
\end{tabular}

Tabelle 1.1-1 Stadieneinteilung der Schwerhörigkeit

Hörschwelle $[\mathrm{dB}]$ im Tonaudiogramm gemittelt bei $0,5,1,2$ und $4 \mathrm{kHz}$

Nach dieser Definition sind etwa $17 \%$ der deutschen Bevölkerung betroffen (Heger und Holube 2010; von Gablenz und Holube 2015). Ursächlich können Umwelteinflüsse wie Lärm, Infektionen, Traumata oder genetische Defekte sein. Beeinträchtigungen des Hörens sind weitverbreitet und treten in allen Altersgruppen auf. Schätzungen gehen weltweit von $5 \%$ Betroffenen aus, was etwa 360 Millionen Menschen entspricht (328 Millionen Erwachsene und 32 Millionen Kinder) (WHO 2012). Für die Betroffenen ergeben sich Probleme in der Kommunikation mit ihrem Umfeld, was bis zur sozialen Isolation führen kann. Bereits Kinder mit geringem Hörverlust zeigen eine gestörte Sprachentwicklung und schlechtere schulische Leistungen (Bess et al. 1998; Walker et al. 2015), wenn das Hörvermögen nicht ausreichend rehabilitiert wird.

Generell werden Schallleitungs- von Schallempfindungsstörungen (sensorineurale Schwerhörigkeit) unterschieden. Diese Arbeit beschäftigt sich mit Schall- 
empfindungsschwerhörigkeiten, also Störungen innerhalb der Cochlea oder der nachgeschalteten verarbeitenden Zentren. Am häufigsten ist hierbei die Funktion der äußeren Haarzellen betroffen, was bei vollständigem Ausfall einen Verlust der nichtlinearen Verstärkung mit Hörschwellenanhebung um $50 \mathrm{~dB}$ (Ryan und Dallos 1975), eine Einschränkung der Frequenzselektivität und das Recruitmentphänomen (stärkere Zunahme der Lautheitsempfindung mit steigendem Schalldruck) zur Folge hat.

Etwa eines von 1000 Kindern leidet an einer kongenitalen bilateralen Schwerhörigkeit, die in etwa $60 \%$ der Fälle genetischen Ursprungs, also hereditär, ist (Abbildung 1.1-2) (Gross et al. 2000; Leitlinie Periphere Hörstörungen im Kindesalter 2013).

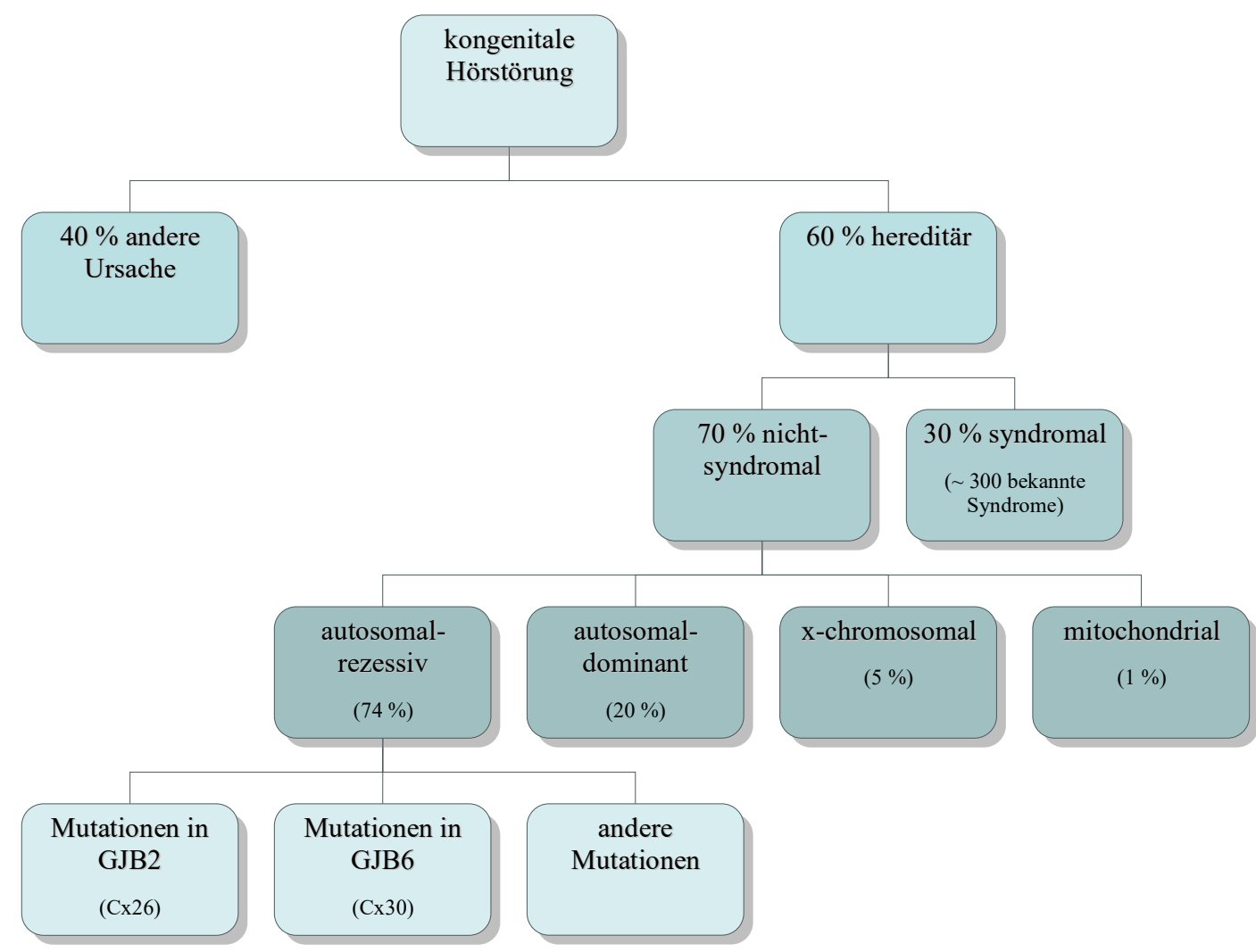

Abbildung 1.1-2 Ätiologie der kongenitalen Schwerhörigkeit (Auszug)

Unter den hereditären Hörstörungen tritt ca. ein Drittel mit begleitenden Symptomen anderer Organsysteme in Form eines Syndroms auf. Die Ursachen der nichtsyndromalen Schwerhörigkeiten weisen eine ausgeprägte Heterogenität auf. Sie werden anhand ihres Vererbungsmusters klassifiziert (Kemperman et al. 2002). Zum Großteil folgen sie einem autosomal rezessiven Erbgang und werden häufig durch Mutationen im GJB2- und GJB6-Gen bedingt (Birkenhäger et al. 
2007). Diese Gene kodieren für die Transmembranproteine Connexin 26 und 30 (Cx26 und -30). Mutationen führen zu Störungen der interzellulären Kommunikation innerhalb der Cochlea.

Trotz der Heterogenität der Schwerhörigkeit-verursachenden Mutationen ist die häufigste Ursache der prälingualen nichtsyndromalen Hörstörungen eine Mutation im GJB2-Gen. Mutationen von GJB2 führen zu syndromaler (25\%) und nicht syndromaler (75\%) Schwerhörigkeit mit rezessivem oder dominantem Erbgang (van Camp und Smith 2017). Damit sind GJB2-Defekte für die Hörforschung von besonderem Interesse.

\subsection{Physiologisches Hören}

Die auditorische Empfindung beschreibt die Sinneswahrnehmung von Schall. Als Schall wird eine mechanische Welle in einem elastischen Medium wie Luft oder Wasser bezeichnet. Der adäquate Reiz für das Hörorgan sind Schallwellen. Diese können in Frequenz und Schalldruck variieren. Der Schalldruck (in Pascal [Pa]) ist die Druckschwankung über dem statischen Luftdruck, die bei der mechanischen Deformation des elastischen Mediums entsteht. Sie kann das SäugetierTrommelfell in Schwingung versetzen und einen Höreindruck vermitteln. Zur Beschreibung der Schallintensität wird der Schalldruckpegel (in Dezibel [dB]) herangezogen. Er stellt ein logarithmisches Verhältnis des gemessenen Schalldrucks zum willkürlich festgelegten Bezugsschalldruck von $2 \times 10^{-5} \mathrm{~Pa}$ dar. Dieses Maß bietet zwei Vorteile: Zum einen setzt es den physikalischen Schalldruck mit der subjektiven Wahrnehmung in Beziehung (Weber-FechnerGesetz), zum anderen dient es dem leichteren Umgang mit den im Vergleich zum statischen Luftdruck um viele Größenordnungen kleineren Schalldrücken, die das Ohr verarbeiten kann. Die Hörschwelle bildet die untere Begrenzung des Hörfeldes. Sie bezeichnet den Schalldruckpegel, der gerade noch wahrnehmbar ist und kann, abhängig von der Frequenz des Stimulus, bei bis zu -5 dB liegen. Nach oben wird das Hörfeld durch die akustische Schmerzschwelle, die zwischen 120 und $140 \mathrm{~dB}$ liegt, limitiert. Das Hörfeld des Menschen umfasst einen Frequenzbereich von $20 \mathrm{~Hz}$ bis etwa $16 \mathrm{kHz}$ (Silbernagl und Klinke 2003). 


\subsection{1. Äußeres Ohr}

Zum äußeren Ohr gehören die Ohrmuschel, der Gehörgang und die Oberfläche des am Ende des Gehörgangs liegenden Trommelfells (Membrana tympani). Das äußere Ohr dient neben der Weiterleitung von Schall dem Schutz des im Knochen liegenden Mittel- und Innenohrs. Die Ohrmuschel reflektiert und verstärkt frequenzspezifisch Schallwellen. Da ihre charakteristische Form je nach Richtung des einfallenden Schalls unterschiedliche Reflektionsmuster bedingt, spielt sie eine Rolle bei der Schallquellenlokalisation.

\subsubsection{Mittelohr}

Schallwellen treffen am Ende des äußeren Gehörgangs auf das Trommelfell und versetzten es damit in Schwingung. Die Gehörknöchelchen (Ossikel), Hammer (Malleus), Amboss (Incus) und Steigbügel (Stapes) bilden eine Kette, die sich zwischen Trommelfell und Hörschnecke in der luftgefüllten Paukenhöhle aufspannt. Sie übertragen Bewegungen des Trommelfells auf das ovale Fenster der flüssigkeitsgefüllten Hörschnecke (Cochlea). In der Paukenhöhle befinden sich neben der Gehörknöchelchenkette der Musculus stapedius und der Musculus tensor tympani, die bei Anspannung, die Übertragung einfallender Schallreize auf das Innenohr dämpfen können. Die Paukenhöhle wird über die Tube, eine Verbindungsröhre zum Nasenrachenraum, belüftet. Die Funktion des Mittelohres besteht in der Impedanzanpassung zwischen der Schallausbreitung in Luft und Flüssigkeit. Das Größenverhältnis zwischen Trommelfelloberfläche und ovalem Fenster sowie die Bewegung der Gehörknöchelchenkette führen zu einer Verstärkung des Drucks bei gleichzeitiger Verringerung der Amplitude.

\subsubsection{Innenohr}

Das Innenohr besteht aus dem Hörorgan (Cochlea) und dem Gleichgewichtsorgan (Vestibulum) und liegt eingebettet in der knöchernen Felsenbeinpyramide. Die Cochlea ist ein flüssigkeitsgefülltes häutiges Schlauchsystem (membranöses Labyrinth) innerhalb eines knöchernen Kanals, der beim Menschen zweieinhalb Mal um eine Achse, den Modiolus, gewunden ist. Innerhalb des membranösen Labyrinths werden drei Kompartimente unterschieden, die Scala tympani, die Scala media und die Scala vestibuli. An zwei Stellen, dem ovalen und dem runden Fenster, ist das häutige Labyrinth nicht knöchern bedeckt. Im ovalen Fenster grenzt die Stapesfußplatte direkt an die Scala vestibuli, die auf ihrer gesamten 
Länge durch die Reissner Membran gegen die Scala media abgegrenzt wird. An der Spitze der Cochlea, dem Apex oder Helicotrema, wird sie durch die Scala tympani fortgesetzt. Diese wird durch die Basilarmembran von der Scala media getrennt und an der Basis der Cochlea durch das runde Fenster begrenzt. Scala vestibuli und tympani beinhalten Perilymphe und kommunizieren über den Aquaeductus cochleae mit cerebrospinalem Liquor. Zwischen Basilar- und Reissner Membran befindet sich die Scala media. Ihre laterale Wand wird von einer bindegewebigen Struktur, dem Ligamentum spirale, gebildet. Sie ist mit Endolymphe gefüllt und birgt das Cortische Organ. Das Cortische Organ trägt die Haarsinneszellen und wird von einer galertartigen kollagenösen Platte, der Tectorialmembran, bedeckt.

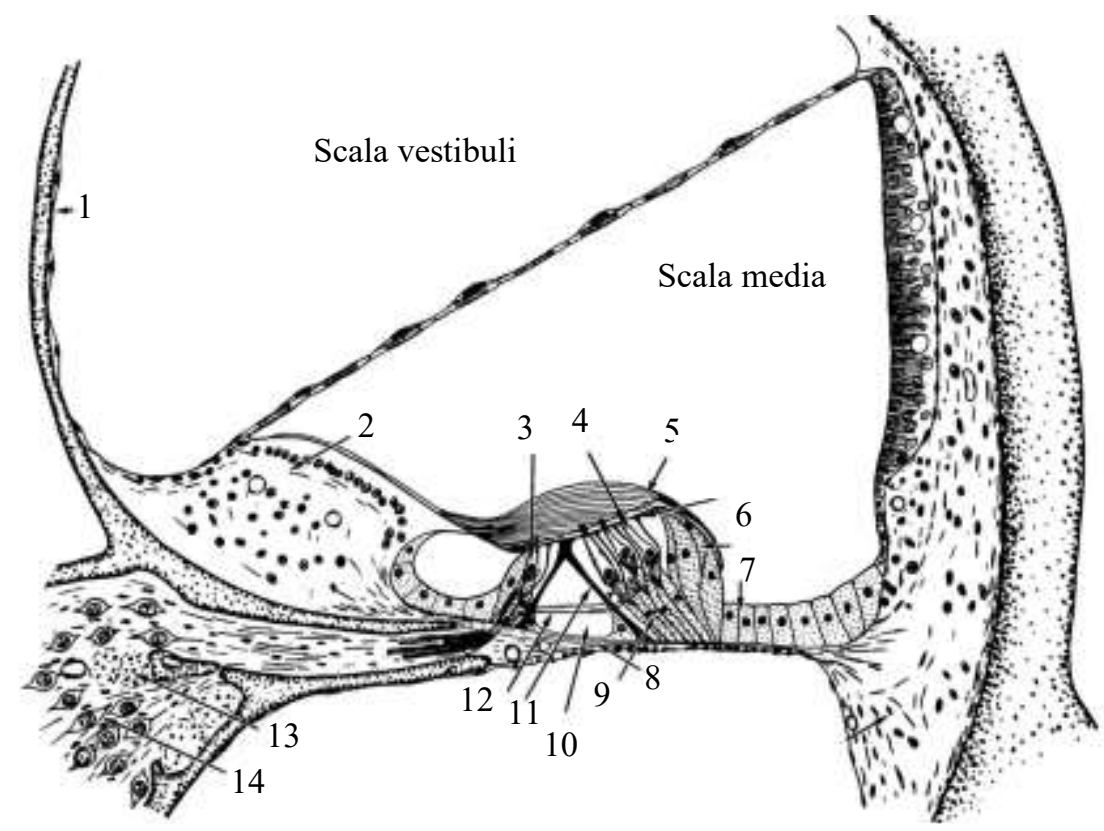

\section{Abbildung 1.2.3-1 Schnitt durch eine Windung der Säugetier-Cochlea}

1: knöchernes Labyrinth, 2: Limbus, 3 und 4: innere und äußere Haarzellen, 5: Tektorialmembran, 6: äußere Grenzzellen (Hensen-Zellen), 7: äußere Stützzellen (Claudius-Zellen), 8: Basilarmembran, 9: äußere Phalangenzellen (Deiter-Zellen), 10: Cortischer Tunnel, 11: äußere Pfeilerzellen, 12: auditorische Nervenfasern, 13: intraganglionäre Fasern, 14: Zellkörper von Spiralganglionneuronen (in ihrer Gesamtheit: Ganglion spirale)

Diese Abbildung wurde zuvor publiziert in „Hearing - anatomy, physiology, and disorders of the auditory system“, Møller AR, Seite 11, Copyright Elsevier 2006 und „Acoustic trauma in the guinea pig", Davis H, The Jounal of the Acoustical Society of America, 1953, Copyright Acoustic Society of America. Reproduktion mit freundlicher Genehmigung des Verlags Elsevier und der Acoustical Society of America.

Die Scala media wird von einem heterogenen Epithel ausgekleidet, das neben den Haarsinneszellen aus mindestens 11 Typen von Stützzellen besteht (Abbildung 
1.2.3-1). Diese spielen bei der mechanischen Unterstützung und Stabilisierung des Cortischen Organs eine Rolle, ohne direkt am Prozess der Schalltransduktion mitzuwirken (Wangemann 2006). Über porenartige Verbindungen untereinander bilden sie ein Netzwerk (epitheliales gap-junction-Netzwerk), das eine interzelluläre Kommunikation ermöglicht und an der Ionenhomöostase der cochleären Flüssigkeiten beteiligt ist (Zhao und $\mathrm{Yu}$ 2006). Dem Ligamentum spirale liegt innen die Stria vascularis auf, ein kapillarreiches, mehrschichtiges Gewebe, das die zentrale Rolle bei der Ionenhomöostase der Endolymphe einnimmt. Peri- und Endolymphe unterscheiden sich maßgeblich in ihrer Zusammensetzung. Die ionale Zusammensetzung der Perilymphe ähnelt der von Liquor cerebrospinalis und Blutplasma. Sie ist reich an Natrium $\left(\mathrm{Na}^{+}\right)$und arm an Kalium $\left(\mathrm{K}^{+}\right)$. Die Endolymphe ist ebenfalls eine extrazelluläre Flüssigkeit, ähnelt in ihrer Zusammensetzung aber dem Zellplasma (Tabelle 1.2.3-1). Die Konzentrationen von $\mathrm{Na}^{+}$und Calcium $\left(\mathrm{Ca}^{2+}\right)$ sind niedrig wohingegen die Konzentration von Bicarbonat $\left(\mathrm{HCO}_{3}{ }^{-}\right)$und $\mathrm{K}^{+}$hoch ist. Ihr Proteingehalt ist gering. Das vorherrschende Kation ist $\mathrm{K}^{+}$, das den Hauptladungsträger für die mechanoelektrische Transduktion in der Cochlea darstellt.

Endo- Intrastriatal- Peri- Liquor Blutlymphe lymphe lymphe cerebrospinalis plasma

$\begin{array}{lccccc}\mathrm{Na}^{+}[\mathrm{mM}] & 1,3 & 85 & 140 & 140 & 145 \\ \mathrm{~K}^{+}[\mathrm{mM}] & 150 & 2 & 4-5 & 3 & 4 \\ \mathrm{Cl}^{-}[\mathrm{mM}] & 130 & 55 & 120 & 120 & 110 \\ \mathrm{HCO}_{3}^{-}[\mathrm{mM}] & 30 & ? & 20 & 20 & 22 \\ \mathrm{Ca}^{2+}[\mathrm{mM}] & 0,02 & 0,8 & 1,2 & 1,2 & 2,6 \\ \text { Proteine }[\mathrm{g} / 1] & 0,2 & ? & 1 & 0,3 & 40-80 \\ \text { Glukose }[\mathrm{mM}] & 0,5 & ? & 4 & 3 & 5\end{array}$

\section{Tabelle 1.2.3-1 Zusammensetzung physiologischer Flüssigkeiten}

Zusammensetzung cochleärer Flüssigkeiten (Auszug) im Vergleich zu Blutplasma und Liquor cerebrospinalis (Salt 1996; Ludolph et al. 2000; Zettl et al. 2005; Nin et al. 2008; AlvarezLeefmans und Delpire 2009; Kim et al. 2015; Delprat und Irving 2016).

Während der Durchmesser des Labyrinths zum Helicotrema hin abnimmt, nimmt die Breite der Basilarmembran zu. Daraus resultieren je nach Ort unterschiedliche Schwingungseigenschaften. An der Basis ist sie resonant mit hohen Frequenzen, 
wohingegen tiefe Frequenzen die Membran an der Spitze in Schwingung versetzen. Unterschiedliche Frequenzen werden daher durch Vibration an unterschiedlichen anatomischen Orten abgebildet und verarbeitet (Tonotopie): Haarsinneszellen und auditorische Nervenfasern fungieren frequenzspezifisch. Diese Tonotopie findet sich entlang der gesamten Hörbahn.

Bewegungen der Stapesfußplatte im ovalen Fenster lösen über eine Wanderwelle in der Perilymphe eine Auslenkung der Basilarmembran aus, der das Cortische Organ aufsitzt.

\subsubsection{Das Cortische Organ}

Die mechanoelektrische Transduktion, also die Umwandlung mechanischer Schwingung in ein elektrisches Zellsignal geschieht im Cortischen Organ. Zwei Arten sensorischer Zellen sind an diesem Prozess beteiligt: Die äußeren Haarzellen (ÄHZ), die eine aktive Verstärkung und Differenzierung von Schall ermöglichen (Fettiplace und Hackney 2006), und die inneren Haarzellen (IHZ), die die Schallinformation an Nervenzellen weitergeben. Für beide Typen von Haarzellen sind die zu einem Haarbündel angeordneten Stereozilien (genauer: Stereovilli) namensgebend. Beim Menschen sind etwa 16.000 Haarzellen auf der Basilarmembran in drei Reihen ÄHZ und einer Reihe IHZ angeordnet. Sie werden durch den Cortischen Tunnel getrennt, der durch innere und äußere Pfeilerzellen gebildet wird.

Die ca. 50-150 Stereovilli an der Oberfläche einer ÄHZ sind in 3-4 Reihen Voder W-förmig in zunehmender Länge angeordnet. An der Oberfläche der IHZ bilden sie die Form einer geschweiften Klammer (Møller 2006). Die Spitzen der ÄHZ-Stereovilli erreichen die darüberliegende Tektorialmembran, die bei Auslenkung der Basilarmembran (Endolymphbewegung) Scherkräfte auf die Stereovilli überträgt. Diese sind durch dünne Filamente (Tip-Links) miteinander verbunden, die sich von der Spitze des jeweils kürzeren Stereovillis zum benachbarten längeren aufspannen. An ihren Ansatzpunkten finden sich ca. zwei mechanosensitive Kationenkanäle (mechanoelektrische Transduktionskanäle) (Beurg et al. 2009). Durch die Scherkräfte können die Tip-Links gedehnt werden, was eine Öffnung der Kanäle zur Folge hat. Dies führt über einen $\mathrm{K}^{+}$-IonenEinstrom aus der Endolymphe in die Haarzelle zur Depolarisation der Zelle (Silbernagl und Klinke 2003). Schließen die Kanäle wieder, folgt die 
Repolarisation. Dazu öffnen spannungs- und $\mathrm{Ca}^{2+}$-abhängige $\mathrm{K}^{+}$-Kanäle an der basolateralen Membran und entlassen $\mathrm{K}^{+}$-Ionen aus den Haarzellen.

Im Patch-clamp Experiment kann eine Depolarisation durch eine an die Zellmembran angelegte elektrische Spannung ausgelöst werden, was eine physiologische Anregung simuliert. So konnte gezeigt werden, dass eine Depolarisation zu einer Längenänderung der äußeren Haarzellen führt (Brownell et al. 1985). Das Motorprotein Prestin befähigt die Zellen, sich aktiv zu verkürzen oder zu strecken (Zheng et al. 2000). Dieser Mechanismus wird als Elektromotilität bezeichnet. Die ÄHZ oszillieren mit der Frequenz des auslösenden Schalls. Die elektrisch getriebene Längenänderung der ÄHZ erlaubt eine frequenzspezifische Verstärkung der Wanderwelle. ÄHZ werden daher als cochleärer Verstärker bezeichnet. Die Verstärkung folgt einem nicht-linearen Muster: Töne hohen Schalldrucks erfahren eine schwächere Verstärkung als Töne geringen Schalldrucks.

Die verstärkte Wanderwelle lenkt die Stereovilli der IHZ aus, was, ebenso wie bei ÄHZ, eine Dehnung der Tip-Links und Öffnung der mechanoelektrischen Transduktionskanäle zur Folge hat. Dies führt zu einem $\mathrm{K}^{+}$-Ionen-Einstrom aus der Endolymphe in die Haarzelle und zur Depolarisation der Zelle, dem Rezeptorpotenzial. Anders als bei den ÄHZ bewirkt die Depolarisation über einen $\mathrm{Ca}^{2+}$-Ionen-Einstrom eine Transmitterausschüttung an der basalen Zellmembran.

\subsection{Das endocochleäre Potenzial und die Stria vascularis}

Das endocochleäre Potenzial (EP) beschreibt ein positives Potenzial der Endolymphe gegenüber der Perilymphe (Von Bekesy 1952). Es beträgt relativ zum umgebenden Gewebe $80-120 \mathrm{mV}$, wobei es von der Basis bis zum Apex einen fallenden Gradienten aufweist. Generiert wird es von der Stria vascularis, einem dreischichtigen Epithel, das aus Basal-, Intermediär- und Marginalzellen aufgebaut ist. Sie bestimmt die Zusammensetzung und produzierte Menge der Endolymphe und ermöglicht damit die Entstehung des EPs. Dies wiederum erzeugt eine in die Haarzelle gerichtete treibende Kraft für $\mathrm{K}^{+}$-Ionen und stellt die Voraussetzung für die Aktivierung der Haarzelle dar.

Die Marginalzellen sind dem Endolymphraum zugewandt und untereinander fest durch tight junctions verbunden. In Richtung des Ligamentum spirale wird die Stria vascularis durch die festen Verbindungen der Basalzellen begrenzt. 
Zwischen den beiden Barrieren findet sich der intrastriatale Raum, in dem die Intermediärzellen und zahlreiche Blutgefäße in einer der Perilymphe ähnlichen Flüssigkeit zu finden sind (Salt et al. 1987).

\subsubsection{Hypothese des $\mathrm{K}^{+}-$Recyclings}

Die Marginalzellen nehmen an ihrer basolateralen Membran $\mathrm{K}^{+}$-Ionen mittels Natrium-Kalium-Pumpen (Na-K-ATPasen) auf. Die dadurch erniedrigte intrazelluläre $\left[\mathrm{Na}^{+}\right]$erzeugt einen nach innen gerichteten $\mathrm{Na}^{+}$-Gradienten, der ein CoTransportprotein (Na-K-Cl-Cotransporter) treibt und so weitere $\mathrm{K}^{+}$-Ionen in die Zelle und damit aus dem intrastriatalen Raum bringt. Die $\mathrm{Cl}^{-}$-Ionen verlassen die Zelle über basolateral gelegene $\mathrm{Cl}^{-}-$Kanäle (Takeuchi et al. 1995). Die $\mathrm{K}^{+}$-Ionen hingegen gelangen an der apikalen Membran durch spannungsabhängige $\mathrm{K}^{+}$Kanäle (KCNQ1/KCNE1) in die Endolymphe (Shen et al. 1997). Die treibende Kraft für die $\mathrm{K}^{+}$-Sekretion ist ein über der apikalen Membran liegendes leicht positives Membranpotenzial (Offner et al. 1987).

Nach dem Eintritt der $\mathrm{K}^{+}$-Ionen in die Haarzellen verlassen sie diese über spannungs- oder $\mathrm{Ca}^{2+}$-abhängige $\mathrm{K}^{+}$-Kanäle (u. a. KCNQ4) an der basolateralen Membran. Von dort gelangen sie entweder in die Perilymphe und diffundieren in Richtung des Ligamentum spirale (Zidanic und Brownell 1990) oder werden von den Stützzellen aufgenommen und über das epitheliale gap-junction-Netzwerk zum Ligamentum spirale transportiert. $\mathrm{K}^{+}$-Ionen scheinen auch über die Reissner Membran und über Stützzellen der basolateralen Scala media aus der Endolymphe zu gelangen. Im Ligamentum spirale werden sie über Na-K-ATPasen und Na-KCl-Cotransporter von Fibrozyten aufgenommen, die ein zweites Zell-Netzwerk (bindegewebiges gap-junction-Netzwerk) bilden (Wangemann 2002). Zu diesem Netzwerk gehören auch die Basal- und Intermediär-Zellen der Stria vascularis. Die $\mathrm{K}^{+}$-Ionen werden von Zelle zu Zelle weitergeleitet und schließlich aus den Intermediärzellen über $\mathrm{K}^{+}$-Kanäle (u. a. KCNJ10) in den intrastriatalen Raum entlassen (Takeuchi und Ando 1999). Es wird angenommen, dass der KCNJ10$\mathrm{K}^{+}$-Kanal in Verbindung mit der hohen intrazellulären $\left[\mathrm{K}^{+}\right]$in den Intermediärzellen und der niedrigen $\left[\mathrm{K}^{+}\right]$im Intrastriatalraum das EP generiert (Takeuchi et al. 2000; Marcus et al. 2002). 


\subsection{Die Synapse der inneren Haarzellen}

Die IHZ des Innenohrs, die die mechanische Energie des Schalls in Rezeptorpotenziale übersetzen, geben zeitlich präzise Botenstoffe (Neurotransmitter) frei und erregen so die Spiralganglionneurone (SGN). In neuronalen Netzwerken werden Informationen über Zell-Zell-Kontakte (Synapsen) übertragen. An die afferente Synapse zwischen IHZ und SGN werden besondere Anforderungen gestellt. Töne müssen mit einer zeitlichen Präzision im Bereich von unter einer Millisekunde über einen weiten Schalldruckbereich über lange Zeiträume verarbeitet werden. Die zeitliche Präzision des auditorischen Systems ermöglicht die Lokalisation einer Schallquelle mit einer Genauigkeit von $3^{\circ}$, was im tieffrequenten Bereich Laufzeitunterschieden zu beiden Ohren von ca. $10 \mu \mathrm{s}$ entspricht. Unabdingbar sind Verlässlichkeit der Kodierung und zeitliche Präzision.

Generell werden zwei Funktionsmechanismen von Synapsen unterschieden, elektrisch und chemisch. Die IHZ-Synapse gehört wie die meisten neuronalen Synapsen zu den chemischen. Als Reaktion auf einen adäquaten Reiz schüttet die übermittelnden Zelle (Präsynapse) Neurotransmitter aus Vesikeln aus. Vermittelt wird die Exozytose über eine erhöhte intrazelluläre $\left[\mathrm{Ca}^{2+}\right]$ durch kurzzeitiges Öffnen spannungsabhängiger $\mathrm{Ca}^{2+}$-Kanäle. Die Neurotransmittermoleküle diffundieren in den synaptischen Spalt und können an spezifische Rezeptorproteine in der Membran der empfangenden Zelle (Postsynapse) binden.

Abhängig von Transmitter, Rezeptor und dazugehörigem Rezeptorkanal wird die postsynaptische Zelle daraufhin angeregt (exzitatorische Synapse) oder gehemmt (inhibitorische Synapse). Zunächst ändert sich lokal ihr Membranpotenzial, was über ein exzitatorisches postsynaptisches Potenzial (EPSP) zur Entstehung eines Aktionspotenzials (AP) beiträgt oder über ein inhibitorisches postsynaptisches Potenzial (IPSP) dessen Bildung erschwert. Inhibitorisch wirkt zum Beispiel die Bindung von Glyzin oder $\gamma$-Aminobuttersäure (GABA) an die jeweiligen Rezeptoren, da sie den Einstrom von $\mathrm{Cl}^{-}$-Ionen und damit eine Hyperpolarisation auslöst. Exzitatorisch wirken unter anderem die Neurotransmitter Glutamat und Aspartat.

Die IHZ-Synapse ist eine exzitatorische Synapse. Die Bindung von Glutamat an AMPA-Rezeptoren in der Membran der SGN führt durch eine Konformations- 
änderung zu einem kurzen, schnellen Öffnen dieser nicht-selektiven KationenKanäle.

\subsubsection{Die Präsynapse}

Die IHZ-Synapse gehört darüber hinaus zu den Bändersynapsen. Diese zeichnen sich durch das synaptische Band aus: eine elektronendichte, ellipsoide Zellorganelle von weniger als einem Mikrometer Durchmesser, um die etwa 100 synaptische Vesikel angeordnet sind (Moser et al. 2006; Nouvian et al. 2006). Diese sind teilweise durch dünne Filamente (5 nm Durchmesser, $40 \mathrm{~nm}$ lang) mit dem Band verbunden. Die meisten Bänder sind an der Plasmamembran lokalisiert, je eins pro aktive Zone. Die aktive Zone bezeichnet den Bereich der Vesikelausschüttung und liegt der postsynaptischen Dichte gegenüber. Weniger als $5 \%$ der Bänder liegen frei im Zytosol vor (Khimich et al. 2005). Größe, Form und Anzahl der Bänder variieren sowohl während der Entwicklung und entlang der tonotopischen Achse (Wong et al. 2014; Meyer et al. 2009), als auch innerhalb einer einzelnen IHZ (Merchan-Perez und Liberman 1996; Frank et al. 2009; Liberman et al. 2011).

Aktive Zonen der Plasmamembran werden durch einen elektronendichten Bereich an der präsynaptischen Membran definiert. Hier sind etwa 14 Vesikel mit der Plasmamembran assoziiert und bilden eine schnell freisetzbare VesikelPopulation. Andere haben weder Kontakt zur präsynaptischen Membran noch zum Band. Die Vesikel der aktiven Zone stellen nur einen kleinen Anteil der in einer IHZ vorhandenen Vesikel dar. Die schnell freisetzbare Vesikel-Population unterstützt die Ausschüttung mehrerer Vesikel innerhalb sehr kurzer Zeit und organisiert so die synchrone synaptische Transmission und damit die postsynaptische Aktivierung (Moser und Beutner 2000). An der aktiven Zone finden sich Anhäufungen von $\mathrm{Ca}^{2+}$-Kanälen (Brandt et al., 2005).

\subsubsection{1. $\mathrm{Ca}^{2+}-$ Kanäle vermitteln die Vesikelfreisetzung}

$\mathrm{Ca}^{2+}$-Ionen fließen an der IHZ-Synapse hauptsächlich über L-Typ $\mathrm{Ca}^{2+}$-Kanäle (genauer über Cav1.3) (Platzer et al. 2000; Brandt et al. 2003; Dou et al. 2004). Sie stellen eine Gruppe von spannungsabhängigen $\mathrm{Ca}^{2+}$-Kanalproteinen dar, die sich anhand ihrer molekularen und biophysikalischen Eigenschaften von anderen $\mathrm{Ca}^{2+}$-Kanälen unterscheiden. 
Grundlegende Kenntnisse über Cav1.3-Kanäle stammen aus Untersuchungen am Tiermodell. Für die Funktion der Synapse und damit für das Hören sind sie essenziell, denn in Cav1.3-defizienten IHZ findet nahezu keine Exozytose statt (Brandt et al. 2003). Die IHZ und ihre Bändersynapsen sind bis zu einem Alter von vier Wochen erhalten. Synapsen von cholinergen MOC-Efferenzen mit IHZ, die sich während der physiologischen Entwicklung bis zum Beginn des Hörens zurückbilden, persistieren. $\mathrm{K}^{+}$-Kanäle (BK-Kanäle) scheinen in der IHZ-Zellmembran zu fehlen. Die zunächst ausgebildeten Bändersynapsen, die afferenten SGN und schließlich auch die IHZ degenerieren mit zunehmendem Alter (50\% mit acht Wochen) (Glueckert et al. 2003).

Spannungsabhängige $\mathrm{Ca}^{2+}$-Kanäle sind Proteinkomplexe, die aus mehreren Untereinheiten aufgebaut sind. Der Komplex wird von einer Poren-formenden Untereinheit, $\operatorname{Cav} \alpha_{1}$, einer $\operatorname{Cav} \beta$ sowie $\operatorname{Cav} \alpha_{2} \delta$ und möglicherweise von einer $\mathrm{Ca}_{\vee} \gamma-$ Untereinheit gebildet. Bisher sind zehn verschiedenen Gene bekannt, die für die $\operatorname{Cav} \alpha_{1}$ kodieren, vier für $\operatorname{Cav} \beta$, acht für $\operatorname{Cav} \gamma$ und vier für $\operatorname{Cav} \alpha_{2} \delta$, eine zusammengesetzte Untereinheit bestehend aus dem Membran-verankerten $\delta$ und dem extrazellulären $\alpha_{2}$ (Hofmann et al. 1999).

Die $\mathrm{Ca}^{2+}$-Kanäle lassen sich nach ihrer Einzelkanal-Leitfähigkeit und ihrer Sensitivität auf verschiedene Wirkstoffe in fünf Gruppen einteilen. L-Typ $\mathrm{Ca}^{2+}$ Kanäle weisen lang andauernde, große Ströme auf. Sie werden durch hohe Spannungen aktiviert und können durch Dihydropyridine, Phenylalkylamine und Benzothiazepine blockiert werden. N- und P/Q-Typ $\mathrm{Ca}^{2+}$-Kanäle öffnen ebenfalls bei hohen Spannungen, haben aber eine geringere Leitfähigkeit als L-Typ $\mathrm{Ca}^{2+}$ Kanäle und können durch spezifische Polypeptid-Gifte von Schnecken oder Spinnen blockiert werden. R-Typ $\mathrm{Ca}^{2+}$-Kanäle öffnen ebenfalls bei hohen Spannungen, sind Giften gegenüber aber resistent. T-Typ $\mathrm{Ca}^{2+}$-Kanäle öffnen bei niedrigen Spannungen und weisen kleine und schnell endende Ströme auf.

Die spannungsabhängigen $\mathrm{Ca}^{2+}$-Kanäle können nach ihren $\alpha_{1}$-Untereinheiten, die die pharmakologischen und elektrophysiologischen Eigenschaften $\operatorname{der} \mathrm{Ca}^{2+}$ Kanäle primär bedingen, weiter klassifiziert werden. Die zusätzlichen $\mathrm{Cav} \beta-$, $\mathrm{Ca}_{v} \gamma$ - und $\mathrm{Ca}_{v} \alpha_{2} \delta$-Untereinheiten wirken modulierend. Im Folgenden wird eine Einteilung genutzt, die nach $\alpha_{1}$-Untereinheit und Genfamilie gruppiert (Ertel et al. 2000). 


\subsubsection{1. $\quad \alpha_{1}$-Untereinheit}

Die Poren-formende $\alpha_{1}$-Untereinheit ist ein großes Protein mit vier homologen Domänen. Sie stammt aus der gleichen multi-Genfamilie wie spannungsabhängige $\mathrm{K}^{+}$- und $\mathrm{Na}^{+}$-Kanäle. Jede ihrer vier Domänen ist aus sechs transmembranen Segmenten (S1-6) und einer Porenregion zwischen S5 und S6 aufgebaut. Das Segment S4 beinhaltet mehrere positiv geladene Anteile und fungiert als Spannungssensor des Kanals. Zahlreiche Interaktionsstellen der $\mathrm{Ca}_{v} \alpha_{1}$-Untereinheit für die anderen Untereinheiten und weitere Moleküle wurden beschrieben (Minor und Findeisen 2010).

\subsection{Cav $\beta-U n t e r e i n h e i t$}

Die Cav $\beta$-Untereinheit ist ein intrazellulär lokalisiertes Protein, das in jedem spannungsabhängigen $\mathrm{Ca}^{2+}$-Kanal enthalten ist. Sie bindet mit ihrer $\alpha$-bindenden Domäne an die intrazelluläre Schleife zwischen Domäne 1 und 2 der $\mathrm{Cav}_{1} \alpha_{1}-$ Untereinheit (van Petegem et al. 2004).

Diverse Kanal-modulierende Effekte werden der $\beta$-Untereinheit zugeschrieben: Sie steigert die $\alpha_{1}$-Untereinheit-Expression an der Plasmamembran (eventuell durch Überdecken eines Retentionssignals des endoplasmatischen Retikulums (Bichet et al. 2000) bzw. durch Inhibition der proteasomalen Degradation (Altier et al. 2011). Sie erhöht die Öffnungswahrscheinlichkeit (Neely et al. 1993). Sie bewirkt eine Hyperpolarisation der spannungsabhängigen Aktivierung (Jones et al. 1998). Außerdem beeinflusst sie die G-Protein-vermittelte Regulation von $\mathrm{Ca}^{2+}$-Kanälen, entweder durch Steigerung (Meir et al. 2000) oder Minderung (Cantí et al. 2000).

Die teils gegensätzlichen Wirkmechanismen lassen sich durch unterschiedliche Subklassen und vor allem unterschiedliche assoziierte $\alpha_{1}$-Untereinheiten erklären. Die Cav $\beta$-Untereinheit gehört der Familie der Membran-assoziierten GuanylatKinasen an (Hanlon et al. 1999), Proteine, die intrazelluläre Signalkaskaden mit multiplen Protein-Protein-Interaktionsdomänen organisieren. Zwei der typischen Domänen können in Cav $\beta$-Isoformen gefunden werden: die Guanylat-KinaseDomäne und die SH3-Domäne. Es wurden Interaktionen mit Proteinen wie dem kleinen G-Protein kir/GEM (Béguin et al. 2001) oder Dynamin, das bei der Endozytose eine Rolle spielt, (Gonzalez-Gutierrez et al. 2007) beschrieben. 


\subsubsection{3. $\quad \operatorname{Cava}_{2} \delta$-Untereinheit}

Diese Untereinheit besteht aus zwei Teilen, der $\alpha_{2}$-Untereinheit und der $\delta$-Untereinheit. Beide werden von derselben mRNA translatiert. Das resultierende Protein wird posttranslational gespalten. Die $\delta$-Untereinheit ist mit einem einzigen transmembranen Segment in der Plasmamembran verankert und mit einer Disulfidbrücke an die extrazelluläre $\mathrm{Cava}_{2}$-Untereinheit gebunden. Es ist nicht bekannt, ob diese Untereinheiten in allen durch hohe Spannungen aktivierten $\mathrm{Ca}^{2+}$-Kanälen in Kombination auftreten.

\subsection{Spannungsabhängige $\mathrm{Ca}^{2+}$-Kanäle der Haarzellen}

Die Depolarisation einer IHZ erhöht die Öffnungswahrscheinlichkeit spannungsabhängiger $\mathrm{Ca}^{2+}$-Kanäle, die sich an der präsynaptischen Membran gruppieren (Roberts et al. 1990; Issa und Hudspeth 1994; Brandt et al. 2005). IHZ (mit DHPsensitiven $\mathrm{Ca}^{2+}$-Strömen, die schnelle Aktivierungskinetiken zeigen) aktivieren bei vergleichsweise negativen Potenzialen (zwischen - 60 und $-50 \mathrm{mV}$ ) und weisen eine geringe Inaktivierung auf (Cui et al. 2007), wodurch sie die den IHZ eigene Exozytoseeigenschaften ermöglichen. Mehr als $90 \%$ der spannungsabhängigen $\mathrm{Ca}^{2+}$-Kanäle innerer Haarzellen sind vom Typ 1.3 (Platzer et al. 2000; Brandt et al. 2003), während der restliche Ionenstrom wahrscheinlich über verschiedene Formen von 1.4 (L-Typ) und 2.3 (R-Typ) $\mathrm{Ca}^{2+}$-Kanälen geleitet wird (Brandt et al. 2003). Die molekulare Identität der zwei letztgenannten ist bisher nicht geklärt. Mäuse, denen die Cav1.3 $\alpha_{1}$-Untereinheit fehlt sind dementsprechend von Geburt an taub (Platzer et al. 2000), was durch mangelnde Exozytose der IHZ bedingt ist (Brandt et al. 2003).

Fluktuationsanalysen von $\mathrm{Ca}^{2+}$-Strömen deuten darauf hin, dass reife apikale IHZ von Mäusen im Schnitt etwa 1700 spannungsabhängige $\mathrm{Ca}^{2+}$-Kanäle enthalten (Brandt et al. 2005). Eine ähnliche Anzahl wurde für Haarzellen im Sacculus des Frosches gefunden (Roberts et al. 1990). Wird eine extra-synaptische Dichte von einem Cav1.3 pro $\mu \mathrm{m}^{2}$ angenommen, resultierten 80 Cav1.3 pro aktive Zone in reifen IHZ (Brandt et al. 2005). In unreifen Mäuse-IHZ sind vorübergehend mehr spannungsabhängige $\mathrm{Ca}^{2+}$-Kanäle exprimiert (Beutner und Moser 2001; Zampini et al. 2010). 


\subsubsection{Molekulare Struktur der Präsynapse und Transmitterfreisetzung}

Die transiente Depolarisation der IHZ-Membran, die von einem Schallereignis ausgelöst wird, führt über einen $\mathrm{Ca}^{2+}$-Einstrom durch $\mathrm{Ca}_{\vee} 1.3$ an der aktiven Zone zur Ausschüttung von Glutamat. Die Bändersynapse ist, im Gegensatz zu anderen neuronalen Synapsen, in der Lage, eine große Anzahl von Vesikeln in sehr kurzer Zeit auszuschütten. Diese hohe Rate wird vermutlich durch das synaptische Band ermöglicht, das verfügbare Vesikel an der aktiven Zone konzentriert. Es stellt schnell und konstant Neurotransmitter bereit (Matthews und Fuchs 2010). Eine ergänzende Hypothese zur Funktion des Bandes besagt, dass es eine Diffusionsbarriere für $\mathrm{Ca}^{2+}$-Ionen darstelle, um an der aktiven Zone rasch hohe $\left[\mathrm{Ca}^{2+}\right] \mathrm{zu}$ erreichen, die wiederum die Transmitterausschüttung vermitteln (Graydon et al. 2011).

Die Präsynapse ist aus vielen typischen synaptischen Proteinen aufgebaut (Zanazzi und Matthews 2009). Das zentrale Protein des Bandes, Ribeye, allerdings ist spezifisch (Schmitz et al. 2000). Eine Übersicht über die molekulare Zusammensetzung der IHZ-Synapse bietet Pangršič et al. 2012. Gerüst-Proteine wie Bassoon und Piccolino, eine kleinere Splice-Variante von Piccolo, das eines der größten Cytomatrix-Proteine an der aktiven Zone chemischer Synapsen darstellt, sind vorhanden (Regus-Leidig et al. 2013). Bassoon verankert offenbar das Band an der präsynaptischen Membran (Khimich et al. 2005; Jing et al. 2013). RIM (Rab3-interacting molecules) werden exprimiert und sind an der Bindung der Vesikel an die präsynaptische Membran beteiligt (Jung et al. 2015b). Ein weiteres bekanntes Gerüst-Protein ist Harmonin, das das Öffnen der Cav1.3 reguliert (Gregory et al. 2013; Joiner und Lee 2015).

Die präzise Regulation der Exozytose beruht auf lokalen Änderungen der $\left[\mathrm{Ca}^{2+}\right]$ i. Mobile $\mathrm{Ca}^{2+}$-Puffer (Calcium-bindende Proteine) verhindern hierzu die zeitliche und räumliche Ausbreitung eingeströmten Calciums. Herkömmliche $\mathrm{Ca}^{2+}$ Sensoren wie Synaptotagmin I/II scheinen zu fehlen. Stattdessen vermittelt vermutlich das Transmembran-Protein Otoferlin die $\mathrm{Ca}^{2+}$-abhängige Fusion der Vesikel mit der Membran (Roux et al. 2006). Darüber hinaus scheint Otoferlin bei der Vorbereitung und beim Nachschub der Vesikel sowie bei der Abstimmung von Exo- und Endozytose eine wichtige Rolle zu spielen (Pangrsic et al. 2010). $\mathrm{Ca}^{2+}$ wird aus dem Zytosol über spezielle Pumpen nach extrazellulär und in 
intrazelluläre Speicher wie das endoplasmatische Retikulum transportiert (Zanazzi und Matthews 2009).

Damit Vesikel mit der präsynaptischen Membran fusionieren können, durchlaufen sie einen Vorbereitungsprozess. Dieser wird grob in das lose Anbinden der Vesikel durch Proteinfilamente an die aktive Zone, das dichte Andocken an dieselbe und anschließend folgende Reifungsschritte unterteilt. Dabei scheinen die Anzahl und Länge der Proteinfilamente eine entscheidende Rolle zu spielen. Anders als an vielen anderen neuronalen Synapsen sind Munc13- und CAPSProteine hier offenbar nicht beteiligt. Stattdessen nimmt wohl Otoferlin eine Schlüsselfunktion beim dichten Anheften mittels kurzer Proteinfilamente ein (Vogl et al. 2015).

Bislang sind viele Aspekte der außergewöhnlichen Freisetzungsmaschinerie der IHZ ungeklärt. Auch die Vesikelfusion und -öffnung scheinen ebenfalls nicht wie in konventionellen neuronalen Synapsen über SNARE-Proteine vermittelt $\mathrm{zu}$ werden (Nouvian et al. 2011). Für den Ablauf der Transmitterfreisetzung existieren verschiedene Hypothesen, da die vollständige Ausschüttung einzelner Vesikel nicht ausreichend erscheint, um die Amplituden der EPSP und ihre Heterogenität zu erklären. Diskutiert wurden die koordinierte Ausschüttung mehrerer Vesikel (Glowatzki und Fuchs 2002; Goutman und Glowatzki 2007) und die Fusion mehrerer Vesikel vor der Ausschüttung (Matthews und Sterling 2008) sowie die Fusion von Vesikeln mit einem gerade in der Ausschüttung befindlichen Vesikel. Die kiss-and-run-Hypothese besagt, dass Vesikel für kurze Zeit eine Pore in der präsynaptischen Membran bilden und einen Teil der enthaltenen Transmitter freisetzen, bevor die Pore verschlossen wird und sie sich in die Zelle zurückziehen. Eine weitere Theorie postuliert die Ausschüttung einzelner Vesikel, wobei neben der vollständigen Entleerung (monophasische EPSP) eine unregelmäßige Transmitterfreisetzung durch eine dynamische Pore (multiphasische EPSP) angenommen wird (Chapochnikov et al. 2014).

\subsubsection{Die Postsynapse}

Die Amplitude und Kinetik der postsynaptischen Antworten hängen vom zeitlichen Verlauf der Glutamatfreisetzung und -entfernung durch Aufnahme bzw. Diffusion sowie von der Komposition der Glutamat-Rezeptoren und ihrer Dichte ab (Traynelis et al. 2010). Diese Komposition ändert sich während der Entwick- 
lung und ist möglicherweise auch danach variabel, was die Feuereigenschaften der SGN modellieren könnte (Reijntjes und Pyott 2016).

Der Einstrom von Kationen (hauptsächlich $\mathrm{Na}^{+}$und $\mathrm{K}^{+}$) bewirkt nach Auslösung eines potenten EPSP eine Depolarisation der Postsynapse (Matsubara et al. 1996; Glowatzki und Fuchs 2002). Es können zwei Typen von EPSP unterschieden werden: monophasisch mit steilem Anstieg und monophasischem Rückgang und multiphasisch mit längerer Dauer und häufig mehrfachen Gipfeln. Es gibt Hinweise darauf, dass SGN zusätzlich NMDA-Rezeptoren exprimieren, die in der schnellen afferenten Übertragung aber wohl keine Rolle spielen und möglicherweise nur unter pathologischen Bedingungen funktionelle Bedeutung erlangen (Ruel et al. 2008b).

Die postsynaptische Dichte ist eine für die Transmitteraufnahme spezialisierte Membranstruktur. Ihre molekulare Zusammensetzung beinhaltet viele Proteine, die von anderen zentralnervösen Synapsen bekannt sind. Eine Besonderheit der SGN ist die Verteilung der AMPA-Rezeptoren, die sich vermehrt in der Peripherie ansiedeln und Ring-ähnliche Strukturen bilden (Meyer et al. 2009).

In der Membran der SGN finden sich spannungsabhängige $\mathrm{Na}^{+}$- und $\mathrm{K}^{+}$-Kanäle. Während die $\mathrm{Na}^{+}$-Kanäle die exzitatorische Aktivität vermitteln, sind die $\mathrm{K}^{+}$Kanäle für die Wiederherstellung und Aufrechterhaltung des Ruhemembranpotenzials entscheidend (für Details s. Kapitel 1.5.1. Das Aktionspotenzial). Zum Ruhemembranpotenzial tragen auch nicht-selektive Kationen- und $\mathrm{Cl}^{-}$-Kanäle sowie Na-K-ATPasen bei. Es wird angenommen, dass unterschiedliche KanalTypen die Feuereigenschaften der Neurone beeinflussen und entwicklungsabhängig sowie plastisch, an den Bedarf angepasst, exprimiert werden. Zudem finden sich spannungsabhängige $\mathrm{Ca}^{2+}$-Kanäle, die vermutlich zur Depolarisation und Formierung der AP beitragen, die Funktionsweise anderer Ionenkanäle modulieren und an intrazellulären Signalwegen beteiligt sind (Reijntjes und Pyott 2016).

\subsubsection{Vesikel-Recycling und Glutamat-Clearance}

Um synaptische Vesikel zu recyceln, werden lateral der aktiven Zone gelegene Membrananteile durch Endozytose in die Zelle zurückgeführt. Die Mechanismen der Endozytose sind weitgehend unbekannt. Neben der kiss-and-run-Hypothese werden die Endozytose großer Membrananteile und eine Clathrin-vermittelte 
Endozytose diskutiert (Zanazzi und Matthews 2009). Clathrin ist ein Protein, das die Einstülpung von Membranteilen und somit die Bildung von Vesikeln vermittelt. Dynamine, kleine GTPasen, ermöglichen die Abschnürung der neu gebildeten Vesikel und deren Transport zur Zielmembran sowie das Verschmelzen mit dieser. Vermutlich nutzen IHZ mehrere Wege der Endozytose. Untersuchungen an Maus-IHZ legen nach milder Exozytose eine Dynaminabhängige Clathrin-vermittelte Endozytose und nach starker Exozytose die Endozytose großer Membrananteile (bulk retrieval) nahe (Neef et al. 2014). Adapterproteinkomplexe vermitteln neben der Clathrin-Bindung an Membranen die Reformierung neuer Vesikel und das Wiederauffüllen der Band-assoziierten Population. Dabei scheint das Protein AP-2 und/oder dessen Interaktion mit Otoferlin für die Bereinigung der aktiven Zone nach abgelaufener Exozytose (active zone clearance) entscheidend zu sein (Jung et al. 2015a). Innerhalb der IHZ müssen Vesikel schnell transportiert werden, um den nötigen Nachschub an Neurotransmittern zu gewährleisten. Dieser Transport geschieht vermutlich über unkonventionelle Myosine (Zanazzi und Matthews 2009). Glutamat wird über den spezifischen Transporter VGlut3 in die Vesikel aufgenommen (Ruel et al. 2008a; Seal et al. 2008).

Um die hochfrequente synaptische Transmission, die das Hören erfordert, leisten zu können, ist sowohl ein schnelles Ein- als auch Abschalten der Signale im Hörnerven nötig. Außer der besonderen Fähigkeiten der Präsynapse einer zeitlich präzisen Transmitterfreisetzung ist dazu die Verfügbarkeit der postsynaptischen AMPA-Rezeptoren unabdingbar. In den synaptischen Spalt freigesetztes Glutamat muss daher schnell entfernt werden. Eine intensive Glutamatausschüttung oder eine mangelnde Entfernung führen zur Akkumulation im synaptischen Spalt. Dies kann zur Desensibilisierung der AMPA-Rezeptoren führen, ihre Funktionsweise negativ beeinflussen oder einen exzitotoxischen Zelltod hervorrufen (Reijntjes und Pyott 2016). Glutamat wird über passive Diffusion und aktive Glutamat/Aspartat-Transporter von umliegenden Stützzellen aufgenommen (Furness und Lawton 2003; Chen et al. 2010). Der aktive Transport scheint besonderes beim Schutz vor Exzitotoxizität eine Rolle zu spielen (Reijntjes und Pyott 2016). Aus den Stützzellen wird es vermutlich, ähnlich wie von anderen neuronalen Synapsen und Gliazellen bekannt, in einen Glutamat-GlutaminKreislauf eingespeist. Glutamin stellt an AMPA-Rezeptoren keinen aktiven 
Liganden dar, weshalb es problemlos in den synaptischen Spalt abgegeben werden kann. Daraus kann es von präsynaptischen Zellen aufgenommen und erneut in Glutamat überführt werden. Die IHZ selbst scheint ebenfalls mit einigen AMPA-Rezeptoren ausgestattet zu sein, wobei deren Funktion bisher nicht hinreichend geklärt ist, aber auf einen Feedback-Mechanismus hindeuten könnte (Ottersen et al. 1998).

\subsection{Innervation der Cochlea}

Innerhalb der Cochlea existieren drei Typen von Nervenfasern, afferente SGN, efferente Nervenfasern (olivocochleäres Bündel) und autonome Nervenfasern (adrenerg). Der achte Hirnnerv, der Nervus vestibulocochlearis, beinhaltet Fasern aus der Cochlea (N. cochlearis) und aus dem Vestibulum (N. vestibularis). Afferente SGN, deren Zellkörper das Spiralganglion im Rosenthal-Kanal im Modiolus bilden, sind bipolare Zellen. Zwei verschiedene Fasertypen sind bislang identifiziert worden. Typ I-SGN sind myelinisiert und haben große Zellkörper. Sie machen etwa $95 \%$ der afferenten Fasern aus und übertragen die auditorische Information zwischen IHZ und den Neuronen des Nucleus cochlearis.

Typ II-SGN sind unmyelinisiert. Sie machen nur etwa $5 \%$ der Hörnervenfasern aus und bilden synaptische Verbindungen zu den ÄHZ. Jede ÄHZ gibt ihre Informationen an 2-3 afferente Typ II-SGN weiter. Jedes der $5 \%$ Typ II-SGN bekommt Informationen von 3-10 ÄHZ (Berglund und Ryugo 1987). Es wird angenommen, dass die Typ II-SGN keine akustischen Informationen kodieren, sondern möglicherweise in der Schmerzwahrnehmung im Ohr eine Rolle spielen (Goutman et al. 2015). Sie könnten auch eine Unterdrückung des cochleären Verstärkers durch das olivocochleäre Bündel vermitteln (Froud et al. 2015). 


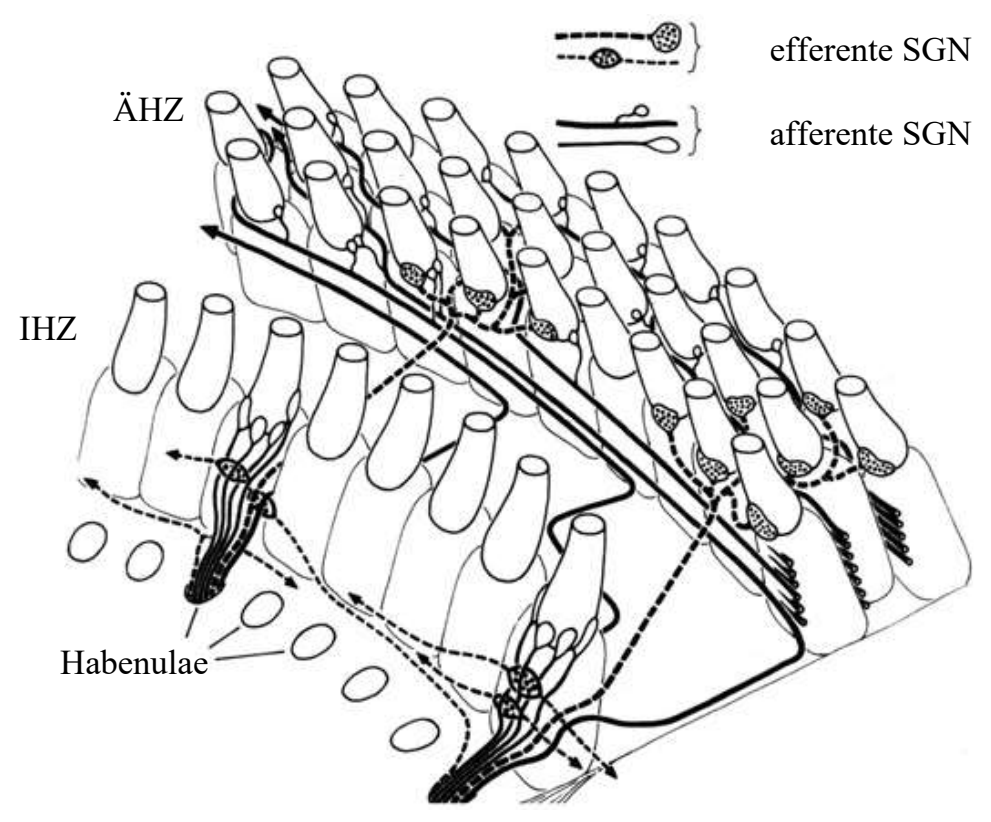

\section{Abbildung 1.5-1 Innervation der Haarzellen}

Schematische Zeichnung der Innervation der Haarzellen durch SGN. ÄHZ: äußere Haarzellen, IHZ: innere Haarzellen.

Diese Abbildung wurde publiziert in „Hearing - anatomy, physiology, and disorders of the auditory system“, AR Møller, Seite 15, Copyright Elsevier 2006. Mit freundlicher Genemigung des Verlags.

Der auditorische Nerv zieht von der Cochlea bis zum Hirnstamm. Jedes der 95 \% Typ I-SGN erhält dabei Informationen aus nur einer IHZ. Eine IHZ gibt ihre Informationen allerdings an mehrere afferente Fasern weiter. Je nach Lokalisation innerhalb der Cochlea variiert ihre Anzahl von unter 10 an der Basis und dem Apex bis zu 15-30 im mittleren Bereich (Rutherford und Moser 2016). Die Typ ISGN einer IHZ unterscheiden sich in ihrer Aktivierungsschwelle und dynamischen Bandbreite, sodass von einer einzelnen Haarzelle ausgehend verschiedene Stimulusintensitätsbereiche kodiert werden können (Liberman 1978).

Neben der afferenten existiert eine efferente Innervation, deren Fasern vom Hirnstamm aus zu den IHZ und ÄHZ ziehen (Abbildung 1.5-1). Unterschieden werden Fasern aus der medialen und Fasern aus der lateralen oberen Olive. Die medialen olivocochleären Efferenzen bilden cholinerge Synapsen zu den ÄHZ aus, deren Aktivierung zu einer Hyperpolarisation der ÄHZ und damit Hemmung der cochleären Verstärkung führt. Dies spielt beim Sprachverstehen im Störgeräusch, bei der Schallquellenlokalisation und beim Schutz der Cochlea vor Lärm eine Rolle. Die lateralen olivocochleären Efferenzen ziehen $\mathrm{zu}$ den auditorischen 
Neuronen im Bereich der afferenten Synapsen der IHZ. In den terminalen Endigungen wurden verschiedene Neurotransmitter (Dopamin, Acetylcholin und GABA) identifiziert, was auf eine komplexe Funktion hindeutet. Die Efferenzen haben wahrscheinlich einen modulierenden Effekt, der in seiner Vielschichtigkeit noch weitgehend unverstanden ist (Rabbitt und Brownell 2011).

\subsubsection{Das Aktionspotenzial}

Innerhalb eines afferenten Typ I-SGNs wird akustische Information durch Aktionspotenziale (AP), gleichförmige schnelle Änderungen der Spannung über der Zellmembran, fortgeleitet. Bedingt durch unterschiedliche Ionenkonzentrationen inner- und außerhalb einer Zelle bildet sich über der Zellmembran ein Ruhemembranpotenzial von -70 bis $-90 \mathrm{mV}$. Dieses kann aufgrund des elektrochemischen Gradienten, unterschiedlicher Permeabilität der Membran für Ionen und aktiver Ionentransporter aufrechterhalten werden. Im Ruhezustand ist die Zellmembran permeabel für $\mathrm{K}^{+}$- und $\mathrm{Cl}^{-}$-Ionen, aber nahezu undurchlässig für $\mathrm{Na}^{+}$und $\mathrm{Ca}^{2+}$. Die Na-K-ATPasen transportieren unter Verbrauch eines ATPMoleküls drei $\mathrm{Na}^{+}$-Ionen aus der Zelle und zwei $\mathrm{K}^{+}$-Ionen hinein. Ein AP bezeichnet eine kurzzeitige Änderung des Ruhemembranpotenzials. Es wird durch Öffnen von Ionenkanälen ausgelöst und folgt dem alles-oder-nichts Prinzip. Nur wenn ein suffizienter Stimulus eintrifft, wird ein AP ausgelöst, dessen Amplitude unabhängig von der Stimulusintensität ist. Die Änderung des Ruhemembranpotenzials löst in benachbarten Abschnitten eines Neurons das Öffnen weiterer Ionenkanäle aus, wodurch es zur Erregungsfortleitung kommt.

Ein AP kann in vier Phasen unterteilt werden. Durch eine adäquate Depolarisation der Membran beginnt die Initiationsphase. Spannungsabhängige $\mathrm{Na}^{+}$-Kanäle ermöglichen einen $\mathrm{Na}^{+}$-Einstrom, der das Öffnen von $\mathrm{K}^{+}$-Kanälen mit anschließendem $\mathrm{K}^{+}$-Ausstrom bedingt. $\mathrm{Da}$ der $\mathrm{Na}^{+}$-Einstrom die KationenKonzentration innerhalb der Zelle erhöht, nimmt das Potenzial über der Membran positive Werte an. Werte von 20 bis $30 \mathrm{mV}$ werden als Overshoot bezeichnet. Noch vor Erreichen des Maximums schließen die $\mathrm{Na}^{+}$-Kanäle. Es folgt die Repolarisation. In den meisten Neuronen sinkt das Membranpotenzial unter den Ausgangswert (Hyperpolarisation), was durch den nach wie vor bestehenden $\mathrm{K}^{+}$Ausstrom durch die langsam schließenden Kanäle bedingt ist. Zudem besteht eine gesteigerte Permeabilität für $\mathrm{K}^{+}$-Ionen durch eine erhöhte $\left[\mathrm{Ca}^{2+}\right]$, die während des 
APs über spannungsabhängige $\mathrm{Ca}^{2+}$-Kanäle in die Zelle einströmen. Spannungsabhängige $\mathrm{Na}^{+}$-Kanäle sind vollständig geschlossen und werden nach Hyperpolarisation wieder aktivierbar. Erst wenn sich die $\left[\mathrm{Ca}^{2+}\right]$ normalisiert, ist das Ruhemembranpotenzial wieder hergestellt.

Neurone können in einer kurzen Zeitspanne nach abgelaufenem AP, der absoluten Refraktärzeit, kein neues AP erzeugen. In der relativen Refraktärzeit ist die Entstehung eines AP nur durch einen stärkeren Stimulus möglich. Verantwortlich hierfür sind die Eigenschaften der spannungsabhängigen $\mathrm{Na}^{+}$- und $\mathrm{K}^{+}$-Kanäle. Nach dem Öffnen gehen die $\mathrm{Na}^{+}$-Kanäle in einen inaktiven Zustand über, aus dem sie erst nach der Hyperpolarisation wieder regeneriert werden. Die $\mathrm{K}^{+}$-Kanäle durchlaufen diese Stadien mit zeitlicher Verzögerung. Die absolute Refraktärzeit endet während der Repolarisation, wenn hinreichend viele $\mathrm{Na}^{+}-$Kanäle wieder aktivierbar sind, die relative dauert länger an, da noch $\mathrm{K}^{+}$-Kanäle offen sind und nicht alle $\mathrm{Na}^{+}-$Kanäle wieder aktivierbar sind.

Die absolute Refraktärzeit ermöglicht eine unidirektionale Weiterleitung entlang des Axons. Signale können so schnell und präzise übermittelt werden, wobei die Information in der Frequenz aufeinanderfolgender AP, in der zeitlichen Abfolge und ihrer Latenz kodiert wird. Für die Verarbeitung auditorischer Reize bedeutet dies, dass die Schallintensität in einem SGN als Entladungsfrequenz verschlüsselt wird. Um den gesamten Bereich der wahrnehmbaren Schalldruckpegel zu kodieren, kommuniziert die IHZ mit SGN unterschiedlicher Erregungsschwellen. Die Verschlüsselung der Reizfrequenz geschieht neben der Tonotopie über Phasenkopplung und Periodizitätsanalyse. Bei großen Reizintensitäten verschiebt sich das Maximum der Basilarmembranschwingung zur Basis der Cochlea, wo ein weiterer Mechanismus für die Reizfrequenzbestimmung genutzt wird: Einzelne Haarzellen depolarisieren jeweils in einer bestimmten Phase der Basilarmembranauslenkung, sodass die Frequenz der Depolarisationen und damit der SGN-AP direkt der Frequenz der Reizschwingungen folgt. Dieses, als Phasenkopplung bezeichnete Phänomen, tritt aufgrund der Membranzeitkonstante der IHZ bei Säugetieren nur bis ca. $1 \mathrm{kHz}$ auf. Dabei feuern die SGN nicht bei jeder Periode der Reizschwingung, sondern nach Auslassen einer bestimmten Anzahl von Perioden, jedoch stets in Phase. 
AP einzelner SGN können intra- (Rutherford et al. 2012) und extrazellulär, wie in dieser Arbeit, abgleitet werden. Ihre synchrone Aktivität kann als Summenaktionspotenzial von der Kopfhaut abgeleitet werden. Es entspricht der ersten von fünf charakteristischen Wellen, die in den ersten $10 \mathrm{~ms}$ als Antwort auf einen akustischen Reiz auftreten. Sie werden als frühe akustisch evozierte Potenziale (FAEP) bezeichnet. In der Klinik wird jede Welle der Aktivierung einer bestimmten Station der Hörbahn zugeordnet (Tabelle 1.5.1-1).

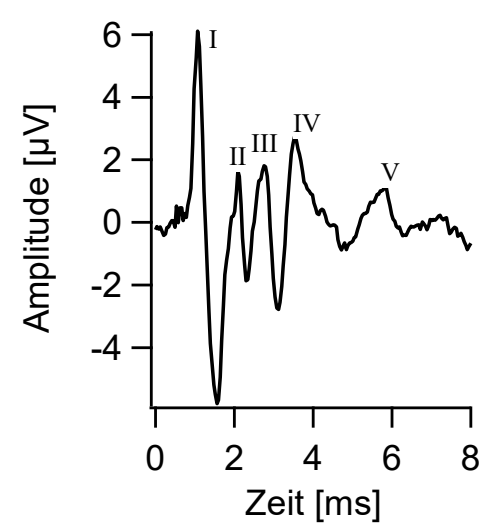

\begin{tabular}{|cl} 
Welle I & $\begin{array}{l}\text { Aktivierung des peripheren Anteils } \\
\text { der SGN }\end{array}$ \\
Welle II & $\begin{array}{l}\text { Aktivierung eines Anteils des } \\
\text { Nucleus cochlearis }\end{array}$ \\
Welle III & $\begin{array}{l}\text { Aktivierung eines Anteils des } \\
\text { Nucleus cochlearis und der oberen } \\
\text { Olive }\end{array}$ \\
\hline Welle IV & $\begin{array}{l}\text { Aktivierung des Kernkomplexes der } \\
\text { oberen Olive }\end{array}$
\end{tabular}
Welle V Aktivierung des Lemniscus lateralis bzw. der Colliculi inferiores

Tabelle 1.5.1-1 Frühe akustisch evozierte Potenziale

Klinische Zuordnung früher akustisch evozierter Potenziale zu ihrem Ursprung (Jewett und Williston 1971; Biacabe et al. 2001) mit Beispiel (repräsentative FAEP einer Maus; eigene Daten)

In der Folge sind mittlere, späte und sehr späte akustisch evozierte Potenziale ableitbar, die die Verarbeitung in nachgeschalteten Zentren bis zum auditorischen Kortex widerspiegeln.

\subsubsection{Das zentrale auditorische System}

SGN ziehen von der Cochlea in den Hirnstamm und erreichen die Nuclei cochleares, die einen Teil der Medulla oblongata darstellen. Einige Fasern laufen von dort zum kontralateralen Colliculus inferior, andere zum ipsilateralen Nucleus olivaris superior, von wo aus sie entweder in den ipsilateralen Colliculus inferior ziehen oder mit den restlichen Fasern aus den Nuclei cochleares als Corpus trapezoideum zum kontralateralen Nucleus olivaris superior kreuzen, um als Lemniscus lateralis über die Nuclei lemnisci laterales in den Colliculus inferior zu gelangen. Während vom ipsilateralen Colliculus inferior Projektionen zum ipsiund kontralateralen Corpus geniculatum mediale im Thalamus aufsteigen, projiziert der kontralaterale Colliculus inferior ausschließlich in das gleichseitige 
Corpus geniculatum mediale. Von hier aus bilden alle Projektionen die rechte bzw. linke Hörstrahlung und werden dem primären auditorischen Cortex im Temporallappen zugeführt. Die tonotope Organisation bleibt in der gesamten Hörbahn erhalten.

\subsection{Interzelluläre Kommunikation in der Cochlea und Connexin26}

Innerhalb der Cochlea finden sich zwei zelluläre Netzwerke, innerhalb derer gap junctions eine interzelluläre Kommunikation ermöglichen. Connexine stellen eine Gruppe von Transmembranproteinen dar, die gap junctions bilden. Je sechs Connexine lagern sich $\mathrm{zu}$ einer Poren-artigen Struktur, dem Connexon (Halbkanal), zusammen. Die Connexone zweier benachbarter adhärenter Zellen bilden gemeinsam die gap juncton (Goodenough 1976; Goodenough und Paul 2009), über die der Austausch von Ionen, Boten- und Nährstoffen erfolgen kann (Harris 2007). Im Menschen sind 21 verschiedene Connexine bekannt (in der Maus 20). Eines der kleinsten ist Connexin26. Das Gen GJB2, das für das 226 Aminosäuren lange Protein kodiert, liegt beim Menschen auf Chromosom 13 und bei der Maus auf Chromosom 14 (Söhl und Willecke 2004). Connexin26 wird in unterschiedlichen Geweben exprimiert. Nachgewiesen wurde es in Hepatozyten (Rosenberg et al. 1992), Keratinozyten, in der Placenta, der Niere, der Schilddrüse (Green et al. 1996), in den Meningen und in der Cochlea (Gerido und White 2004). Die Expression im Gehirn ist unwahrscheinlich (Söhl et al. 2004), obwohl in seltenen Fällen bei GJB2-Mutationen von zerebellären Defekten berichtet wurde (Titeux et al. 2009). In der Cochlea wurden neben Cx26 auch Cx29, Cx30, Cx31, Cx43, Cx45 und Cx50 nachgewiesen. Die vorherrschenden Connexine des epithelialen gap-junction-Netzwerks sind Cx26 und Cx30, wobei sie homo- und heteromere Connexone bilden (Sun et al. 2005). Im bindegewebigen gap-junctionNetzwerk ist außerdem Cx31 zu finden (Wangemann 2002; Jagger und Forge 2015).

\subsection{Das Keratitis-Ichthyosis-Taubheitssyndrom}

Das Keratitis-Ichthyosis-Taubheitssyndrom (KIT) bezeichnet eine Erkrankung, die sich durch eine vaskularisierende Keratitis des Auges, eine Verhornungsstörung der Haut und eine kongenitale sensorineurale Schwerhörigkeit 
auszeichnet. Ausprägung und Manifestation der Symptome sind variabel. Betroffene Patienten leiden unter einer chronischen Entzündung und progredienten Neovaskularisation der Cornea, die zu Photophobie, Hornhautulzerationen und -trübungen (Pannusbildung), einem Visusverlust und zur Erblindung führen können. Neben palmoplantaren Hyperkeratosen finden sich erythematöse, hyperkeratotische Plaques u. a. an Wangen und Kinn. Die gesamte Epidermis ist verdickt (Akanthosis). Eine vermehrte Schuppung der Haut ist zu beobachten (Ichthyosis). Diese Hautveränderungen können mit vermindertem Schwitzen einhergehen und die Hautatmung behindern, was rezidivierende virale, bakterielle und mykotische Infektionen bedingen kann. Schwere Septikämien können in einigen Fällen früh zum Tod führen (Gilliam und Williams 2002). Partieller oder kompletter Verlust von Kopfbehaarung, Augenbrauen und Wimpern (Alopecia, Hypotrichosis) sowie Dysplasien von Nägeln, Zähnen und Mundschleimhaut wurden beschrieben. Es besteht darüber hinaus ein erhöhtes Risiko für die Entstehung von Plattenepithelkarzinomen (Richard et al. 2002). Neben sporadisch auftretenden Mutationen im GJB2-Gen, die das KIT hervorrufen, sind autosomaldominante und -rezessive Erbgänge beschrieben. Eine der ursächlichen Mutationen ist Cx26S17F, bei der das n-terminale hydrophile Serin an Position 17 durch das lipophile Phenylalanin ausgetauscht ist (Richard et al. 2002).

\subsection{Mausmodell}

Da Mäuse genetisch gut manipulierbar sind und das Innenohr der Maus eine große Ähnlichkeit mit dem des Menschen aufweist, stellen Mausmodelle eine wichtige Größe in der Erforschung von syndromaler und nichtsyndromaler Schwerhörigkeit dar. Die Übereinstimmungen zwischen Maus- und humanem Genom (beinah $80 \%$ der Mausgene scheinen einem orthologen menschlichen Gen zu entsprechen) ermöglichen die Identifizierung von Genen, die in die Entstehung menschlicher Schwerhörigkeit involviert sind. In dieser Arbeit wurden zwei Mausmodelle untersucht. Die Mutationen, die diese aufweisen, betreffen Gene, deren Produkte zum einen an der Übertragung auditorischer Signale von der Bändersynapse der IHZ zum Hörnerven, zum anderen an der Regulation der cochleären Ionen-Homöostase beteiligt sind. 


\subsection{Fragestellung}

Innerhalb der Cochlea dient ein empfindliches Ionengleichgewicht einer spezialisierten synaptischen Maschinerie. Genetische Mutationen cochleärer Proteine haben in beiden Bereichen gravierende Auswirkungen. Durch die Untersuchung transgener Mausmodelle, in denen Proteine fehlen oder fehlerhaft exprimiert werden, können Rückschlüsse auf deren physiologische Funktion gezogen und Pathomechanismen von Erkrankungen aufgedeckt werden. Das Verstehen zugrundeliegender Pathomechanismen ist häufig Voraussetzung für eine effektive Therapie.

Diese Arbeit beschäftigt sich mit der Charakterisierung des Hörphänotyps zweier schwerhöriger Mausmodelle unter Etablierung und Anwendung systemphysiologischer Methoden. Zum einen wird untersucht, wie sich die Knockout-Mutation der $\mathrm{Cav}_{2} \beta_{2}$-Untereinheit des Cav1.3 an der IHZ-Synapse auf neuronaler Ebene auswirkt, zum anderen werden die Folgen der Punktmutation Cx26S17F im GJB2-Gen untersucht. 


\section{Material und Methoden}

Alle dargestellten Experimente wurden nach nationalem Tierschutzgesetz und mit Genehmigung der Universität Göttingen und des Niedersächsischen Landesamts für Verbraucherschutz und Lebensmittelsicherheit durchgeführt.

\subsection{Charakterisierung der Mauslinien}

\subsubsection{Mauslinie $\operatorname{Cav} \beta_{2}^{-1-}$}

Die in dieser Arbeit vorgestellten Experimente wurden an Knockout-Mäusen der $\beta_{2}$-Untereinheit der Cav1.3 durchgeführt. Da die Expression des Proteins im Herzmuskel für das Überleben der Tiere essenziell ist, wurde eine transgene Expression im Herzmuskel unter Kontrolle des Myosin-Schwerketten-Promotors wiederhergestellt (Ball et al. 2002). Die hier verwendeten Tiere haben einen gemischten genetischen Hintergrund aus 129/Sv, C57B1/6 und FVB.

Als Kontrollen dienten altersentsprechende C57B1/6-Mäuse. Es wurden Männchen und Weibchen im Alter von P21-P28 (FAEP und Distorsionsprodukte otoakustischer Emissionen (DPOAE)), P56-P63 (Immunhistochemie) und im Alter von P40-P70 (Mikroelektroden-Ableitungen) verwendet. Äußerlich wiesen die Tiere keine offensichtlichen Abnormalitäten auf.

Von Dr. rer. nat. J. Neef durchgeführte Patch-clamp-Experimente an $\mathrm{Cav} \beta_{2}{ }^{-/-}$-IHZ zeigten eine deutlich reduzierte Exozytose (um 68 \%). Diese wurde hauptsächlich durch die vergleichbar herabgesetzte Anzahl der membranständigen Cav1.3 bedingt. Ferner waren die entwicklungsbedingt vermehrte Expression und Clusterbildung von BK-Kanälen in IHZ herabgesetzt sowie ihre Öffnungseigenschaften verändert. Die während der Entwicklung vorhandene direkte efferente Innervation der IHZ konnte in $\mathrm{Cav}_{\mathrm{v}} \beta_{2}{ }^{-/}$-Mäusen auch nach Hörbeginn nachgewiesen werden. Eine Degeneration innerer oder äußerer Haarzellen wurde nicht gefunden.

\subsubsection{Mauslinie $\mathrm{C} \times 26^{+/ \mathrm{S} 17 \mathrm{~F}}$}

Im Menschen führt die Connexin26-Mutation S17F zum Keratitis-IchthyosisTaubheitssyndrom (Richard et al. 2002). Neben einer sensorineuralen Schwerhörigkeit leiden betroffene Patienten unter Akanthosen, Hyperkeratosen und einer chronisch vaskularisierenden Keratitis. Zum besseren Verständnis der Erkrankung 
wurde in der Arbeitsgruppe von Prof. Willecke in Bonn eine Mauslinie mit dieser Mutation erzeugt.

Um eine mögliche embryonale Letalität durch Defekte der Placentafunktion (Gabriel et al. 1998), wie sie beim vollständigen Fehlen von Cx26 auftritt, zu vermeiden, wurde bei der Erzeugung der $\mathrm{Cx} 26^{+/ \mathrm{S} 17 \mathrm{~F}}$ ein konditionaler Ansatz gewählt. Nach homologer Rekombination in embryonalen Stammzellen wird die Mutation unter dem endogenen Cx26-Promoter exprimiert. Dabei ist das wildtypCx26-Gen von loxP-Stellen flankiert. Nach einer vom Otogelin-Promoter getriebenen Cre-vermittelten Deletion der zwischen den loxP-Stellen liegenden Sequenzen wird die Cx26S17F-Mutation unter der Kontrolle des endogenen Cx26-Promoters exprimiert. Heterozygote Tiere wurden mit Phosphoglyzeratkinase-Cre-Mäusen, die die Cre-Rekombinase unter dem PhosphoglyzeratkinaseCre Promotor exprimieren, verpaart, um eine ubiquitäre Expression von Cx26S17F zu erreichen (für Details s. Schütz 2011). Im Rahmen dieser Arbeit wurde der Hörphänotyp in zwei unterschiedlichen Mausstammhintergründen (C57B1/6 und 129/Sv) untersucht. Es wurden Tiere im Alter von P58-P246 verwendet.

Während beim Menschen nur die homozygote Cx26S17F-Mutation zum beschriebenen Krankheitsbild führt, sterben homozygote Mausmutanten $\left(\mathrm{Cx} 26^{\mathrm{S} 17 \mathrm{~F} / \mathrm{S} 17 \mathrm{~F}}\right)$ aufgrund eines Placentadefekts spätestens am elften Tag der embryonalen Entwicklung (Gabriel et al. 1998). Dagegen treten phänotypische Merkmale analog der Erkrankung bei heterozygoten Mäusen $\left(\mathrm{Cx} 26^{+/ \mathrm{S} 17 \mathrm{~F}}\right)$ bereits in den ersten Lebenstagen auf. Sie sind deutlich kleiner als ihre Geschwister, weisen schuppige Haut auf, verkürzte Schwänze mit wunden Spitzen und unterentwickelte Pfoten. Das Bild der phänotypischen Anomalien ähnelt dem betroffener KIT-Patienten. Adulte $\mathrm{Cx} 26^{+/ \mathrm{S} 17 \mathrm{~F}}$-Mäuse zeigen Hyperkeratosen und Akanthosen an Palmae und Plantae, spärlichen Haarwuchs und annuläre Einschnürungen der Schwänze. Je nach Ausprägung des Phänotyps kann sich die Größendifferenz zu ihren Geschwistern verringern. Veränderungen der Cornea konnten nicht nachgewiesen werden (Schütz 2011).

Die Charakterisierung des Hautphänotyps wurde in der Arbeitsgruppe von Prof. Willecke durchgeführt. Den Hautphänotyp und die Körpergröße betreffend war die Ausprägung der Mutation in Mäusen mit C57Bl/6-Hintergrund stärker als in 
129/Sv-Mäusen. Die Ausprägung zeigte sich aber auch zwischen Individuen desselben Hintergrunds variabel. $\mathrm{Cx} 26^{+/ \mathrm{S} 17 \mathrm{~F}}$-Neugeborene hatten eine Überlebensrate von 30-40 \%. Mit dem Auftreten sichtbarer Hautveränderungen (P6-7) sank die Sterberate deutlich.

\subsection{Frühe akustisch evozierte Potenziale}

Für die Erzeugung und Präsentation der akustischen Reize sowie für die Aufnahme der Messdaten wurden ein Tucker Davis Technologies System II oder III mit einer BioSig32 Software (Tucker Davis Technologies, Alachua, USA) und ein Hochfrequenz-Freifeldlautsprecher (Monacor, Bremen, Deutschland) verwendet.

Die Stimulusintensität wird in Dezibel SPL root mean square (RMS) für tonale Stimuli oder in Dezibel SPL peak equivalent für Clicks angegeben. Tonimpulse (4, 8, 12, 16, 24, $32 \mathrm{kHz}, 10 \mathrm{~ms}$ Plateau, $1 \mathrm{~ms} \cos ^{2}$-Rampen) oder Clicks von $0,03 \mathrm{~ms}$ Dauer wurden mit einer Frequenz von $20 \mathrm{~Hz}$ ipsilateral präsentiert. Der maximal getestete Pegel war $100 \mathrm{~dB}$ (90 dB für $\mathrm{Cav} \beta_{2}$-Tiere) für Tonimpulse und $130 \mathrm{~dB}$ für Clicks. Die Kalibrierung des Lautsprechers erfolgte mit einem 1/4-Zoll Mikrophon (Brüel\&Kjær, Nærum, Dänemark; Modell 4939).

Die Tiere wurden mittels intraperitonealer Injektion von Ketamin $(125 \mathrm{mg} / \mathrm{kg})$ und Xylazin $(2,5 \mathrm{mg} / \mathrm{kg})$ narkotisiert. Über das aufgezeichnete Elektrokardiogramm wurde die Tiefe der Anästhesie kontrolliert. Die rektal gemessene Körpertemperatur wurde mittels temperaturkontrollierter Heizmatte (Hugo Sachs Elektronik - Harvard Apparatus, March, Deutschland) konstant auf $37^{\circ} \mathrm{C}$ gehalten. Subdermal eingebrachte Insulininjektionsnadeln über dem Mastoid, dem Vertex und dem Rücken dienten als Elektroden. Die zwischen ihnen gemessene Potenzialdifferenz wurde verstärkt (50000-fach), gefiltert (Tiefpass, $4 \mathrm{kHz}$; Hochpass, $100 \mathrm{~Hz}$ ) und mit einer Rate von $50 \mathrm{kHz}$ über $20 \mathrm{~ms}$ aufgezeichnet. Es wurden 2 x 2000 Mittelungen aufgenommen, um für jede Stimulusintensität gemittelte FAEP-Wellen zu erhalten. Die Hörschwelle wurde mit einer Genauigkeit von $10 \mathrm{~dB}$ definiert als der niedrigste Pegel, der in beiden AufzeichnungsSpuren reproduzierbar eine visuell detektierbare Welle als Antwort auf den Stimulus zeigte. 


\subsection{Distorsionsprodukte otoakustischer Emissionen}

Zur Funktionsprüfung des cochleären Verstärkers wurden Distorsionsprodukte otoakustischer Emissionen (DPOAE) gemessen. Für die Messung der DPOAE erfolgten Narkose und Temperaturkontrolle ebenso wie für die FAEP beschrieben. Über einen CD-Spieler und ein ED1/EC1 Lautsprechersystem (Tucker Davis Technologies, Alachua, USA) wurden zwei Sinustöne (im Verhältnis: f2/f1 = 1,2) generiert und durch trichterförmige Sonden in den Gehörgang der Mäuse geleitet. Ein ebenfalls in der Sonde enthaltenes Mikrophon (Sennheiser, Barleben bei Magdeburg, Deutschland) wurde auf eine Intensität von $60 \mathrm{~dB}$ SPL geeicht und auf das Trommelfell ausgerichtet. Das über das Mikrophon erhaltene Signal wurde verstärkt (Midiman M-audio DMP3; Hallbergmoos, Deutschland), mit einer 24-bit-Sound-Karte (Noxon, ehemals Terratec, Nettetal, Deutschland) digitalisiert und mittels schneller Fourier-Transformation analysiert.

\subsection{Das endocochleäre Potenzial}

Für die Messung des EPs erfolgten Narkose und Temperaturkontrolle ebenso wie für die FAEP beschrieben. Eine Tracheotomie ermöglichte den Gebrauch einer Kopfhalterung bei erhaltener Spontanatmung. Über einen postaurikulären Zugang wurde das Mittelohr der Maus (Bulla) aufgesucht und breit eröffnet. Die knöcherne Abdeckung der Skala media der basalen Windung wurde vorsichtig mit einem Skalpell entfernt. Als Referenzelektrode wurde ein AgCl-Draht in einer Glasführungsschiene in der Nackenmuskulatur platziert. Das EP wurde über einen Impedanzwandler, verbunden mit einem Voltmeter, mit einem PC mittels von G. Hoch geschriebener Scilab software (Consortium Scilab, Le Chesnay, Frankreich) aufgezeichnet. Als Messelektrode wurde ein AgCl-Draht in einer GlaskapillarMikroelektrode, gefüllt mit $4 \mathrm{M} \mathrm{KCl}$ und $2 \%$ Methylenblau verwendet. Das gemittelte Potenzial, gemessen auf der Oberfläche des Ligamentum spirale, diente als DC Referenzpotenzial. Mit einem Mikromanipulator (World Precision Instruments, Sarasota, USA) wurde die Elektrode in die Skala media eingeführt, bis der charakteristische Anstieg des gemessenen Potenzials zu beobachten war und ein stabiles Plateau erreichte. Stabile Potenziale wurden über mindestens $60 \mathrm{~s}$ abgeleitet. Nach der Messung wurde am Ligamentum spirale erneut das Referenzpotenzial ermittelt. Das EP wurde von beiden Cochleae eines Tieres abgeleitet. Zur Verifizierung des Ursprungs des gemessenen Potenzials wurden 
die Tiere während der zweiten Messung durch Asphyxie getötet, um das bekannte Zusammenbrechen des EPs beobachten zu können (Bosher 1979; Komune et al. 1983; Melichar und Syka 1987).

\subsection{Statistische Auswertung}

Die Analyse der Daten erfolgte mit Microsoft Excel und Statistica (StatSoft, Tulsa, USA). Graphen wurden in Igor Pro (Wavemetrics, Portland, USA) erstellt. Zur Prüfung signifikanter Unterschiede wurden der Mann-Whitney U-Test (FAEP Click, EP und Spontanaktivitätsraten) oder eine Kruskal-Wallis-ANOVA (FAEP tonale Stimuli) durchgeführt. Auf Normalverteilung wurde mittels Shapiro-WilkTest untersucht. Bei allen Vergleichen war zumindest ein Teil der Daten nicht normalverteilt. Eine Kumulierung des $\alpha$-Fehlers wurde nach Bonferroni korrigiert. Signifikante Unterschiede sind wie folgt gekennzeichnet: *: $p<5 \%$;*: $p<1 \%$ Um das Hörvermögen unterschiedlicher Frequenzen zusammenzufassen und eine Kategorisierung vornehmen zu können, wird für klinische Studien eine Mittelung der Hörschwelle bei 0,5, 1, 2 und $3 \mathrm{kHz}$ empfohlen (Gurgel et al. 2012). In Anlehnung daran wurden hier, entsprechend dem Hörfeld von Mäusen, die Schwellen bei 8, 12, 16 und $24 \mathrm{kHz}$ gemittelt und zu einer Reinton-Hörschwelle zusammengefasst.

\subsection{Extrazelluläre Mikroelektroden-Ableitungen von einzelnen Hörnervenfasern}

Die Einzelfaser-Ableitungen von auditorischen Neuronen wurden wie von Taberner und Liberman (2005) und Strenzke et al. (2009) beschrieben durchgeführt. Für die Generierung der Stimuli und die Aufnahme der Antworten wurden ein Tucker Davis Technologies System III und ein ELC-03XS Verstärker (NPI Electronics, Tamm, Deutschland) verwendet, die mit einer Matlab software (MathWorks, Natick, USA) betrieben wurden. Dargeboten wurden die Stimuli über einen Freifeldlautsprecher (JBL 2404) (JBL Professional, Northridge, USA).

Nach Einleitung einer intraperitonealen Narkose mit Urethan $(1,3 \mathrm{mg} / \mathrm{kg})$, Xylazin $(5 \mathrm{mg} / \mathrm{kg})$ und Buprenorphin $(0,1 \mathrm{mg} / \mathrm{kg})$ wurden die Tiere tracheotomiert, um die Spontanatmung in einer stereotaktischen Kopfhalterung zu ermöglichen. Die Körpertemperatur wurde mittels temperaturkontrollierter Heizplatte (Harvard Apparatus, Holliston, USA) und einer Umgebungstemperatur 
von etwa $30^{\circ} \mathrm{C}$ in einer schallisolierten Messkammer konstant gehalten. Das äußere Ohr sowie die Haut des Hinterhauptes wurden entfernt. Über einen occipitalen Zugang wurde eine partielle Hemicerebellektomie links durchgeführt, um den Nucleus cochlearis und den vorderen Bogengang in der Apertura externa canaliculi cochleae des Os temporale darzustellen. Eine mit $3 \mathrm{M} \mathrm{NaCl}$ und $2 \%$ Methylenblau gefüllte Glaskapillar-Mikroelektrode wurde mit Hilfe eines Inchworm Mikromanipulators (EXFO Burleigh, Mississauga, Canada) durch den Nucleus cochlearis hindurch in Richtung des inneren Gehörgangs gesteuert. Dazu wurde die Elektrodenspitze etwa $1 \mathrm{~mm}$ medial des medio-caudalen Pols des durch den Knochen scheinenden Canalis semicircularis anterior platziert und in der Sagittalebene $24^{\circ}$ vorwärts geneigt. Während den Tieren mit einer Rate von $10 \mathrm{~Hz}$ Breitband-Rausch-Impulse dargeboten wurden, wurde das abgeleitete Elektrodensignal auditiv und visuell überwacht, um durch den akustischen Reiz aktivierte Neurone zu finden. Nach der Messung der Spontanaktivitätsrate (SR) eines Neurons, wurden die frequenzspezifischen Schwellen für Tonreize bestimmt. $15 \mathrm{~ms}$ dauernde Tonimpluse in zunehmender Frequenz (initial 1/2-Oktavschritte) wurden dargeboten und die jeweilige Rate der Antwort-AP analysiert. Durch einen automatisch ablaufenden adaptiven Algorithmus wurde die Schwelle für jede untersuchte Frequenz mit einer Präzision von $2 \mathrm{~dB}$ ermittelt. Dazu wurde der Wald's Sequential Probability Ratio Test verwendet. Die Schwelle war dabei definiert als ein Anstieg von $20 \mathrm{AP} / \mathrm{s}$ innerhalb von $20 \mathrm{~ms}$ vom Beginn des Tonimpulses. Im Bereich der jeweils niedrigsten Schwelle wurde die FrequenzSchrittweite halbiert, um schließlich die charakteristische Frequenz (CF) mit einer Auflösung von 1/32 Oktave zu definieren. Weitere Untersuchungen wurden mit Reintonreizen der CF durchgeführt. Für Neurone, deren CF aufgrund zu geringer AP-Raten nicht mittels Frequenzabstimmung identifiziert werden konnte, wurde die Frequenz mit bester AP-Antwort bei hohen Stimuluspegeln gesucht. Zu Beginn der Versuchsreihe gelang dies manuell, später durch einen systematisch ablaufenden Algorithmus. Mit der ermittelten CF als Stimulus wurde bei $30 \mathrm{~dB}$ oberhalb der Schwelle ein Post-Stimulus-Zeit-Histogramm (PST) erstellt, anhand dessen Musters die Klassifizierung des Neurons erfolgte. Darauf folgte die Messung einer Raten-Pegel-Funktion (RLF (rate-level-function)) und einer Vorwärtsmaskierung. 
Für die anschließende Analyse wurden von PD Dr. med. N. Strenzke geschriebene Matlab-Routinen verwendet, die zur AP-Identifizierung (Unterscheidung zwischen AP und Rauschen) die aufgenommen Spuren mit Schablonen verglichen. Diese wurden für jedes Neuron individuell anhand eines manuell festgesetzten Schwellenwerts (Amplituden [V]) für AP erstellt. Der Erfolg dieser Prozedur wurde durch Inspektion der nach Form sortierten identifizierten Wellen kontrolliert und die Qualität der Aufzeichnung auf einer Bewertungs-Skala subjektiv bewertet. Die Mehrheit der Bewertungen wurde durch eine unabhängige, erfahrene zweite Person, die in Bezug auf den Genotyp der Tiere verblindet war, überprüft. In die finale Auswertung gingen nur Datensätze ein, bei denen die große Mehrheit der AP klar vom Rauschen abgrenzbar war. Nach der Klassifikation (für Details s. Kapitel 6.1. Klassifikation von auditorischen Neuronentypen) wurden die Daten in einer Microsoft Access Datenbank (Microsoft Corporation, Redmond, USA) gespeichert.

\subsection{Immunhistochemie}

\subsubsection{Lösungen}

Alle Lösungen sind, wenn nicht anders beschrieben, in Aqua dest. angefertigt.

\section{Name}

$\begin{array}{ll}\text { 1. Antikörper } & \begin{array}{l}\text { Neurofilament } 200 \text { (Nervenfaser 200) } \\ \text { anti-mouse, 1/400 in GSDB }\end{array} \\ \text { 2. Antikörper } & \begin{array}{l}\text { goat-anti mouse (Alexa 488-konjugiert } \\ \text { green (Invitrogen, Carlsbad, Kalifor- } \\ \text { nien, USA), } 1 / 200 \text { in GSDB }\end{array} \\ \text { Phalloidin (red) } & 1 / 200 \text { in GSDB } \\ \text { Hoechst (blue) } & 1 / 200 \text { in GSDB } \\ \text { FA } & 4 \% \text {-ige Lösung aus } 120 \text { mM PBS und } \\ & 37 \% \text {-iger Formaldehydlösung } \\ \text { PBS (phosphate buffered saline) } & 140 \mathrm{mM} \mathrm{NaCl} \\ \text { (Sigma-Aldrich, St. Louis, Missouri, } & 2,7 \mathrm{mM} \mathrm{KCl} \\ \text { USA) } & 8 \mathrm{mM} \mathrm{Na2HPO4} \\ & 1,5 \mathrm{mM} \mathrm{KH2PO4} \\ \text { GSDB (goat serum dilution buffer) } & 16 \% \text { normal goat serum } \\ & 450 \mathrm{mM} \mathrm{NaCl} \\ & 0,3 \% \text { Triton X-100 (Sigma-Aldrich, St. } \\ & \text { Louis, Missouri, USA) } \\ & 20 \mathrm{mM} \text { Phosphatpuffer }\end{array}$


Waschpuffer

$450 \mathrm{mM} \mathrm{NaCl}$

$0,3 \%$ Triton X-100

$20 \mathrm{mM}$ Phosphatpuffer

PB (240 mM) (phosphate buffer) $194 \mathrm{mM} \mathrm{Na} 2 \mathrm{HPO} 4$

$46 \mathrm{mM} \mathrm{NaH} 2 \mathrm{PO} 4$

Tabelle 2.7.1-1 Lösungen und deren Zusammensetzung

\subsubsection{Präparation der Cochleae}

Die Tiere wurden in $\mathrm{CO}_{2}$-Narkose dekapitiert und die Cochleae entnommen. Ovales und rundes Fenster wurden eröffnet und der Knochen über der mittleren und apicalen Windung entfernt. Die Cochleae wurden mit $4 \%$-iger Formaldehydlösung perfundiert und anschließend für eine Stunde darin fixiert. Nach zehnminütigem Waschen in PBS wurden sie mit 0,5 M EDTA (Sigma-Aldrich, St. Louis, Missouri, USA) über Nacht decalzifiziert und erneut in PBS gewaschen. Der Knochen über der basalen Windung und die dorsale Seite der Cochlea wurden inzidiert, um den Antikörperlösungen das Erreichen ihrer Zielstrukturen zu erleichtern. Die Präparate wurden bei Raumtemperatur eine Stunde in GSDB inkubiert, um unspezifische Bindungsstellen zu blockieren. Über Nacht wurden sie bei $4^{\circ} \mathrm{C}$ mit dem ersten Antikörper inkubiert. Nach dreimaligem Waschen in Waschpuffer für jeweils zehn Minuten, wurden die Präparate zwei Stunden bei Raumtemperatur mit dem zweiten Antikörper, Phalloidin und Hoechst inkubiert. Es erfolgte dreimaliges Waschen in Waschpuffer für jeweils zehn Minuten und die Umbettung in $5 \mathrm{mM}$ PB für mindestens fünf Minuten. Das Corti-Organ samt Modiolus und Ganglion spirale der einzelnen Windungen wurde aus den Cochleae herauspräpariert und in DAKO fluorescence mounting medium (DAKO, Glostrup, Dänemark) auf Objektträgern platziert und mit Deckgläschen bedeckt. Je eine Cochlea wurde ganz belassen und an einem Cryostat (Leica, Wetzlar, Deutschland; Modell CM-3050-S) der Länge nach $200 \mu \mathrm{m}$ dick geschnitten.

\subsubsection{Mikroskopie}

Unter einem Konfokal-Mikroskop (63x/1.40 NA Objektiv; Leica TCS SP5, Leica Mikrosysteme, Wetzlar, Deutschland) wurden Bilder der Präparate angefertigt. Die Anregung erfolgte mit einem 405 nm Dioden-Laser, einem 488 nm ArgonLaser und einem $561 \mathrm{~nm}$ Helium-Neon-Laser. Die Laser-Intensität und die Verstärkung des Photomultipliers wurden angepasst, um die Fluoreszenzerfassung 
$\mathrm{zu}$ optimieren ohne eine Sättigung zu erreichen. Als Ausgangswerte wurden Laser-Intensität und Verstärkung auf $15 \%$ und $820 \mathrm{~V}(405 \mathrm{~nm}), 100 \%$ und $1083 \mathrm{~V}(488 \mathrm{~nm})$ sowie $20 \%$ und $1074 \mathrm{~V}(561 \mathrm{~nm})$ eingestellt. Es wurden Einzelschicht-Schnitte auf einer Ebene $10-15 \mu \mathrm{m}$ unterhalb (basal) der Nuclei der IHZ angefertigt. Die Bildaufnahme geschah mit 16 bit, einer Auflösung von 8192 x 8192 px, 4-facher Mittelung und einer Geschwindigkeit von $400 \mathrm{~Hz}$.

Bilder wurden mit Leica LAS AF Lite software aufgenommen und in ImageJ bearbeitet. Für die Dichtebestimmung auditorischer Neurone in histologischen Spiralganglionschnitten wurde ein kreisförmiger Bildausschnitt mit einem Durchmesser von 97,5 $\mu \mathrm{m}$ aus dem medialen Bereich des Ganglions gewählt. Auf einer Fläche von 481,2 $\mu \mathrm{m}^{2}$ wurden Zellkerne gezählt (Abbildung 2.7.3-1).

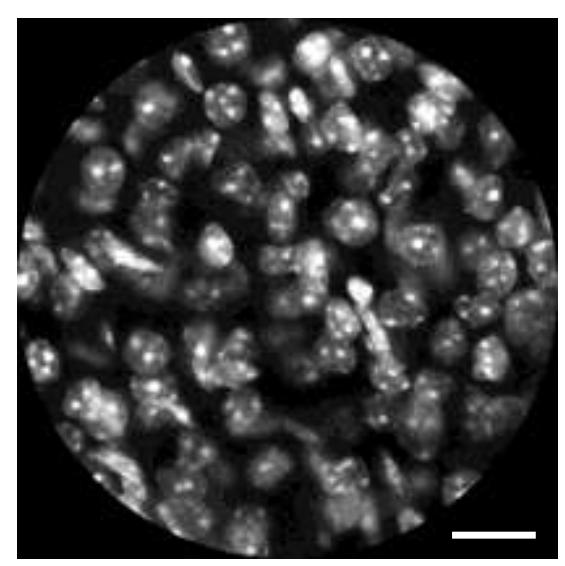

Abbildung 2.7.3-1 Spiralganglionneurone

Exemplarische Zählfläche. Maßstab $20 \mu \mathrm{m}$

Alle angeschnittenen Kerne in der Randzone wurden einbezogen. Ihre Anzahl wurde extrapoliert, um die Dichte im Bezug auf $1000 \mu \mathrm{m}^{2}$ angeben zu können. 


\section{Ergebnisse}

\section{1. $C a v \beta_{2}{ }^{-1-}-$ Mäuse weisen ein geringes Restgehör auf}

\subsubsection{Frühe akustisch evozierte Potenziale und Distorsionsprodukte otoakustischer Emissionen}

Zur Funktionsprüfung des auditorischen Systems wurden zunächst DPOAE und FAEP gemessen. Trotz der Präsenz der ÄHZ (Neef et al. 2009) wurden DPOAE, die die cochleäre Verstärkung widerspiegeln, nur in zwei von zehn Ohren nachgewiesen (Abbildung 3.1.1-1). Diese waren in ihrer Amplitude deutlich reduziert.

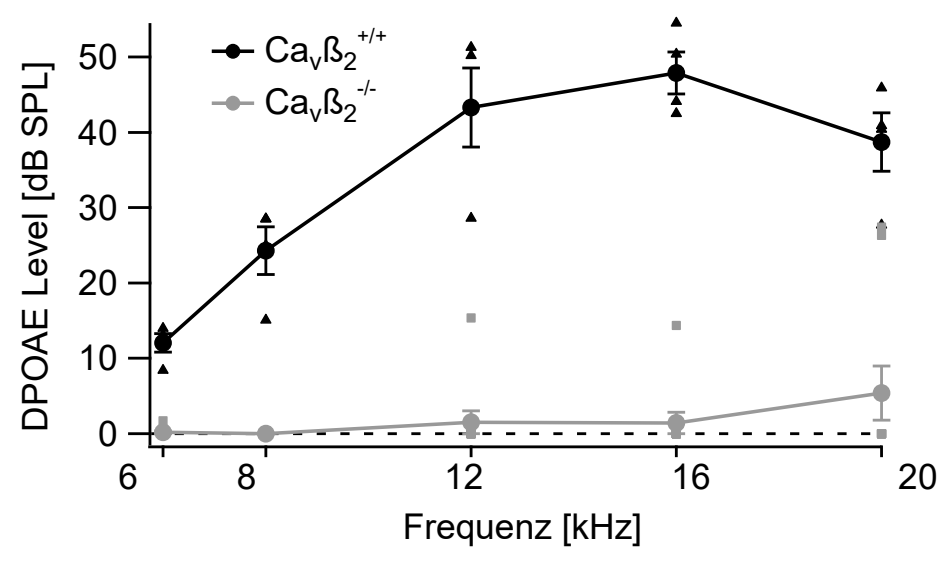

\section{Abbildung 3.1.1-1 Distorsionsprodukte otoakustischer Emissionen}

Gemittelte DPOAE-Pegel relativ zum Hintergrundgeräusch.

In $\mathrm{Cav}_{2} \beta_{2}{ }^{+/+}$-Tieren (schwarz) waren DPOAE bei allen getesteten Frequenzen deutlich sichtbar. Im Gegensatz dazu fehlten sie in $\mathrm{Cav}_{2} \beta_{2}^{-{ }^{-}}$-Tieren weitgehend. Bei hohen Frequenzen waren möglicherweise in einzelnen Individuen DPOAE schwach vorhanden. Dreiecke und Rechtecke representieren Ausreißer.

Stichprobengröße: $\mathrm{Ca}_{v} \beta_{2}{ }^{+/+}$schwarz, $\mathrm{n}=4 ; \mathrm{Ca}_{\mathrm{v}} \beta_{2}{ }^{-/}$hellgrau, $\mathrm{n}=10$

Bei der Ableitung der FAEP konnten messbare Antworten von $\mathrm{Cav} \beta_{2}{ }^{-/-}$-Tieren erst mit hohen Stimulationspegeln erreicht werden. In Abbildung 3.1.1-2 sind diese zusammen mit denen von $\mathrm{Cav}_{2}{ }_{2}{ }^{+/+}$-Tieren dargestellt. Eine Aufzeichnung ohne detektierbare Antwort (bei $80 \mathrm{~dB}$ ) ist zum Vergleich mit abgebildet. In den Messdaten der $\mathrm{Ca}_{v} \beta_{2}{ }^{-/-}$-Tiere sind die klare Abgrenzung und Identifizierung der Wellen I-V nicht möglich. Nichtsdestotrotz sind eine deutliche Verringerung der Amplituden und eine Erhöhung der Latenzen zu erkennen. 


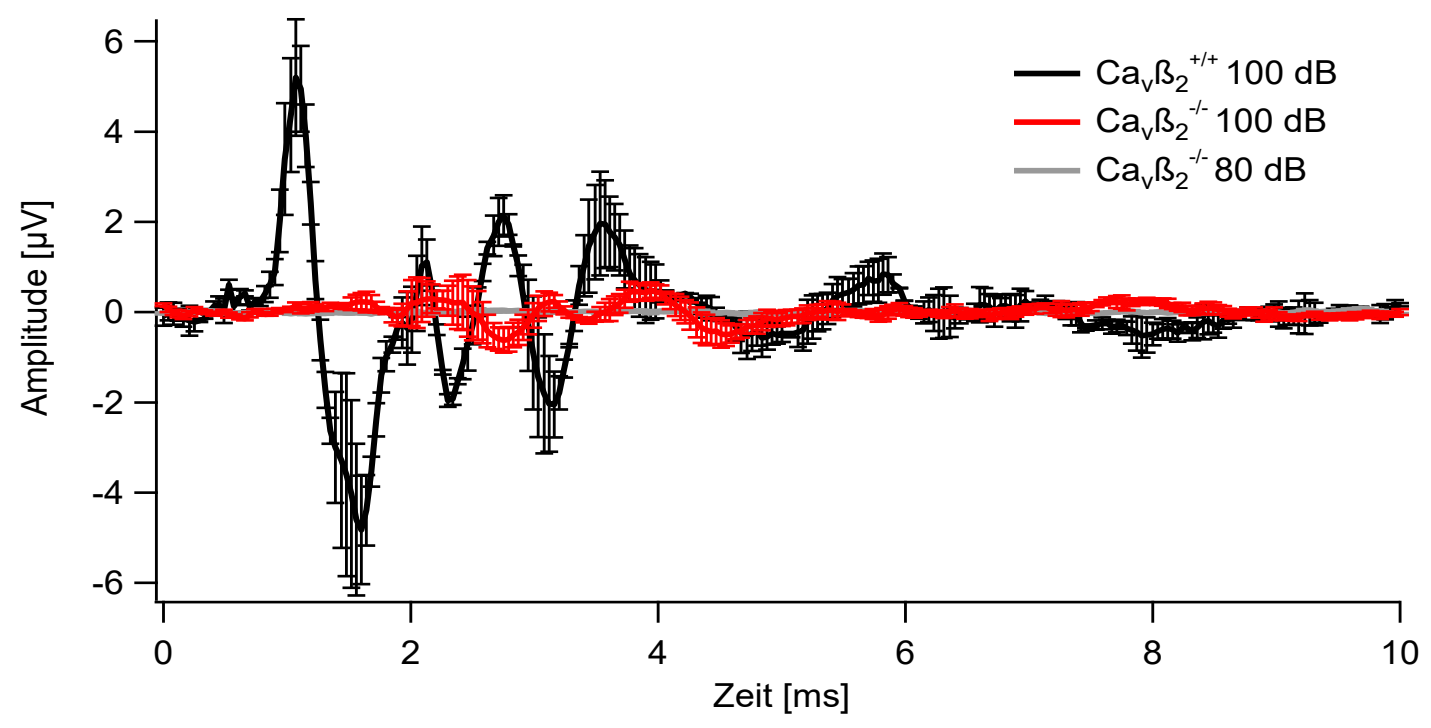

Abbildung 3.1.1-2 Frühe akustisch evozierte Potenziale

FAEP-Wellen als Antwort auf einen überschwelligen Click-Stimulus von $\mathrm{Cav}_{v} \beta_{2}{ }^{+/+}-$und $\mathrm{Cav}_{2} \beta_{2}{ }^{-/}$Mäusen. Zum Vergleich ist die Aufnahme von $\mathrm{Ca}_{v} \beta_{2}{ }^{-/-}$-Tieren mit unterschwelligem Reiz gezeigt, in der eine nachweisbare Antwort-Welle fehlt. Fehlerbalken zeigen den SEM.

Stichprobengröße: $\mathrm{Ca}_{\vee} \beta_{2}^{+/+}$schwarz, $\mathrm{n}=2 ; \mathrm{Ca}_{\vee} \beta_{2}{ }^{-/-} \operatorname{rot}(100 \mathrm{~dB}), \mathrm{n}=5 ; \mathrm{Ca}_{\vee} \beta_{2}{ }^{-/-}$hellgrau $(80 \mathrm{~dB})$, $\mathrm{n}=5$

$\mathrm{Cav}_{2} \beta_{2}^{--/}$-Mäuse zeigten eine profunde Schwerhörigkeit für Clicks (Hörschwelle $90 \pm 3,5 \mathrm{~dB}$ ). Die Hörschwelle konnte für Sinustöne mit den verfügbaren Lautsprecherleistungen nicht bestimmt werden, d.h. die Reinton-Hörschwelle lag oberhalb von $>90 \mathrm{~dB}$. Im Vergleich zu ihren $\mathrm{Cav} \mathrm{B}_{2}{ }^{+/+}$-Kontrollen betrug die Hörschwelleerhöhung 68,6 dB für Clicks und $>67,8 \mathrm{~dB}$ für Reintöne; Abbildung 3.1.1-3).

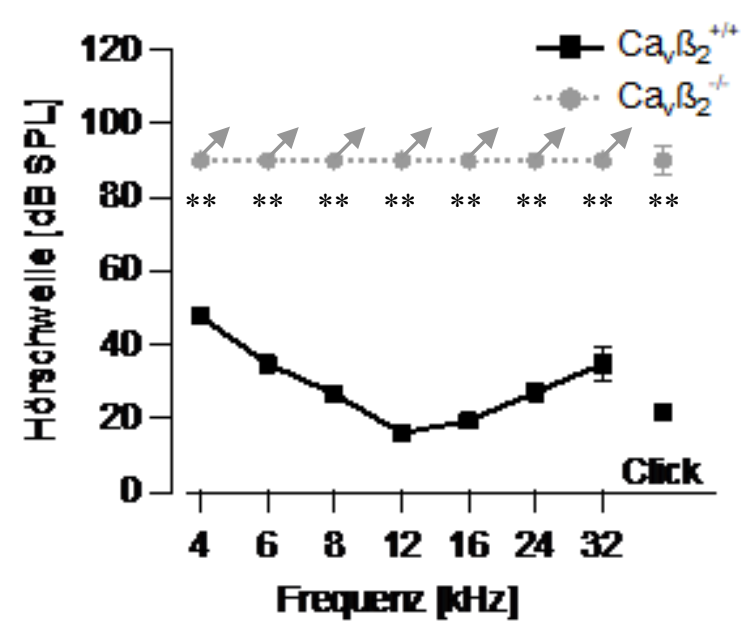

Abbildung 3.1.1-3 Hörschwellen

$\mathrm{Ca}_{v} \beta_{2} 2^{-/-}$-Tiere zeigten für Clicks eine Hörschwelle von $90 \mathrm{~dB}$. Für tonale Stimuli lag die Schwelle über $90 \mathrm{~dB}$ (maximal getesteter Pegel). **: p $<1 \%$. Fehlerbalken zeigen den SEM.

Stichprobengröße: $\mathrm{Ca}_{\vee} \beta_{2}{ }^{+/+}$schwarz, $\mathrm{n}=9 ; \mathrm{Ca}_{\vee} \beta_{2}{ }^{-/-}$hellgrau, $\mathrm{n}=5$ 


\subsubsection{Extrazelluläre Mikroelektroden-Ableitungen}

Für das bessere Verständnis der Auswirkungen des zellphysiologischen Phänotyps wurden extrazelluläre Messungen im auditorischen Nerven und im Nucleus cochlearis durchgeführt. Im Vergleich zu Untersuchungen an $\mathrm{Cav} \beta_{2}{ }^{+/+}$-Mäusen konnte bei $\mathrm{Cav}_{v} \beta_{2}{ }^{-/-}$-Mäusen nur wenig akustisch evozierte Aktivität der einzelnen Neurone detektiert werden, und diese nur mit Reizpegeln von mehr als $100 \mathrm{~dB}$. Das Hauptaugenmerk wurde auf Neurone gerichtet, die nach unseren Kriterien SGN entsprechen (für Details s. Kapitel 6.1. Klassifikation von auditorischen Neuronentypen).

\subsubsection{Spontanaktivitätsraten der Spiralganglionneuronen sind verringert}

Die SR der $\operatorname{Cav} \beta_{2}{ }^{-/-}$-SGN war im Vergleich zu Cav $\beta_{2}{ }^{+/+}$-SGN geringfügig ver-

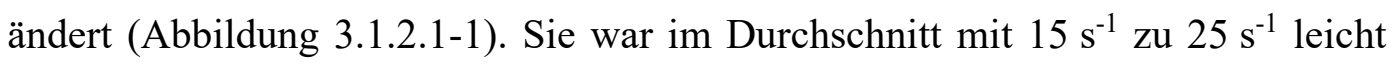
reduziert. Ihr Variationskoeffizient betrug $86,4 \%$ bzw. 124,3\%, was eine geringere Streuung in $\mathrm{Cav}_{2} \beta_{2}^{-/-}$-SGN suggeriert.

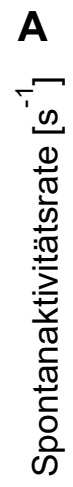
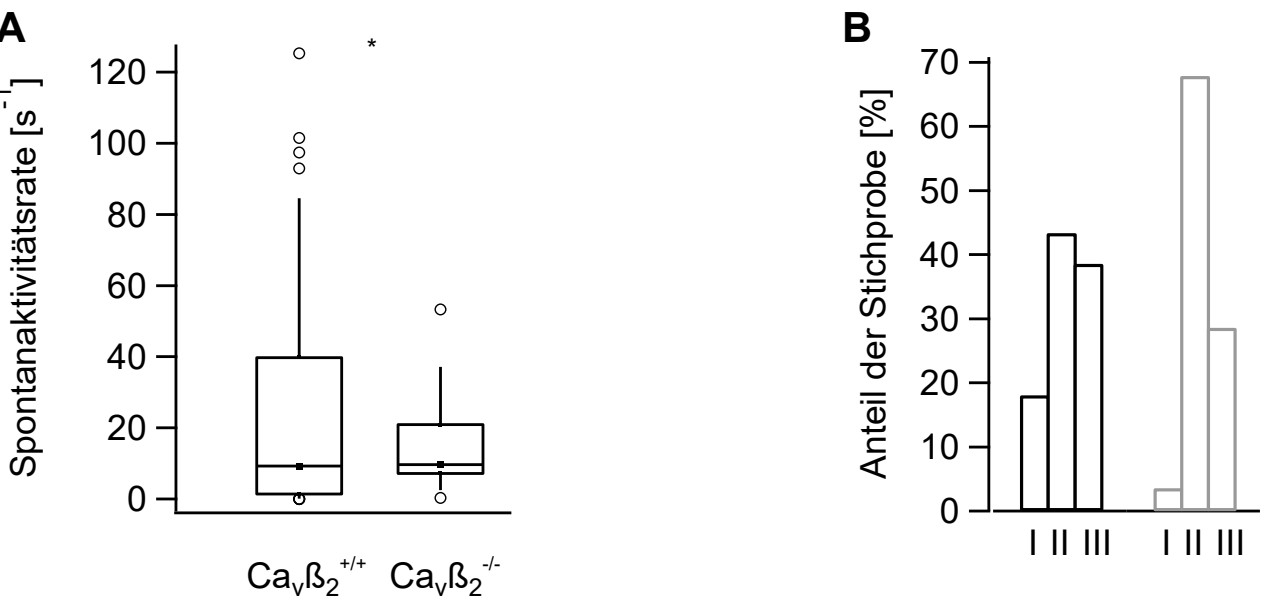

\section{Abbildung 3.1.2.1-1 Verteilung der Spontanaktivitätsraten}

A: Boxplot mit Median, oberem und unterem Quartil, Antennen zeigen oberes und unteres Dezil, Ausreißer sind definiert als unterhalb der 5. bzw. oberhalb der 95. Perzentile gelegen. *: $\mathrm{p}<5 \%$. B: Einteilung in Gruppen nach Liberman: Gruppe I: SR $<0,5 \mathrm{~s}^{-1}$, Gruppe II: $>0,5$ und $<18 \mathrm{~s}^{-1}$ sowie Gruppe III: $>18 \mathrm{~s}^{-1}$ ). In $\mathrm{Cav}_{v} \beta_{2}{ }^{-/-}$überwogen SGN mit mittlerer SR.

Stichprobengröße: $\mathrm{Cav}_{\vee} \beta_{2}^{+/+}$schwarz, $\mathrm{n}=83 ; \mathrm{Cav} \beta_{2} 2^{-/-}$hellgrau, $\mathrm{n}=28$ 


\subsubsection{Die Frequenzabstimmung ist abgeflacht}

Die Frequenzabstimmung der $\operatorname{Cav} \beta_{2}{ }^{--}-$Mäuse zeigte im Vergleich zu den typisch trichterförmigen Kurven $\operatorname{der} \mathrm{Cav}_{2} \beta_{2}^{+/+}$-Kontrollen breite, flache Verläufe (Abbildung 3.1.2.2-1).

A

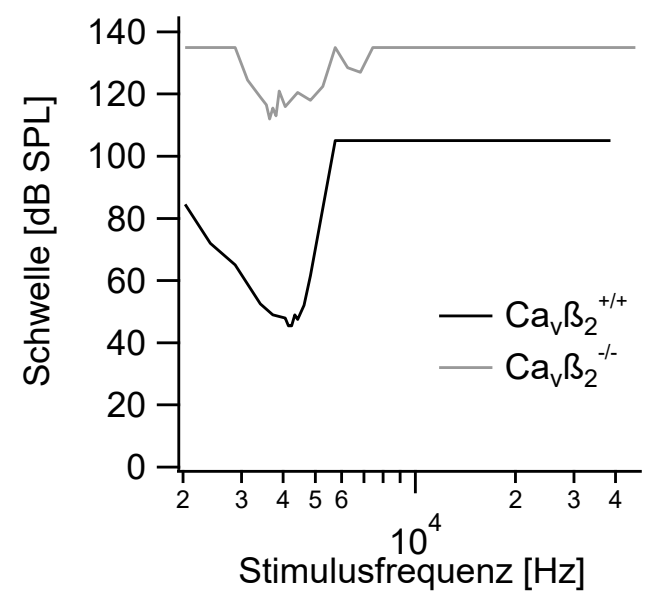

C

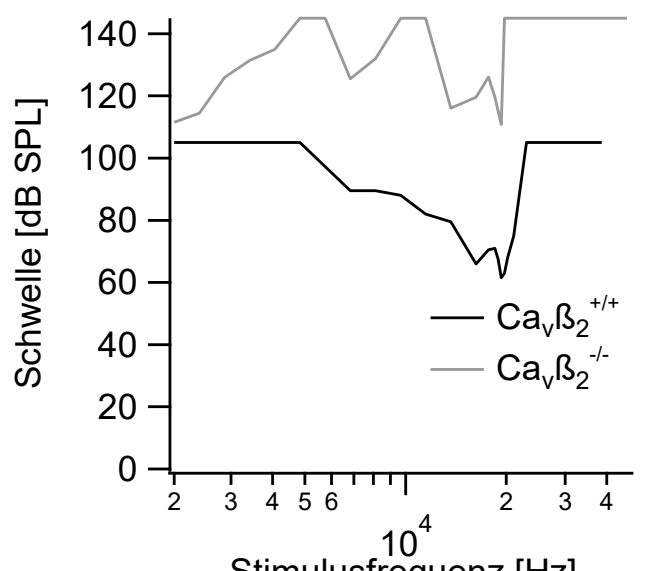

B

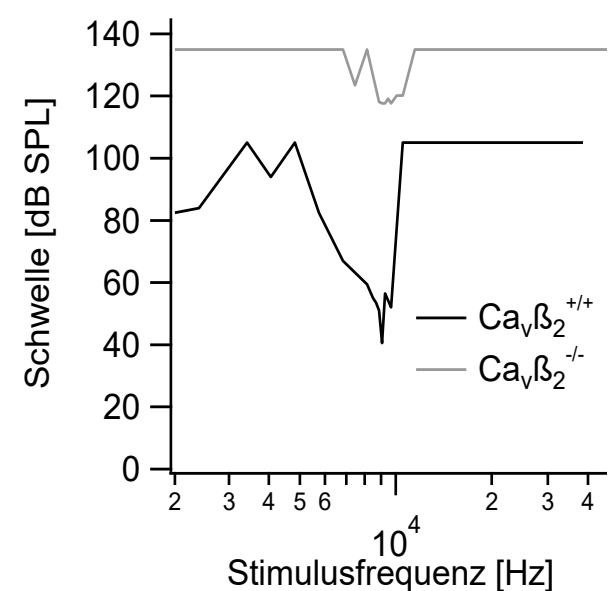

D

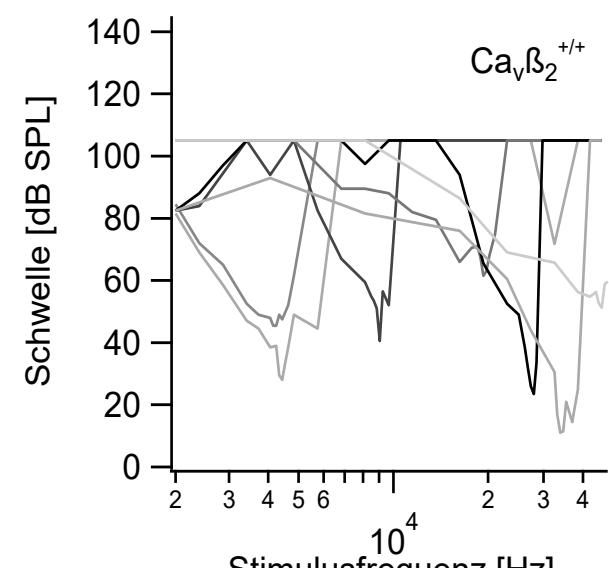

Abbildung 3.1.2.2-1 Frequenzabstimmungen

A-C: Exemplarische Darstellung von Frequenzabstimmungen unterschiedlicher SGN. Ausgewählt wurden die besten $\mathrm{Cav}_{v} \beta_{2}{ }^{-/-}$-Frequenzabstimmungen und im Vergleich $\mathrm{zu} \mathrm{Cav}_{v} \beta_{2}{ }^{+/+}$-Frequenzabstimmungen mit ähnlicher charakteristischer Frequenz aufgetragen. A: CF um $4 \mathrm{kHz}$. B: CF um $9 \mathrm{kHz}$. C: $\mathrm{CF}$ um $20 \mathrm{kHz}$. D: Repräsentative $\mathrm{Cav}_{\mathrm{v}} \beta_{2}{ }^{+/+}$-Frequenzabstimmungen mit unterschiedlichen CF zur Übersicht.

Dargestellt sind die besten $\mathrm{Cav}_{v} \mathrm{\beta}_{2}{ }^{-/}$-Beispiele im Vergleich zu korrespondierenden Kontrollen. Eine Quantifizierung der Frequenzabstimmung mit herkömmlichen Mitteln wie dem $\mathrm{Q}_{10 \mathrm{~dB}}$ (Breite der Kurve $10 \mathrm{~dB}$ über der Schwelle) war nicht möglich, da die Differenz zwischen Schwelle und maximaler Lautsprecherleistung häufig weniger als $10 \mathrm{~dB}$ betrug. Zudem musste die charakteristische Frequenz aufgrund niedriger AP-Raten vieler SGN durch alternative Algorithmen 
geschätzt werden (s. Kapitel 2.6. Extrazelluläre Mikroelektroden-Ableitungen von einzelnen Hörnervenfasern).

Die Form der Frequenzabstimmungen $\operatorname{der} \mathrm{Cav} \beta_{2}{ }^{-/-}$-SGN passt zum Fehlen von DPOAE und somit zu einem Defekt der cochleären Verstärker-Mechanismen. Die Schwellen der SGN sind entsprechend der FAEP angehoben. Die mittlere Schwelle beträgt für $\mathrm{Cav}_{\vee} \beta_{2}{ }^{+/+}-\mathrm{SGN} 33,1 \pm 2 \mathrm{~dB}(\mathrm{n}=168)$ und für $\mathrm{Ca}_{\vee} \beta_{2}{ }^{-/-}-\mathrm{SGN}$ $114,8 \pm 2,3 \mathrm{~dB}(\mathrm{n}=101)$.

Die charakteristischen Frequenzen $\operatorname{der} \mathrm{Cav} \beta_{2}{ }^{+/+}$-SGN waren im gestesteten Spektrum breit gestreut. Im Gegensatz hierzu finden sich bei $\mathrm{Cav}_{v} \beta_{2}{ }^{-/-}$-SGN auffallend viele tieffrequente SGN. Eine Übersicht bietet Abbildung 3.1.2.3-5, in der die Stimulusfrequenzen gegen die Stimuluspegel zur Messung des PST aufgetragen sind. Da sich die Frequenzabstimmung der $\mathrm{Cav}_{2} \beta_{2}^{-/-}$-SGN wie oben erwähnt schwierig gestaltete, wurde hier auf die Darstellung der charakteristischen Frequenzen in Abhängigkeit von der Schwelle verzichtet.

\subsubsection{Post-Stimulus-Zeit-Histogramme zeigen evozierte neuronale Aktivität}

Für die meisten SGN wird angenommen, dass ab $20 \mathrm{~dB}$ oberhalb der Schwelle keine Steigerung der AP-Rate mehr zu verzeichnen ist, wenn der Stimuluspegel steigt (Taberner und Liberman 2005). Daher wurde der Tonimpuls zur Erstellung eines PSTs mit einer Intensität von $30 \mathrm{~dB}$ über der ermittelten Schwelle präsentiert. Da die Schwelle der $\mathrm{Cav}_{2} \beta_{2}{ }^{-/}-\mathrm{SGN}$ sehr dicht an der Leistungsgrenze des Lautsprechers lagen, konnten diese im Schnitt nur $10 \mathrm{~dB}$ überschwellig gereizt werden (Abbildung 3.1.2.3-1).

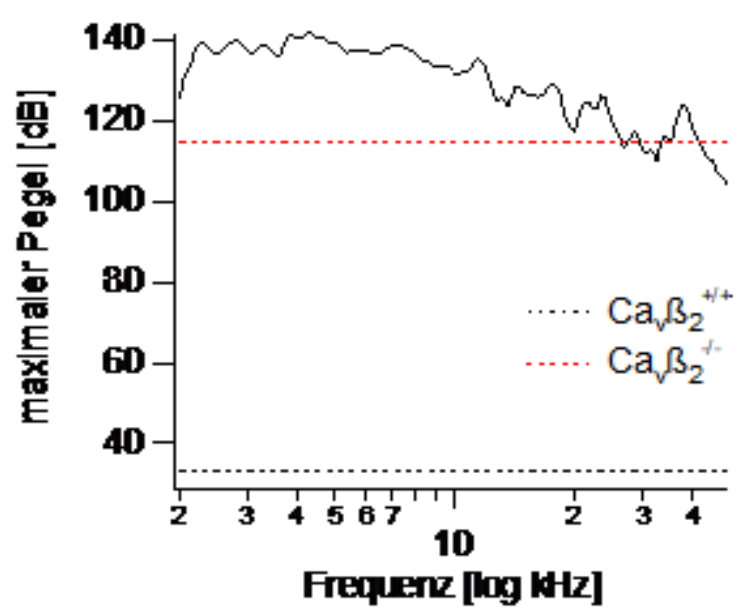

Abbildung 3.1.2.3-1 Maximale Lautsprecherleistung

Maximale Lautsprecherleistung in Abhängigkeit von der Frequenz. Die gestrichelten Linien zeigen die mittlere Schwelle der SGN für $\mathrm{Ca}_{v} \beta_{2}{ }^{+/+}$in schwarz und $\mathrm{Ca}_{\vee} \beta_{2}{ }^{-/-}$in rot. 
Ein Tonimpuls dauerte $50 \mathrm{~ms}$ und wurde mit einem Interstimulusintervall von 100 ms präsentiert. Die Antworten auf 200 Wiederholungen des Stimulus wurden aufgezeichnet und die AP ausgezählt. Bei einer resultierenden Zahl von $<400$ AP wurden die Antworten weiterer 200 Wiederholungen aufaddiert. Die AP wurden innerhalb von $1 \mathrm{~ms}$-Zeitfenstern addiert und durch die Länge des Zeitfensters geteilt. Die resultierende AP-Rate wurde dann gegen die Zeit aufgetragen. Abbildung 3.1.2.3-2 A zeigt zwei repräsentative Originalaufnahmen von SGNAntworten auf eine dreimalige Wiederholung des $50 \mathrm{~ms}$ Stimulus.

A
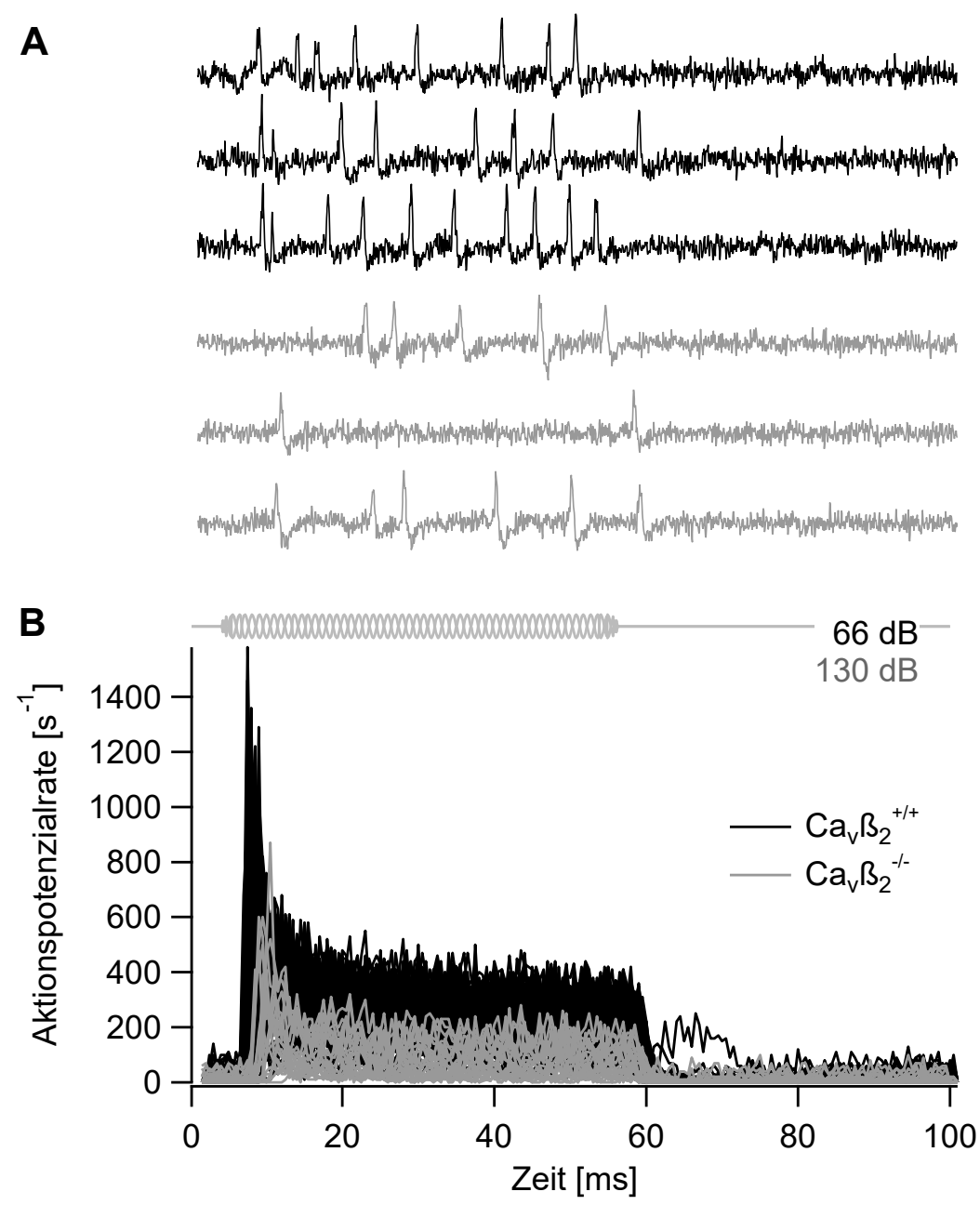

Abbildung 3.1.2.3-2 Evozierte Spiralganglionneuron-Aktivität

A: Je drei Original-Antworten auf einen 50 ms-Stimulus. B: PST einzelner SGN. Schematische Darstellung des Stimulus im oberen Abschnitt mit mittlerer Stimulusintensität.

Stichprobengröße: $\mathrm{Ca}_{V} \beta_{2}{ }^{+/+}$schwarz, $\mathrm{n}=81 ; \mathrm{Ca}_{V} \beta_{2} 2^{-/-}$hellgrau, $\mathrm{n}=22$

Abbildung 3.1.2.3-2 B zeigt die einzelnen PST von $\mathrm{Cav}_{2} \beta^{+/+}-$und $\mathrm{Cav} \beta_{2} 2^{-/-}$SGN. $\mathrm{Zu}$ sehen ist ein hoher Anfangs-Gipfel gefolgt von einer exponentiellen Adaptation auf ein Plateau mit geringeren Raten. Dies charakteristische Muster ist in der Darstellung der gemittelten Antworten (Abbildung 3.1.2.3-3 A) noch leichter 
nachzuvollziehen. In Abbildung 3.1.2.3-3 B sind PST dargestellt, die mit einer Stimulationsintensität von $10 \mathrm{~dB}$ über der Schwelle generiert wurden. Sie wurden aus der Messung der RLF (s. Kapitel 3.1.2.4. Raten-Pegel-Funktionen der $\operatorname{Cav} \beta 2^{-/-}$ -Spiralganglionneurone können nur unvollständig abgebildet werden) kalkuliert und spiegeln nicht die maximalen Antworten der SGN wieder, dienen aber der Vergleichbarkeit für gleiche Stimulationsbedingungen.
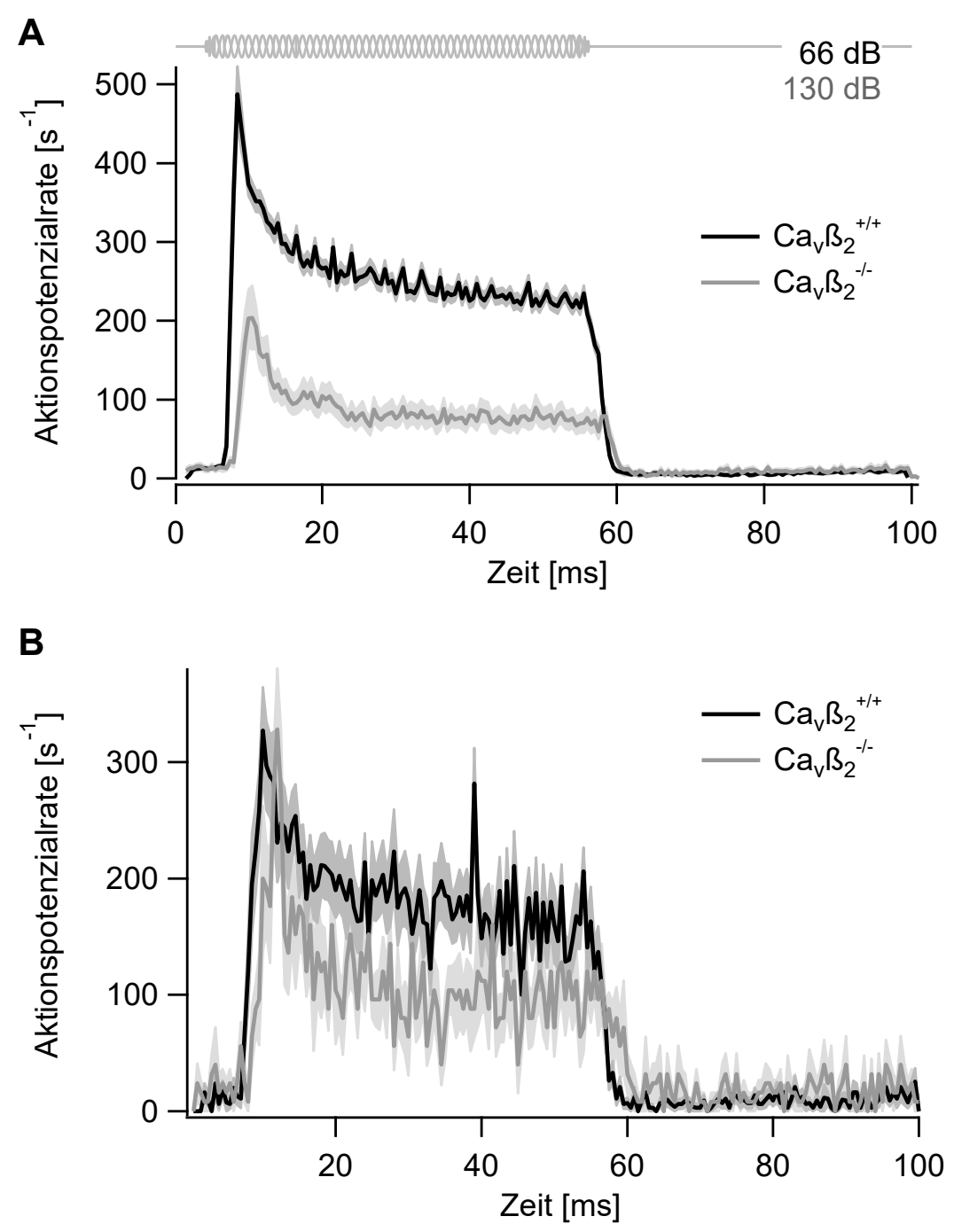

Abbildung 3.1.2.3-3 Post-Stimulus-Zeit-Histogramme

A: PST aller SGN gemittelt. Schematische Darstellung des Stimulus im oberen Abschnitt mit mittlerer Stimulusintensität. B: Ergebnisse für vergleichbare Stimulationsbedingungen mit $10 \mathrm{~dB}$ über der Schwelle, kalkuliert aus RLF.

Die aufgehellten Flächen zeigen den SEM.

Stichprobengröße: A: $\operatorname{Cav}_{2} \beta_{2}^{+/+}$schwarz, $\mathrm{n}=81 ; \operatorname{Cav}_{2}{ }^{-/-}$hellgrau, $\mathrm{n}=22 ; \mathbf{B}: \mathrm{Cav}_{\mathrm{v}} \beta_{2}^{+/+}$schwarz, $\mathrm{n}=47$; $\mathrm{Cav}_{\mathrm{v}} \beta_{2}^{-/-}$hellgrau, $\mathrm{n}=13$.

Werden die gemittelten PST verglichen, zeigen sich die AP-Raten der $\operatorname{Cav} \beta_{2}{ }^{-/-}$ SGN um $62 \%$ verringert. Sie erscheinen sowohl während des Spitzen-Gipfels 
(59\%) als auch während des Adaptations-Plateaus (65\%) deutlich vermindert (Abbildung 3.1.2.3-4 A).
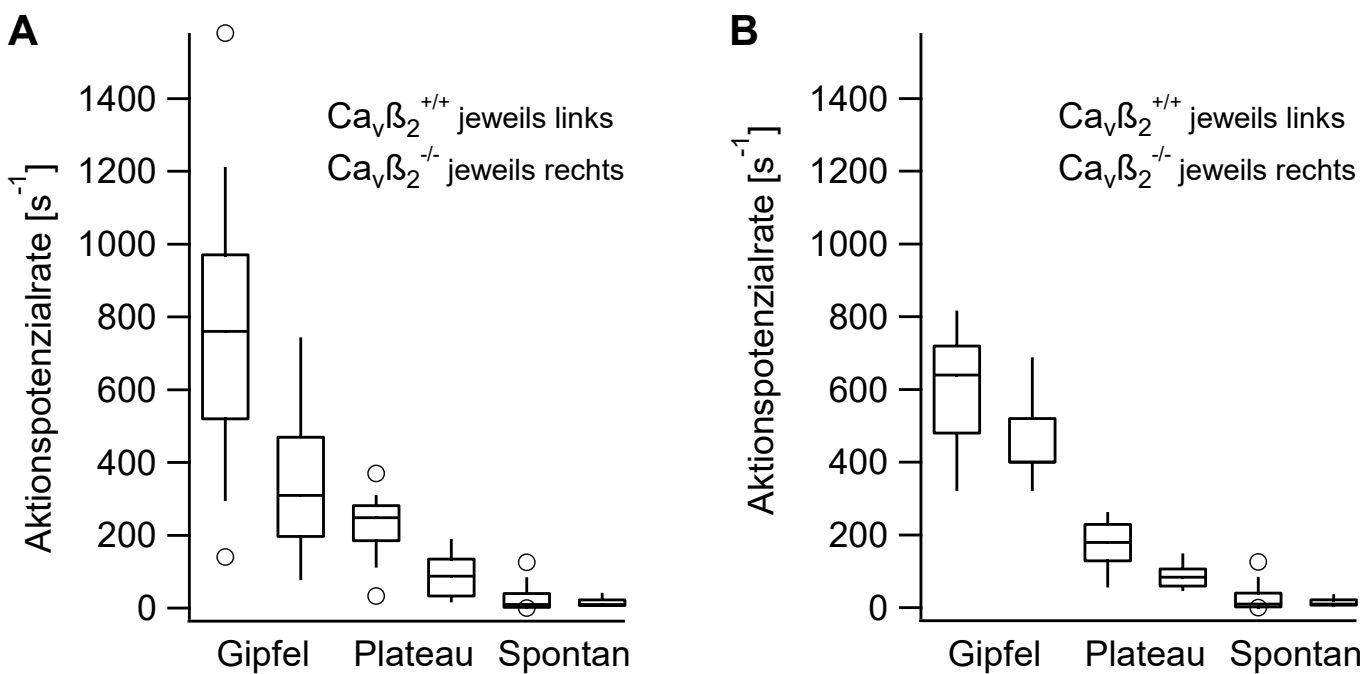

\section{Abbildung 3.1.2.3-4 Vergleich unterschiedlicher Aktionspotenzialraten}

Evozierte AP-Raten von SGN aus den PST im Vergleich zur Spontanaktivität. Dargestellt sind Boxplots der Anfangsgipfel-, der Plateau- und der Spontanaktivitätsraten mit Median, oberem und unterem Quartil, Antennen zeigen oberes und unteres Dezil, Ausreißer sind definiert als unterhalb der 1. bzw. oberhalb der 99. Perzentile gelegen. Die Ergebnisse der $\mathrm{Cav} \beta_{2}{ }^{-/-}$-SGN sind jeweils rechts abgebildet. A: Ergebnisse für eine Stimulation mit $30 \mathrm{~dB}$ über der Schwelle für $\mathrm{Ca}_{v} \beta_{2}^{+/+}$und $10 \mathrm{~dB}$ über der Schwelle für $\mathrm{Ca}_{v} \beta_{2}{ }^{-/}$. B: Ergebnisse für eine Stimulation mit $10 \mathrm{~dB}$ über der Schwelle, kalkuliert aus RLF.

Stichprobengröße: A: $\mathrm{Ca}_{V} \beta_{2}{ }^{+/+}: \mathrm{n}=81 ; \mathrm{Ca}_{V} \beta_{2}{ }^{-/-}: \mathrm{n}=22$. B: $\mathrm{Ca}_{V} \beta_{2}{ }^{+/+}: \mathrm{n}=47 ; \mathrm{Ca}_{V} \beta_{2} 2^{-/-}: \mathrm{n}=13$.

Werden $\mathrm{Cav} \beta_{2}{ }^{+/+}$-SGN entsprechend der Stimulation von $\mathrm{Cav}_{2} \beta_{2}{ }^{-/-}-\mathrm{SGN}$ nur $10 \mathrm{~dB}$ oberhalb der Schwelle stimuliert, findet man eine Verringerung der AP-Rate gegenüber $30 \mathrm{~dB}$ überschwellig um lediglich $45 \%$ (38\% für den Gipfel und $53 \%$ für das Adaptations-Plateau; Abbildung 3.1.2.3-4 B). Es ist anzunehmen, dass bei $30 \mathrm{~dB}$-überschwelliger Reizung der $\mathrm{Cav}_{\mathrm{v}} \beta_{2}{ }^{-/-}$-SGN eine vergleichbare Zunahme der AP-Rate gefunden würde. Diese Ergebnisse deuten daraufhin, dass die durch patch-clamp nachweisbare Reduktion der präsynaptische Exozytose $\operatorname{der} \operatorname{Cav} \beta_{2}{ }^{-/-}$IHZ zu der gestörten Schallkodierung in Form einer Reduktion von AP-Raten beiträgt.

Eine Übersicht über die Stimuluspegel bietet die folgende Abbildung (Abbildung 3.1.2.3-5). Sie sind hier in Abhängigkeit von der Stimulusfrequenz dargestellt. Die Pegel zur Stimulation von $\mathrm{Cav}_{v} \beta_{2}{ }^{-/-}$-SGN liegen erwartungsgemäß, trotz eingeschränkter Lautsprecherleistung, deutlich höher. Zudem, möglicherweise durch die Lautsprecherleistung verzerrt, weisen sie eine geringere Streuung auf. 


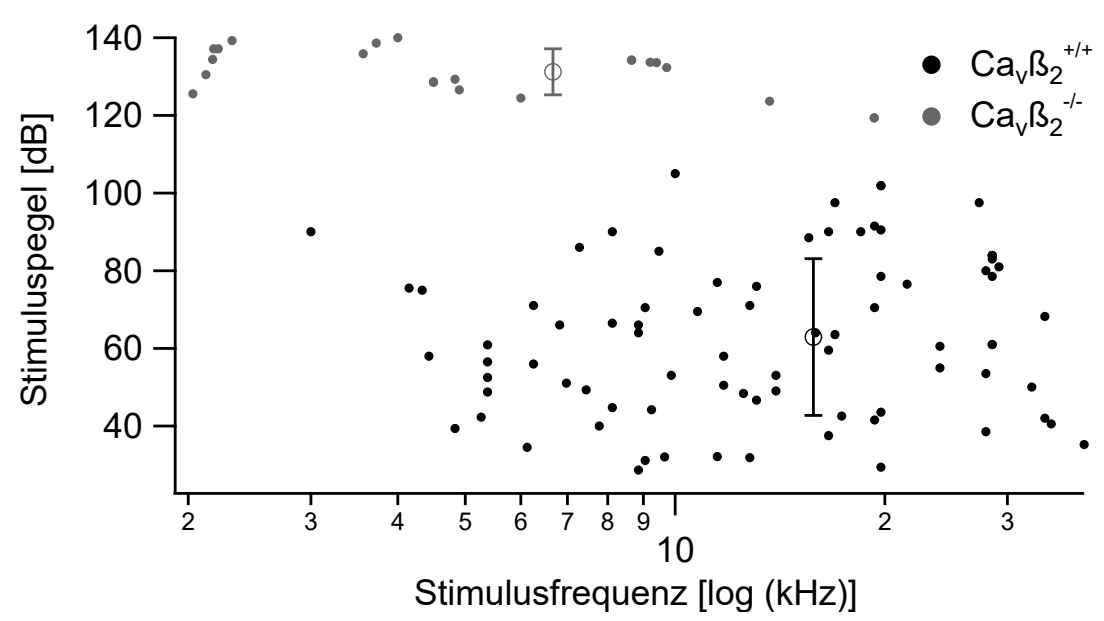

Abbildung 3.1.2.3-5 Stimulusfrequenzen in Abhängigkeit vom Stimuluspegel

Zur Einschätzung der Verteilung der Schwellen und charakteristischen Frequenzen. Die Kreise zeigen den Mittelwert, die Fehlerbalken die Standardabweichung.

Stichprobengröße: $\mathrm{Cav} \beta_{2}{ }^{+/+}$schwarz, $\mathrm{n}=81 ; \mathrm{Cav} \beta_{2}{ }^{-/ /}$hellgrau, $\mathrm{n}=22$

Die Latenzen des ersten APs nach Stimulusbeginn und ihre Varianz geben Auskunft über die Qualität der Schallkodierung. Für eine präzise Kodierung eines Stimulus ist neben einer kurzen Latenz vor allem eine geringe Varianz erforderlich. Bei $\mathrm{Ca}_{v} \mathrm{\beta}_{2}^{+/+}$-SGN betrug der Median der Latenzen der ersten AP 4,5 ms, wohingegen bei $\operatorname{Cav} \beta_{2}{ }^{-/}$-SGN die ersten AP mit einer Verzögerung von $6,1 \mathrm{~ms}$ auftraten. Abbildung 3.1.2.3-6 lässt eine positive Korrelation zwischen der Latenz und ihrer Varianz erahnen.

Für die meisten physiologisch arbeitenden SGN von Mäusen wird eine Latenz von $\leq 5 \mathrm{~ms}$ angenommen (Taberner und Liberman 2005). Da mit abnehmender Aktivitätsrate des Neurons eine Zunahme der Varianz anzunehmen ist, verwundert das Ergebnis der $\mathrm{Cav}_{2}{ }_{2}^{-/-}$-SGN nicht. Darüber hinaus wurde ein Zusammenhang zwischen der CF eines SGNs und der Latenz des ersten APs beschrieben. Durch die Wanderwelle der Basilarmembran, die sich von der Basis zum Apex ausbreitet, steigt die Latenz mit abnehmender CF (Furman et al. 2013). 


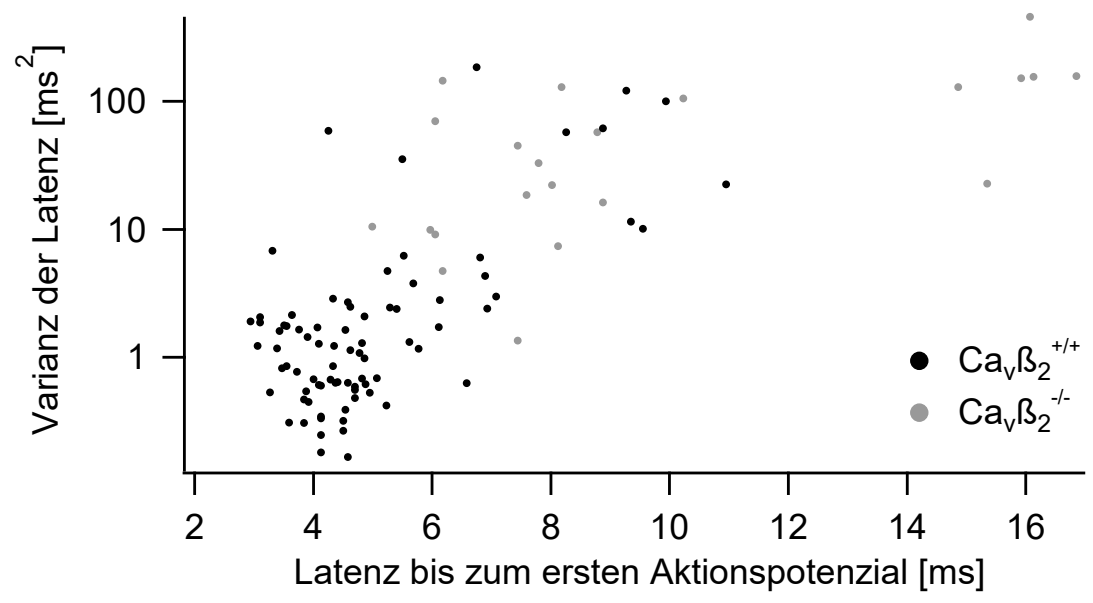

Abbildung 3.1.2.3-6 Latenz des ersten Aktionspotenzials

Dargestellt ist der Median der Latenzen des jeweils ersten APs nach Stimulusbeginn in Abhängigkeit von der Varianz der Latenzen.

Stichprobengröße: $\mathrm{Ca}_{\mathrm{V}} \beta_{2}{ }^{+/+}$schwarz, $\mathrm{n}=81 ; \mathrm{Ca}_{\mathrm{V}} \beta_{2}{ }^{-/-}$hellgrau, $\mathrm{n}=22$

Auffällig ist eine kleine Gruppe von SGN, die eine Latenz von $>14 \mathrm{~ms}$ aufweisen. Es ist nicht auszuschließen, dass es sich hierbei um Nukleus cochlearis-Neurone handelt.

\subsubsection{Raten-Pegel-Funktionen $\operatorname{der} \mathrm{Cav} \beta_{2}{ }^{-1-S p i r a l g a n g l i o n n e u r o n e ~ k o ̈ n n e n ~}$ nur unvollständig abgebildet werden}

Um die Schallkodierung über einen größeren Bereich von Schalldruckpegeln zu messen, wurde die charakteristische Frequenz mit verschiedenen Pegeln in $5 \mathrm{~dB}-$ Schritten in zufälliger Reihenfolge präsentiert. Es erfolgten 25 Wiederholungen pro Pegel. Der Tonimpuls dauerte wie für das PST $50 \mathrm{~ms}$ und wurde mit einem Interstimulusintervall von $100 \mathrm{~ms}$ präsentiert. Die AP-Raten wurden über die Dauer des Stimulus gemittelt und gegen den entsprechenden Pegel aufgetragen, woraus sich eine RLF ergibt (Abbildung 3.1.2.4-1). 


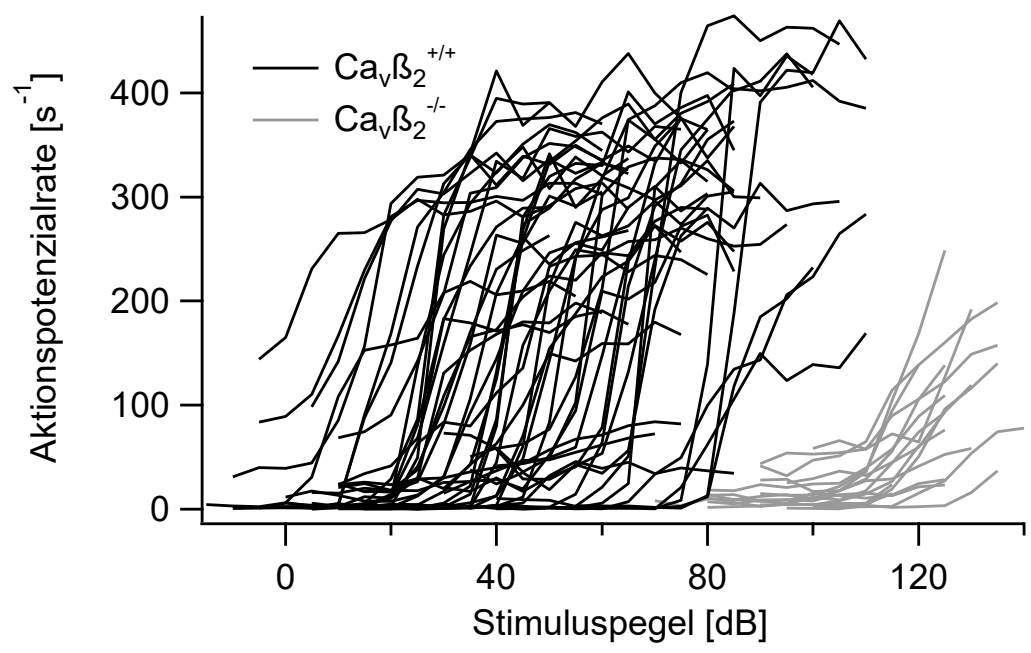

Abbildung 3.1.2.4-1 Raten-Pegel-Funktionen

Gezeigt sind AP-Raten je eines SGN bei unterschiedlichem Pegel der CF.

Stichprobengröße: $\mathrm{Cav} \beta_{2}{ }^{+/+}$schwarz, $\mathrm{n}=49 ; \mathrm{Cav} \beta_{2}{ }^{-/-}$hellgrau, $\mathrm{n}=18$

Die dargestellten Wachstumsfunktionen verlaufen sigmoidal. Sie unterscheiden sich in ihrer Spontanaktivität, ihren Schwellen und dynamischen Bereichen. Der Beginn einer jeden Kurve auf y-Achsen-Niveau zeigt die SR. Am Übergang des flachen in den steilen Anteil liegt die Schwelle. Sie ist definiert als eine Zunahme der SR um 20 Hz. Der steile Anteil kennzeichnet den dynamischen Bereich. Um diesen zu ermitteln, werden SR und maximale evozierte Rate verglichen. Die Spanne an Stimuluspegeln, durch die $80 \%$ der Differenz der AP-Rate von SR zu maximaler Rate hervorgerufen werden, stellt den dynamischen Bereich dar. Die Kurven erreichen schließlich im zweiten flachen Anteil ihr Maximum in Form eines Plateaus, auf dem keine weitere Steigerung der AP-Raten zu verzeichnen ist. Für die meisten SGN von Wildtyp-Mäusen wird eine Sättigung der AP-Raten bei $20 \mathrm{~dB}$ oberhalb der Schwelle gefunden (Taberner und Liberman 2005). Da die $\mathrm{Ca}_{\vee} \beta_{2}{ }^{-/-}$-SGN erst auf sehr hohe Stimuluspegel antworteten und die Lautsprecherleistung begrenzt war, konnte ihr dynamischer Bereich nur unvollständig erhoben werden. Ob sich der dynamische Bereich von $\mathrm{Cav}_{2}{ }^{+/+}-$und $\mathrm{Cav} \beta 2^{-{ }^{--}}$-SGN unterscheidet, bleibt daher unklar. 


\subsubsection{Die Vorwärtsmaskierung erscheint regelrecht}

Die Vorwärtsmaskierung bezeichnet die Reduktion einer evozierten AP-Rate eines SGN durch das Vorschalten eines Maskierungs-Impulses. Die Erholung der evozierten AP-Rate als Funktion des Zeitintervalls zwischen Maskierungs-Impuls und Test-Stimulus folgt einem exponentiellen Verlauf (Harris und Dallos 1979). Die Vorwärtsmaskierung erlaubt Rückschlüsse auf die schnelle Adaptation und Erholung von dieser. Die schnelle Adaptation wird vermutlich primär durch die partielle Leerung der schnell freisetzbaren Vesikel-Population bedingt und die Erholung spiegelt dementsprechend die Wiederauffüllung dieser Population wieder. Technisch wird hier, wie für das PST, ein überschwelliger Stimulus dargeboten, dem jedoch ein $100 \mathrm{~ms}$ langer Maskierungs-Impuls vorausgeht. Der zeitliche Abstand der beiden Stimuli wird während der Messung vergrößert. Da die Messung der Vorwärtsmaskierung als letzte erfolgte und die Kontaktzeit von Elektrode und SGN in den meisten Fällen begrenzt war, wurden zu wenige Daten erhoben, um sie statistisch auswerten zu können. Die verfügbaren Daten zeigten, wie erwartet, reduzierte Raten für den Spitzen-Gipfel und das Adaptationsplateau in den $\mathrm{Cav} \beta_{2}{ }^{-/-}$-SGN, jedoch keinen offensichtlichen Unterschied bei der Wiederauffüllung der schnell freisetzbaren Vesikel-Population.

\subsubsection{Die Immunhistochemie zeigt keine Auffälligkeiten}

Zum Ausschluss einer SGN-Degeneration in Folge der profunden Schwerhörigkeit wurden immunhistochemische Färbungen cochleärer Häutchen-Präparate angefertigt (Abbildung 3.1.3-1). Für $\operatorname{Cav} \beta_{2}{ }^{+/+}$- und $\operatorname{Cav} \beta_{2}{ }^{-/-}$- SGN ergab die Dichtebestimmung in allen drei Windungen $\sim 200$ Zellkerne $/ 1000 \mu \mathrm{m}^{2}$. Für die apikale Windung betrug sie 199,8 $\pm 8\left(\operatorname{Cav} \beta_{2}{ }^{+/+}, \mathrm{n}=7\right)$ und $204,9 \pm 5,3\left(\operatorname{Cav} \beta_{2}{ }^{-/-}\right.$, $\mathrm{n}=5)$, für die mittlere $201 \pm 7\left(\operatorname{Cav} \beta_{2}{ }^{+/+}, \mathrm{n}=7\right)$ und 207,8 $\pm 1,7\left(\operatorname{Cav} \beta_{2}{ }^{-/-}, \mathrm{n}=6\right)$ und für die basale 193,7 $\pm 9,7\left(\mathrm{Cav}_{2} \beta_{2}^{+/+}, \mathrm{n}=5\right)$ und $189,8 \pm 6,2\left(\operatorname{Cav} \beta_{2}{ }^{-/-}, \mathrm{n}=6\right)$. Insgesamt sind die Unterschiede vernachlässigbar klein. 

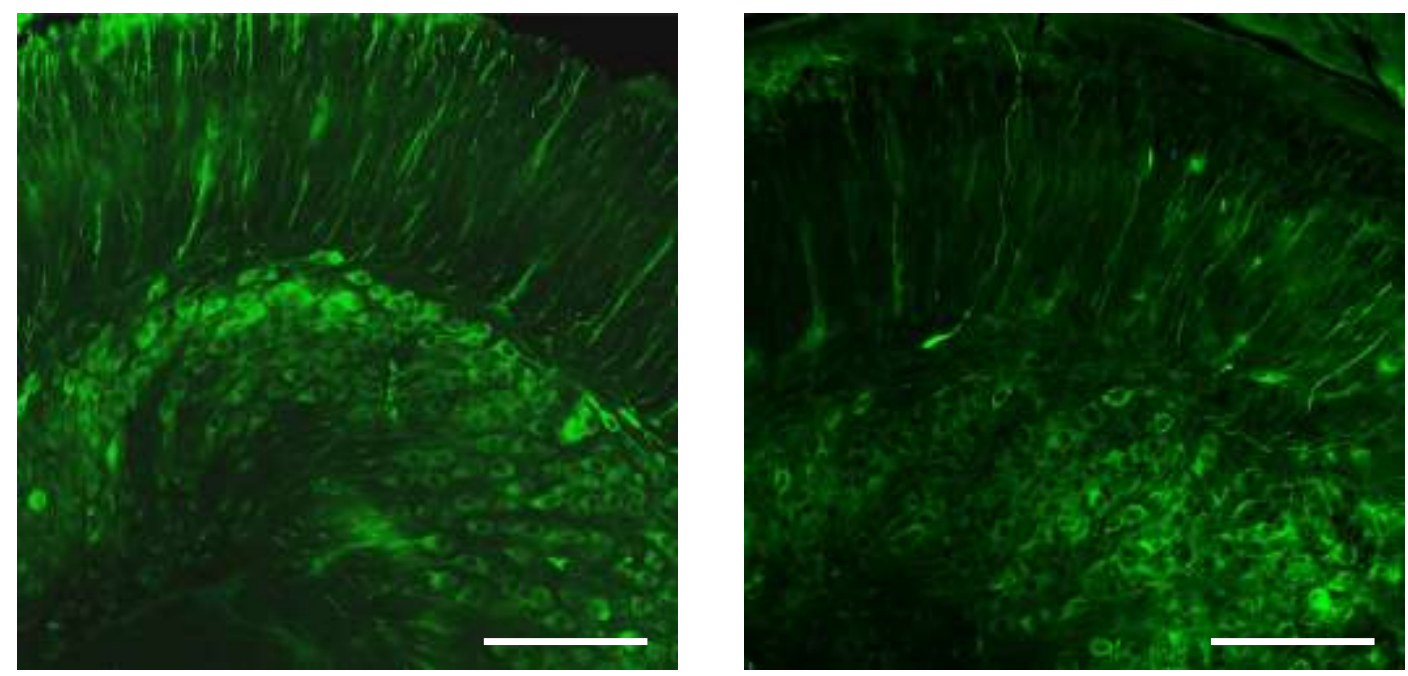

Abbildung 3.1.3-1 Immunhistochemie der Spiralganglionneurone

SGN der apikalen Windung in $\mathrm{Ca}_{v} \beta_{2}^{+/+}$- (links) und $\mathrm{Ca}_{v} \beta_{2}{ }^{-/-}$-Cochlea (rechts), repräsentative Beispiele immunhistochemisch gefärbter mikroskopischer Aufnahmen von Neuronen, die um den Modiolus angeordnet sind (grün, Neurofilament 200). Maßstab $100 \mu \mathrm{m}$

Die Zellmorphologie der $\mathrm{Ca}_{v} \beta_{2}{ }^{--}$-SGN erschien bei visueller Begutachtung unverändert. In Form, Größe, Kern-Plasma-Relation und Färbeverhalten sind zwischen $\mathrm{Cav}_{v} \beta_{2}{ }^{-/-}$- und $\mathrm{Cav}_{2} \beta_{2}^{+/+}$-SGN keine Unterschiede auszumachen. Auch eine Lückenbildung zwischen den Neuronen wurde nicht gefunden. $\operatorname{Cav} \beta_{2}{ }^{-/-}$-Präparate wiesen keine offensichtlichen Anzeichen einer Atrophie oder Degeneration der SGN auf. Die Phalloidinfärbung zeigte mit angeschnittene, v-förmige Stereozilien innerer und äußerer Haarzellen. In der Hoechst-Färbung stellten sich ihre Zellkerne vollständig und intakt dar.

\subsection{Untersuchung des Hörphänotyps von $\mathrm{C} 26^{+/ \mathrm{S} 17 \mathrm{~F}}-$ Mäusen}

\subsubsection{Die Funktion der äußeren Haarzellen ist erloschen}

Die Funktion der ÄHZ wurde frequenzspezifisch mittels DPOAE untersucht. Aufgrund der kleinen Größe des Mäuse-Gehörgangs war die Kalibrierung und Bestimmung der Reizintensität nur bedingt möglich. Daher wird hier lediglich die Aussage getroffen, dass $50 \%$ der $\mathrm{Cx} 26^{+/+}$-Mäuse bei zwei der getesteten Frequenzen $(12$ und $16 \mathrm{kHz})$ otoakustische Emissionen zeigten, diese bei $\mathrm{Cx} 26^{+/ \mathrm{S} 17 \mathrm{~F}_{-}}$ Mäusen jedoch völlig ausblieben. Es ist somit von einem Ausfall der ÄHZFunktion auszugehen. 


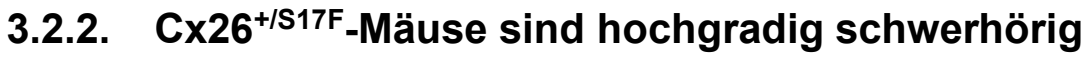

Um eine Aussage über die Funktion des auditorischen Systems treffen zu können, wurden FAEP gemessen. $\mathrm{Cx} 26^{+/ \mathrm{S} 17 \mathrm{~F}}$-Mäuse wiesen eine profunde bzw. hochgradige (129/Sv bzw. C57B1/6) Schwerhörigkeit auf. Zur Vereinfachung wird im Folgenden für beide Maushintergründe von hochgradiger Schwerhörigkeit gesprochen. Ihre Schwellen für Clicks lagen $50 \mathrm{~dB}(129 / \mathrm{Sv})$ bzw. $40 \mathrm{~dB}$ (C57B1/6) über denen ihrer Kontrollen. Die absoluten Hörschwellen sind in Abbildung 3.2.2-1 dargestellt und betrugen für Clicks 85,0 $\pm 4,7 \mathrm{~dB}(129 / \mathrm{Sv})$ bzw. 73,3 $\pm 14,5 \mathrm{~dB}(\mathrm{C} 57 \mathrm{Bl} / 6)$.
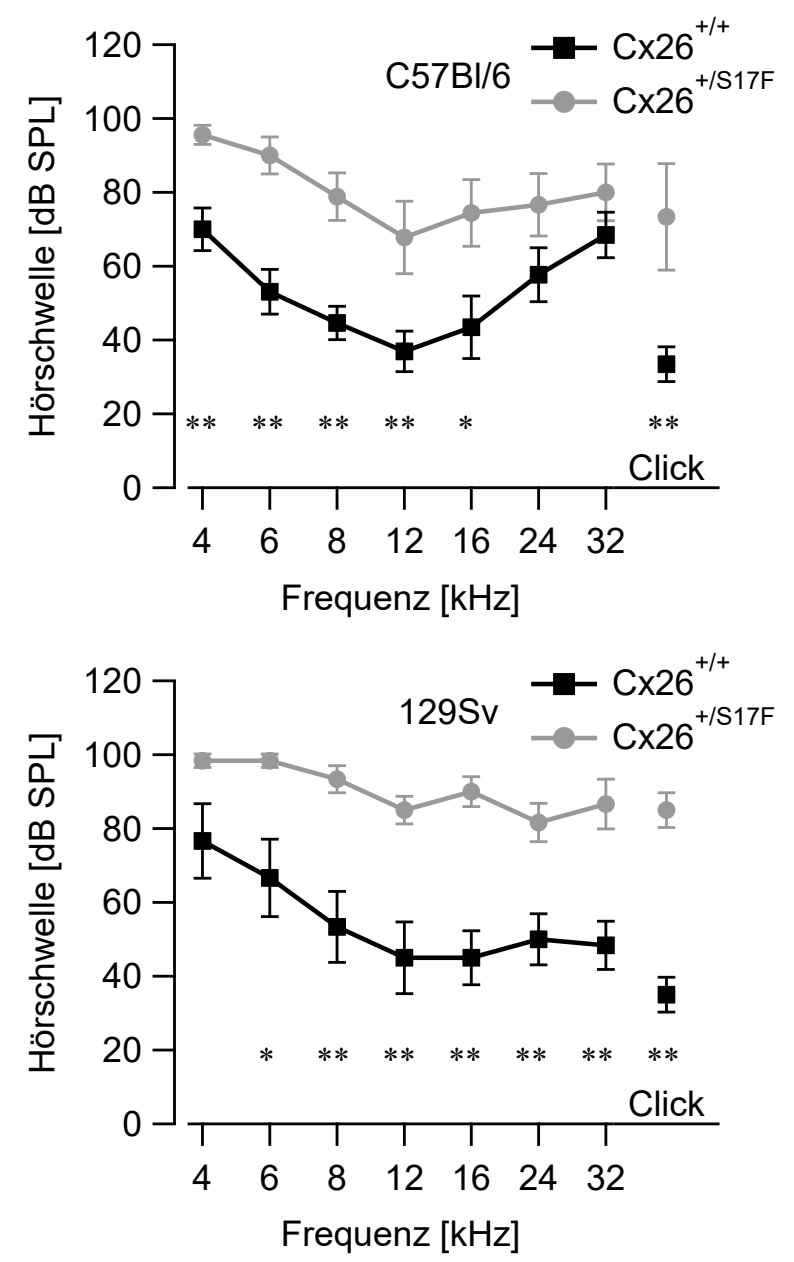

\section{Abbildung 3.2.2-1 Hörschwellen}

Dargestellt sind gemittelte Hörschwellen in grau von $\mathrm{Cx} 26^{+/ \mathrm{S} 17 \mathrm{~F}}$ - und in schwarz von $\mathrm{Cx} 26^{+/+}$Mäusen für unterschiedliche Frequenzen und einen Clickstimulus. Im Bild oben der genetische Hintergrund C57Bl/6, im Bild unten 129/Sv. *: $p<5 \%, * *: p<1 \%$. Fehlerbalken zeigen den SEM.

Stichprobengröße: $\mathrm{C} 57 \mathrm{~B} 1 / 6$ : $\mathrm{Cx} 26^{+/+}$schwarz, $\mathrm{n}=13 ; \mathrm{Cx} 26^{+/ \mathrm{S} 17 \mathrm{~F}}$ hellgrau, $\mathrm{n}=9 ; 129 / \mathrm{Sv}: \mathrm{Cx} 26^{+/+}$ schwarz, $\mathrm{n}=6 ; \mathrm{Cx} 26^{+/ \mathrm{S} 17 \mathrm{~F}}$ hellgrau, $\mathrm{n}=6$ 
Die gemittelte Reinton-Hörschwelle lag mit 87,5 $\pm 4,5 \mathrm{~dB}$ (129/Sv) bzw. 74,4 \pm 4,2 dB (C57Bl/6) um 39 dB (129/Sv) bzw. 29 dB (C57Bl/6) höher als die der entsprechenden Kontrollen.

Die Hörergebnisse der Kontrollen sind, im Vergleich zu anderen in unserem Labor an der gleichen Messapparatur untersuchten Tieren, als mittelgradig schwerhörig einzustufen. Statistische Signifikanz erreichten die Unterschiede zwischen Mutanten und Kontrollen bei Tieren mit 129/Sv-Hintergrund für die getesteten Frequenzen von $6-32 \mathrm{kHz}$ und den Click. Für die C57B1/6-Tiere hingegen waren die Hörschwelle für 4-16 kHz und den Click signifikant erhöht.

$\mathrm{Cx} 26^{+/ \mathrm{S} 17 \mathrm{~F}}$-FAEP wiesen zudem verringerte Amplituden auf. Ihre Latenzen waren unverändert. Eine Anhebung der Hörschwellen auf über $70 \mathrm{~dB}$ wie bei den $\mathrm{Cx} 26^{+/ \mathrm{S} 17 \mathrm{~F}}$-Mäusen lässt sich nicht allein durch einen Verlust der ÄHZ-Funktion erklären.

\subsubsection{Das endocochleäre Potenzial ist reduziert und korreliert mit der Hör- schwelle}

Da Cx26 in den gap-junction-Netzwerken der Cochlea exprimiert wird, wurden die cochleäre Ionenhomöostase und die Funktion der Stria vascularis anhand des EPs beurteilt. Die Messungen ergaben für C57Bl/6-Tiere ein gemitteltes EP von $110 \pm 2,5 \mathrm{mV}\left(\mathrm{Cx} 26^{+/+}\right) \mathrm{zu} 84,4 \pm 6,2 \mathrm{mV}\left(\mathrm{Cx} 26^{+/ \mathrm{S} 17 \mathrm{~F}}\right)$ und für 129/Sv-Tiere ein $\mathrm{EP}$ von $98 \pm 6,7 \mathrm{mV}\left(\mathrm{Cx} 26^{+/+}\right) \mathrm{zu} 55,5 \pm 6,2 \mathrm{mV}\left(\mathrm{Cx} 26^{+/ \mathrm{S} 17 \mathrm{~F}}\right)$ (Abbildung 3.2.3-1). $\mathrm{Cx} 26^{+\mathrm{S} 17 \mathrm{~F}}$-Mäuse zeigten also eine signifikante Reduktion des EPs um 23,3\% (C57Bl/6) bzw. 43,3 \% (129/Sv). Die beobachtete EP-Reduktion war in Mäusen mit einem 129/Sv-Hintergrund deutlicher ausgeprägt. Der absolute Mittelwert der $\mathrm{Cx} 26^{+/ \mathrm{S} 17 \mathrm{~F}}$-Mäuse mit C57B16-HIntergrund ist mit $84,4 \mathrm{mV}$ als normwertig anzusehen. 


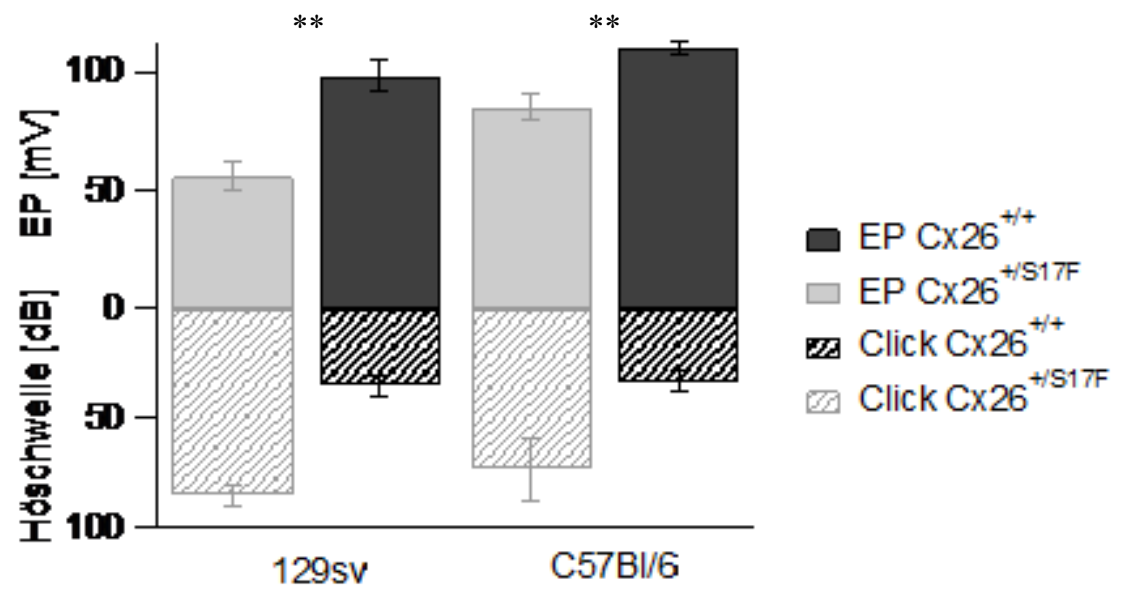

Abbildung 3.2.3-1 Das endocochleäre Potenzial

Die Mittelwerte des endocochleären Potenzials (oben) und der Hörschwelle für Clicks (unten, schraffiert) sind zum Vergleich für beide untersuchten Maushintergründe dargestellt. **: $\mathrm{p}<1 \%$. Fehlerbalken zeigen den SEM.

Stichprobengröße: C57B1/6 (rechts): $\mathrm{Cx}_{2} 6^{+/+}$schwarz, $\mathrm{n}=9 ; \mathrm{Cx} 26^{+/ \mathrm{S} 17 \mathrm{~F}}$ hellgrau, $\mathrm{n}=4 ; 129 / \mathrm{Sv}$ links: $\mathrm{Cx} 26^{+/+}$schwarz, $\mathrm{n}=6$; $\mathrm{Cx} 26^{+/ \mathrm{S} 17 \mathrm{~F}}$ hellgrau, $\mathrm{n}=7$

Die EP-Reduktion korrelierte mit der Erhöhung der Hörschwellen. Zur Quantifizierung wurde Spearmans Rangkorrelationskoeffizient berechnet. In Abbildung 3.2.3-2 ist die Hörschwelle für Clicks gegen das EP aufgetragen. Da die FAEPMessung am linken Ohr der Tiere durchgeführt wurde, wurden dementsprechend nur EP linker Cochleae verwendet.

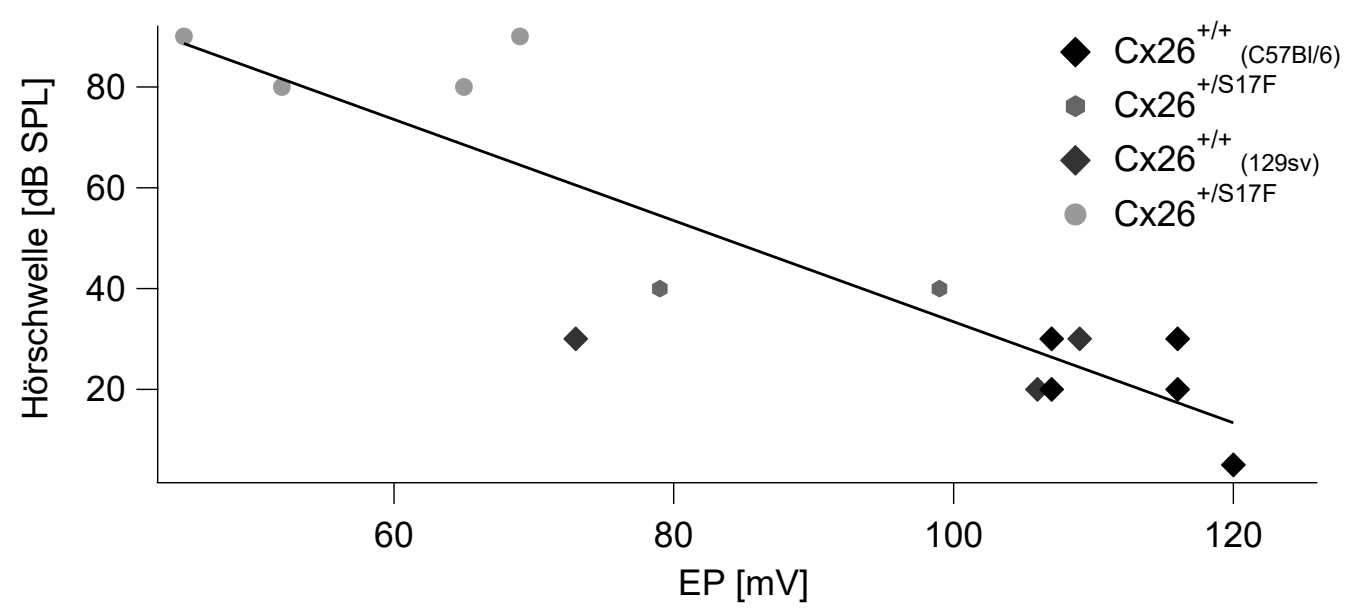

Abbildung 3.2.3-2 Das endocochleäre Potenzial und die Hörschwelle

Hörschwellen für den Click in Abhängigkeit vom EP für beide Maushintergründe mit Regressionsgerade. $\mathrm{C} \times 26^{+/+}$dunkelgrau, $\mathrm{C} \times 26^{+/ \mathrm{S} 17 \mathrm{~F}}$ hellgrau; genetischer Hintergrund $\mathrm{C} 57 \mathrm{~B} 1 / 6$ jeweils dunkel dargestellt.

Stichprobengröße: $\mathrm{n}=14$ 
Es ergab sich ein Spearman's rho von $\rho=-0,84(\mathrm{C} 57 \mathrm{Bl} / 6)$ bzw. $\rho=-0,77$ $(129 / \mathrm{Sv})$. In der Annahme einer linearen Korrelation wurde Pearson's Korrelationskoeffizient erhoben. Er betrug $r=-0,75$ (C57B1/6) bzw. $r=-0,84$ $(129 / \mathrm{Sv})$. Damit resultiert eine negative Korrelation zwischen EP und Hörschwellen, wobei diese in $\mathrm{Cx} 26^{+/ \mathrm{S} 17 \mathrm{~F}}$-Mäusen mit $129 / \mathrm{Sv}$-Hintergrund deutlicher zur Ausprägung kommt.

\subsubsection{Expression von $\mathrm{Cx} 26$ in der Cochlea}

In adulten $\mathrm{Cx} 26^{+/ \mathrm{S} 17 \mathrm{~F}}$-Cochleae wurden in der Arbeitsgruppe von Prof. Willecke Immunfluoreszensanalysen zur Expression von Cx26 und Cx30 durchgeführt. Es wurden keine von $\mathrm{Cx} 26^{+/+}$-Cochleae abweichenden Expressionsmuster gefunden. Beide Connexine wurden in den Stützzellen des Cortischen Organs, den Fibrozyten des Spirallimbus und -ligaments sowie den Basalzellen der Stria vascularis nachgewiesen. Die Intensität erschien jedoch besonders in den Fibrinozyten des Spirallimbus vermindert. Die Sinneszellen wiesen keinerlei Immunreaktivität für $\mathrm{Cx} 26$ oder 30 auf. Eine gesteigerte Apoptose, eine Zelldegeneration oder andere morphologische Unterschiede zu Cx26 $6^{+/+}$-Mäusen wurden nicht gefunden. 


\section{Diskussion}

In dieser Arbeit wurde die Hörfunktion von zwei Mausmutanten charakterisiert, in denen der präsynaptische $\mathrm{Ca}^{2+}$-Einstrom $\left(\mathrm{Cav}_{2} \beta_{2}\right)$ in $\mathrm{IHZ}$ bzw. der cochleäre Kaliumkreislauf (Cx26) durch gezielte Mutagenese gestört wurde. Es wurden systemphysiologische Methoden etabliert und angewandt, die Einblicke in die Rolle der $\mathrm{Ca}^{2+}$-Kanaluntereinheit $\mathrm{Cav}_{2} \beta_{2}$ in der Schallkodierung ermöglichten. $\mathrm{Ca}_{v} \beta_{2}$ ist dabei, vermutlich durch die positive Regulation der Zahl synaptischer $\mathrm{Ca}^{2+}$-Kanäle, essenziell für die synaptische Transmission an der IHZ-Synapse und hat darüber hinaus eine wichtige Rolle in den $\ddot{A} H Z$. Diese wurde jedoch nicht weiter untersucht. Die Untersuchung der Auswirkung der Punktmutation S17F im GJB2-Gen, die das humane KIT-Syndrom auslöst, wies auf die Senkung des EPs als wichtigen Pathomechanismus Cx26-bedingter Schwerhörigkeiten hin.

\subsection{Mauslinie $\mathrm{Cav} \beta_{2}{ }^{-1-}$}

Mittels FAEP wurde bei den $\mathrm{Cav}_{2} \beta_{2}^{-/-}$-Mäusen eine profunde Schwerhörigkeit nachgewiesen. Extrazelluläre Mikroelektroden-Ableitungen einzelner SGN zeigten eine für die beobachtete Reduktion der präsynaptischen Exozytose zu erwartende Verminderung der spontanen und Schall-evozierten Feuerraten. Die Einzelfaser-Ableitungen deckten weitere Besonderheiten $\operatorname{der} \mathrm{Cav}_{v} \beta_{2}{ }^{-/-}$-Mäuse auf. Ihre SGN zeigten von der Norm abweichende Eigenschaften. In der Gesamtheit antwortete der auditorische Nerv auf ein schmaleres Frequenzspektrum.

Bei einem direkten Vergleich von FAEP- mit Einzelfaser-Schwellen muss beachtet werden, dass sich die Messbedingungen unterscheiden. So wird die Ohrmuschel der Tiere für die Einzelfaser-Ableitungen entfernt, womit keine physiologischen Bedingungen herrschen. Das intakte äußere Ohr trägt zur konstanten Temperatur bei und verstärkt den Schall im Bereich von $2-5 \mathrm{kHz}$ (eigene Resonanzfrequenz). Wird die Cochlea um $5-10^{\circ} \mathrm{C}$ heruntergekühlt, verändern sich die Feuereigenschaften der SGN (Ohlemiller und Siegel 1994; Ohlemiller und Siegel 1998).

Die Funktion der ÄHZ erwies sich trotz ihres Vorhandenseins im adulten Tier als eingeschränkt (DPOAE und Frequenzabstimmungen). Der zugrundeliegende Mechanismus muss in weiterführenden Studien untersucht werden. 


\subsubsection{Warum zeigt die Immunohistochemie keine Zelldegeneration?}

Sensorineurale Schwerhörigkeit führt in aller Regel $\mathrm{zu}$ einem progredienten Verlust von SGN, z. B. bei hereditärer Schwerhörigkeit, nach toxischer Schädigung oder akustischem Trauma (Webster und Webster 1981; Kujawa und Liberman 2009; Kujawa und Liberman 2015). Bei hereditären Schwerhörigkeiten geschieht die Degeneration oft langsamer und ihr Ausmaß ist abhängig vom jeweiligen genetischen Defekt. Kongenital taube weiße Katzen leiden unter einem Verlust ihrer SGN-Dichte auf $17 \%$ des Normwertes. Die Schwerhörigkeit evoziert signifikante morphologische und physiologische Veränderungen in der Cochlea, wobei diese mit der Dauer der Hörbeeinträchtigung zunehmen (Hardie und Shepherd 1999). Ausgehend von den oben beschriebenen Befunden wäre in $\mathrm{Cav}_{\mathrm{V}} \mathrm{\beta}_{2}{ }^{-/-}$-Tieren eine SGN-Degeneration $\mathrm{zu}$ erwarten, die $\mathrm{zu}$ den verringerten Amplituden der evozierten Potenziale und ihren verlängerten Latenzen beitragen könnte.

$\mathrm{Cav}_{\mathrm{V}} \mathrm{\beta}_{2}^{-/-}$-Cochleae wiesen trotz ihrer hochgradigen Dysfunktion keine morphologischen Zeichen einer SGN-Degeneration auf: Die SGN-Dichte entsprach der von $\mathrm{Cav}_{2}{ }_{2}^{+/+}$-Mäusen. Die hier verwendeten Versuchstiere waren maximal zehn Wochen alt. Abgeleitet von anderen Tiermodellen wird in diesem Alter keine altersbedingte SGN-Degeneration erwartet (Webster und Webster 1981). Dieser Aspekt muss bedacht werden, da der Entwicklungs-Phänotyp der $\mathrm{Cav}_{\vee} \beta_{2}{ }^{-/-}$-Mäuse mit unreifen IHZ einen im Vergleich $\mathrm{zu}$ ihren Kontrollen differenten Alterungsprozess der cochleären Strukturen bedingen könnte. Die Unreife könnte einen Schutz vor altersbedingten Veränderungen, Haarzell-Verlust und SGNDegeneration bieten und so einen aus anderen Gründen resultierenden SGNVerlust maskieren.

Für die Evaluation der SGN-Dichte wurden Zellkerne im Rosenthal-Kanal gezählt. Somit sind möglicherweise andere Zellen wie Gliazellen oder Fibroblasten mit einbezogen und könnten das Ergebnis verfälschen. Dennoch zeigte die Neurofilament-Färbung keine Degeneration der SGN. Außerdem belegen histologische Studien an hochgradig schwerhörigen Tieren einen Rückgang aller Zellen im Rosenthal-Kanal (Shepherd und Hardie 2001).

Die geringste Neuronendichte fand sich in dieser Untersuchung sowohl in $\mathrm{Cav}_{2}{ }^{+/+}$- als auch in $\mathrm{Cav} \beta_{2}{ }^{-/-}$-Cochleae in den basalen Windungen. Es ist davon 
auszugehen, dass es sich dabei um ein präparationsbedingtes Phänomen handelt, da die Präparation des Cortischen Organs im basalen Bereich schwierig ist.

Trotz defekter IHZ-Synapse waren in $\mathrm{Cav}_{2} \beta_{2}^{-/-}$-Mäusen Haarzellen und SGN vorhanden. An einem Tiermodell, das im Alter von sechs Wochen die IHZ verliert, konnte auch drei Monate nach IHZ-Verlust keine SGN-Degeneration nachgewiesen werden (Zilberstein et al. 2012). Dies legt nahe, dass andere Faktoren als intakte IHZ-Synapsen das SGN-Überleben beeinflussen. Stützzellen, vor allem die Grenz- und Phalangenzellen, die am basalen Pol der IHZ mit den unmyelinisierten Nervenendigungen in Kontakt stehen, scheinen hier gute Kandidaten zu sein (Sugawara et al. 2005). Dennoch scheint die Exozytose der IHZ eine Rolle für das SGN-Überleben zu spielen. Cav $\beta_{2}{ }^{---}$-Mäuse mit einer residualen Freisetzungsfunktion der IHZ weisen bis zu einem Alter von neun Wochen keine SGN-Degeneration auf.

Bei Cav1.3 $3^{-/}$-Mäusen hingegen, deren IHZ keine nennenswerte exozytische Funktion besitzen (Brandt et al. 2003), sind deutliche SGN-Verluste zu verzeichnen (Platzer et al. 2000; Glueckert et al. 2003), Die verbliebene, geringgradige Exozytose von $\mathrm{Cav}_{v} \beta_{2}{ }^{-/-}$-IHZ verhindert offenbar eine Degeneration der SGN sowie den Verlust von ÄHZ- und später IHZ. Die Degeneration der Cav1.3 $3^{-/-C o c h l e a e}$ folgt einem Muster und zieht sich entgegen dem anderer Taubheitsmodelle (White et al. 2000; Hequembourg und Liberman 2001) vom Apex zur Basis, in der gleichen Reihenfolge in der die Zellen während der Entwicklung gebildet werden. Obwohl in der apikalen Cochlea von $\mathrm{Cav}_{\mathrm{v}} \beta_{2}{ }^{-/-}$-Mäusen immunhistochemisch keine Degeneration von Haarzellen und SGN nachgewiesen werden konnte, darf angenommen werden, dass, sollte sie auftreten, wie in den meisten Taubheitsmodellen ein Untergang von Sinnesepithel nahe der Basis der Cochlea beginnt. Eine vorausgehende Funktionsstörung der ÄHZ könnte die besonders im Hochtonbereich eingeschränkte Frequenzabstimmung in $\mathrm{Cav}_{2}{ }_{2}{ }^{-/}-\mathrm{SGN}$ erklären. Eine andere Möglichkeit ist eine altersabhängige progrediente SGN-Degeneration, die sich in den untersuchten Tieren noch nicht bemerkbar macht. Dies scheint allerdings wenig wahrscheinlich, weil es keine Prodromalzeichen wie einen Synapsenverlust gibt. Zusammenfassend scheint dem Vorhandensein von IHZ bzw. ihrer Exozytose vor der Adoleszenz eine wichtige Rolle zuzukommen, entweder durch direkte Einwirkung auf die SGN oder indirekt über eine Beeinflussung der Stützzellfunktion, da eine komplett erloschene Exozytose der 
IHZ wie in Cav1.3 $13^{-/-}$-Mäusen eine Degeneration der SGN, der ÄHZ und schließlich der IHZ nach sich zieht.

\subsubsection{Haben die hohen Stimulationspegel einen Einfluss auf die Mess- ergebnisse?}

Die untersuchten Tiere wurden während der Einzelfaser-Ableitungen hohen Schalldruckpegeln ausgesetzt. Diese könnten zu einer akuten Lärm-induzierten Hörstörung mit Schwellenanstieg führen. Akustische Traumata gehen typischerweise mit einer erhöhten Hörschwelle und einer Verschlechterung der Frequenzabstimmung einher (Salvi et al. 2000). Die Identifizierung typischer histopathologischer Charakteristika eines akuten temporären Lärm-induzierten Hörschwellenschwunds ist schwierig. Es wurden aufgetriebene Nervenendigungen der SGN an der IHZ-Synapse (Robertson 1983; Puel et al. 1998; Wang et al. 2002), Verlust der afferenten SGN (Kujawa und Liberman 2009), Schädigungen der Stereovilli äußerer und innerer Haarzellen, Verlust der Haarzellen, Schädigung der Stützzellen und Verringerungen des cochleären Blutflusses beschrieben (Nordmann et al. 2000). Veränderungen im EP scheinen keine Rolle zu spielen (Hirose und Liberman 2003). Die cochleäre Basis und damit die Wahrnehmung hoher Frequenzen scheinen besonders stark betroffen $\mathrm{zu}$ sein. Obwohl in entsprechenden Tiermodellen die ÄHZ-Funktion initial eingeschränkt ist und damit hauptsächlich zum temporären Hörschwellenschwund beiträgt, zeigt sich auch eine neuronale Beteiligung. Nach vollständiger Regeneration der Hörschwelle wird trotz wiederhergestellter ÄHZ-Funktion eine Verringerung der neuronalen Antwort-Amplituden, auch hier besonders im hochfrequenten Bereich, gefunden. Bei einem temporären Lärm-induzierten Hörschwellenschwund kommt es zu einer irreversiblen Schädigung afferenter Hörnervenfasern. Diese erfolgt in den ersten 24 Stunden nach Lärmexposition. Die Anzahl der Bänder pro IHZ sinkt etwa um $50 \%$ und proportional dazu die Dichte der unmyelinisierten SGN unterhalb der IHZ. Die Zahl der SGN unterliegt in den folgenden Wochen und Monaten einem progredienten Rückgang (Kujawa und Liberman 2009). In der zitierten Studie lag der früheste getestete Zeitpunkt 24 Stunden nach Lärmexposition. Es ist aber davon auszugehen, dass die Schädigung direkt nach der Lärmexposition vorliegt (Ruel et al. 2007) und somit die Versuchsbedingungen während der Einzelfaser-Ableitungen ihr Ergebnis beeinflussen. Der Pathomechanismus eines permanenten Hörschwellenschwunds ist vermutlich die Zer- 
störung der mechano-sensiblen Haarbündel und Haarzellen und wahrscheinlich primär (ohne Haarzell-Verlust) und sekundär (mit Haarzell-Verlust) der SGN. Ein Grund ist vermutlich eine postsynaptische Glutamat-Exzitotoxizität, die während einer Überexposition hoher Schalldruckpegel auftritt (Le et al. 2017). Exzitotoxische Einflüsse erscheinen bei $\operatorname{Cav}_{2} \beta_{2}^{-/-}$-Tieren aber durch den verminderten $\mathrm{Ca}^{2+}$-Einstrom unmöglich.

Bei einem permanenten Lärm-induzierten Hörschwellenanstieg erfolgt die Degeneration der SGN-Somata mit zeitlicher Verzögerung (Liberman 2017). Eine mögliche Erklärung bietet die Neurotrophin-Kaskade. Neutrophin 3 (NT-3), das Schlüsselneurotrophin der Cochlea, wird von IHZ und Stützzellen als Antwort auf eine Neuroregulin-Ausschüttung des Neurons abgegeben (Gillespie und Shepherd 2005). Eine Blockade dieser Kaskade führt zu einer primären SGN-Degeneration (Stankovic et al. 2004). Im Gegenzug scheint die Neurotrophin-Gentherapie einen therapeutischen Ansatz gegen eine SGN-Degeneration zu bieten. Werden Neurotrophine (NT-3 oder der brain derived neurotrophic factor (BDNF)) mittels viraler Vektoren in die von SGN-Degeneration betroffene Cochlea eingebracht, steigt das SGN-Überleben signifikant an (Wise et al. 2011; Atkinson et al. 2012; Fukui und Raphael 2013). Auch Agonisten des Rezeptors (TrkB) für NT-3 und BDNF haben im Tierexperiment, ohne viralen Vektor in das Mittelohr eingebracht, einen positiven Effekt auf das SGN-Überleben gezeigt (Yu et al. 2013). Untersuchungen haben gezeigt, dass NT-3 für die Formierung und den Erhalt von Haarzellsynapsen erforderlich ist und wohl hauptsächlich von den Stützzellen produziert wird. Darüber hinaus scheint NT-3 eine Wiederherstellung der cochleären Funktion und Regeneration der Bändersynapsen nach akustischem Trauma bedingen zu können (Wan et al. 2014).

Die durch den Lärm-induzierten Untergang der unmyelinisierten SGN entstehende räumliche Distanz zwischen Effektor- und Empfängerzelle könnte die Neurotrophin-Kaskade unterbrechen und so für die Degeneration von SGN verantwortlich sein. Warum sie mit einer Verzögerung nach Wochen oder Jahre eintritt, ist unklar. Auch wenn der histologische Nachweis einer normalen Zahl von Bändersynapsen gegen eine lärmbedingte Schädigung spricht, kann weder ein temporärer noch ein permanenter versuchsbedingter Schwellenschwund ausgeschlossen werden. 
Efferente Feedback-Mechanismen können einen Schutz vor Lärm-induziertem Hörschwellenschwund bieten (Maison et al. 2013). Da $\mathrm{Cav} \beta_{2}^{-/-}$-Mäuse einen unreifen IHZ-Phänotyp mit persistierender efferenter Innervation aufweisen, wäre ein Effekt denkbar. Allerdings wird der Schutzmechanismus hauptsächlich über die ÄHZ vermittelt, was eine Auswirkung dieses Effekts unwahrscheinlich macht.

\subsubsection{Warum sind die Aktionspotenzialraten der $\operatorname{Cav} \beta_{2}{ }^{-1-S p i r a l g a n g l i o n-~}$ neurone niedrig?}

Die SR der $\mathrm{Ca}_{v} \beta_{2}{ }^{-/-}$-SGN unterscheiden sich von denen der $\mathrm{Ca}_{v} \beta_{2}{ }^{+/+}$-Tiere. SGN mit sehr geringen und mit hohen Raten wurden nicht gefunden. Als Quelle für die Spontanaktivität wird die $\mathrm{Ca}^{2+}$-vermittelte Ausschüttung von Neurotransmitter bei stochastischer Öffnung von $\mathrm{Ca}^{2+}$-Kanälen am Ruhepotenzial der IHZ angenommen (Robertson und Paki 2002). Ist die Kommunikation zwischen der IHZ und ihrer Afferenz gestört, wie durch die verringerte Exozytosefähigkeit der $\mathrm{Cav}_{2} \mathrm{~B}_{2}^{-/-}$-IHZ, kann eine geminderte SR resultieren. Auch kann ein vollständiges Sistieren der spontanen Aktivität in Tiermodellen mit IHZ-Schädigung nachgewiesen werden. Kongenital taube weiße Katzen z. B. zeigen eine massive SGN-Degeneration und einen Untergang des Cortischen Organs. Sie leiden unter einer abnormen cochleären Morphologie. Geräusch-evozierte Aktivität ist nicht messbar. Die SGN-Degeneration korreliert mit dem Grad ihres IHZ-Verlusts. Die SR ihrer verbleibenden SGN und die Verteilung der SR des auditorischen Nerven sind reduziert (Ryugo et al. 1998). In dieser Untersuchung war die Abwesenheit von SGN ohne Spontanaktivität auffällig. Zudem fand sich eine eingeschränkte SR-Verteilung.

Nach akustischem Trauma mit permanentem Hörschwellenschwund wird eine Reduktion der SR beschrieben (Liberman und Dodds 1987). Sie wird in dieser Studie mit einer Schädigung der IHZ-Stereovilli in Verbindung gebracht. Eine zweite Gruppe von SGN, die erhöhte SR aufwiesen, scheint mit einer Schädigung der ÄHZ bzw. ihrer Stereovilli in Zusammenhang zu stehen. Da Cav $\beta_{2}{ }^{-/-}$-Cochleae keine funktionellen ÄHZ besitzen, ist eine steigernde Wirkung des akustischen Traumas auf die SR nicht zu erwarten. Hinzu kommt, dass unreife SGN weniger spontan aktiv sind als reife, die Heterogenität der SR erscheint nach P7 (Walsh und McGee 1987). So könnte sich auch der unreife Haarzell-Phänotyp auf die SR auswirken. 


\subsubsection{Die Eigenschaften der Spiralganglionneurone sind von der Lokalisa- tion der aktiven Zone an der inneren Haarzellmembran abhängig}

Ein Aspekt, der Einfluss auf die Fasereigenschaften haben soll, ist die Lokalisation ihrer Synapse an der IHZ. So weisen Afferenzen, die die IHZ an der der ÄHZ zugewandten Seite kontaktieren (lateroapicaler Pol), Charakteristika der Gruppe III-SGN (hohe SR, niedrige Schwelle) auf, wohingegen Afferenzen an der Modiolus-zugewandten Seite (basaler Pol) Charakteristika der Gruppe I-SGN (niedrige SR, hohe Schwelle) besitzen (Liberman 2017). Diese Charakteristika korrelieren außerdem mit Form und Größe der präsynaptischen Bänder und der postsynaptischen AMPA-Rezeptor-Dichte. Ohn et al. beschreiben eine ausschließlich positive Korrelation zwischen Markern prä- und postsynaptischer Stärke. Große aktive Zonen am basalen Pol korrelierten mit großen Bändern und einer hohen Anzahl an Cav1.3 sowie großem $\mathrm{Ca}^{2+}$-Einstrom bei hoher Aktivierungsschwelle (Ohn et al. 2016). Andere Autoren beschreiben große Bänder, große angeheftete Vesikel und kleine AMPA-Rezeptor-Gruppierungen in Gruppe I- und II-SGN. Möglich ist, dass ein großes längliches Band eine weniger gut synchronisierte Vesikelausschüttung und damit multiphasische EPSP vermittelt, wohingegen ein kleines rundes Band in Verbindung mit einer dichten AMPARezeptor-Gruppierung eine schnelle synaptische Transmission über monophasische EPSP ermöglicht (Liberman et al. 2011). Diese widersprüchlichen Ergebnisse erklären sich eventuell durch die unterschiedliche Lokalisation der untersuchten IHZ innerhalb der Cochlea.

Auch die Amplituden und der mono- beziehungsweise multiphasische Verlauf der an einer Synapse typischerweise auftretenden EPSP könnten die Feuereigenschaften der SGN bestimmen (Grant et al. 2010). Die Eigenschaften der $\mathrm{Ca}^{2+}$ Kanäle (in ihrer Gesamtheit an einer aktiven Zone Mikrodomäne genannt) spielen für die Heterogenität der IHZ-Synapsen eine wichtige Rolle. Innerhalb einer IHZ weisen die aktiven Zonen variable $\mathrm{Ca}^{2+}$-Strom-Amplituden und Spannungsabhängigkeiten auf. So könnten die Raten der Transmitterausschüttung zwischen aktiven Zonen einer IHZ variieren, weil unterschiedlich viele Cav1.3 (Dichte und Verteilung) mit abweichenden Öffnungseigenschaften exprimiert werden (Frank et al. 2009; Meyer et al. 2009). Da die aktiven Zonen mit großen $\mathrm{Ca}^{2+}{ }^{2}$ StromAmplituden während des Hörbeginns erscheinen und in diesem Zeitraum auch erstmals Gruppe III-SGN gefunden werden, wird ein Zusammenhang zwischen 
maximalem $\mathrm{Ca}^{2+}$-Strom und Feuerrate vermutet (Wong et al. 2013). Demnach erscheint es logisch, dass in $\mathrm{Cav} \beta_{2}{ }^{-/-}$-Mäusen, deren IHZ deutlich geringere $\mathrm{Ca}^{2+}$ Ströme aufweisen, keine SGN mit SR $>60 \mathrm{~s}^{-1}$ gefunden wurden (Abbildung 4.1.3.1-1).

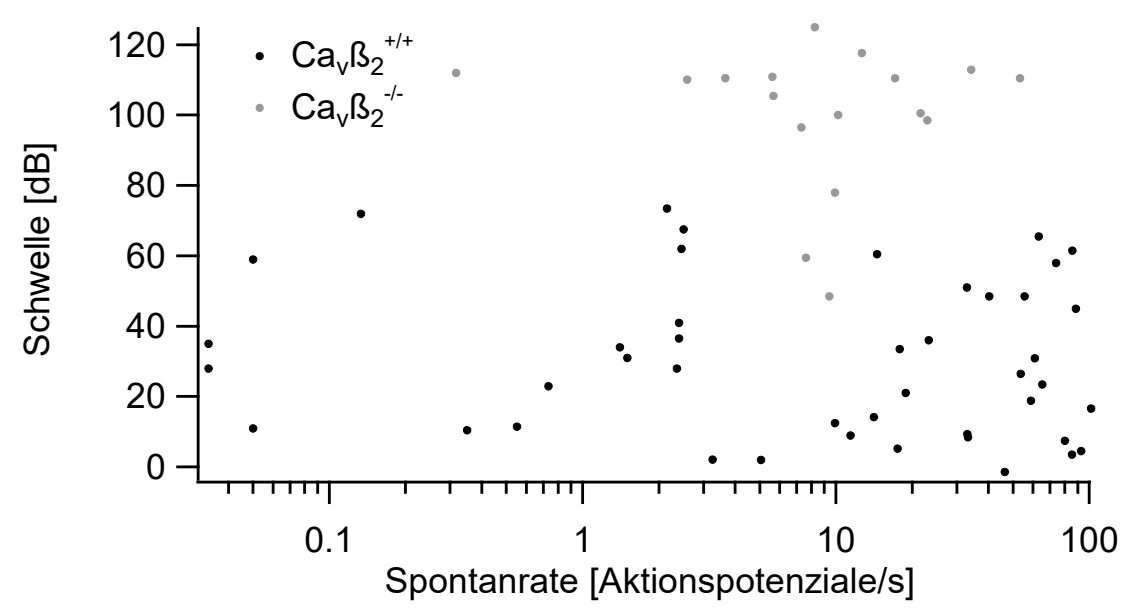

Abbildung 4.1.3.1-1 Spontanaktivitätsraten in Abhängigkeit von der Schwelle

SR in Abhängigkeit von der Schwelle, ermittelt aus RLF (log aufgetragen zur besseren Übersicht) Stichprobengröße: $\mathrm{Cav}_{v} \beta_{2}^{+/+}$schwarz, $\mathrm{n}=48 ; \mathrm{Cav}_{\vee} \beta_{2}{ }^{-/-}$hellgrau, $\mathrm{n}=17$

Möglicherweise hat auch die efferente Innervation während der Entwicklung beziehungsweise die räumliche Distanz zu den Efferenzen einen Einfluss auf die Größe der AMPA-Rezeptor-Gruppierung und damit auf die Feuereigenschaften der SGN. Da am basalen Pol der IHZ ein Bündel efferenter Fasern zieht, ergibt sich eine Proportionalität der Distanz zur Größe der AMPA-RezeptorGruppierung und zur SR (Liberman et al. 2011; Yin et al. 2014).

\subsubsection{Eine versuchsbedingte Verzerrung ist denkbar}

$\mathrm{Da}$ in dieser Untersuchung in $\operatorname{Cav} \beta_{2}{ }^{-/-}$-Tieren keine SGN mit hohen SR und niedrigen Schwelle gefunden wurden, ist es denkbar, dass sie in der Stichprobe nicht enthalten sind. In diesem Fall wäre die mittlere Schwelle der $\operatorname{Cav} \beta_{2}{ }^{-/-}$-Tiere falsch hoch bestimmt worden. Allerdings konnte hier weder für $\mathrm{Cav}_{v} \beta_{2}{ }^{-/-}$- noch für $\mathrm{Cav}_{2}{ }^{+/+}$-Tiere eine Korrelation zwischen den oben genannten Charakteristika nachgewiesen werden.

\subsubsection{Warum ist die Frequenzabstimmung abgeflacht?}

Die Frequenzabstimmkurven $\operatorname{der} \mathrm{Cav}_{2} \beta_{2}{ }^{+/+}$-SGN zeigten die, auch für andere Säugetiere charakteristischen, V-förmigen, spitz zulaufenden Kurven mit einer 
langsamer abfallenden Empfindlichkeit im Bereich tieferer Frequenzen. Die Frequenzabstimmkurven $\operatorname{der} \operatorname{Cav} \beta_{2}{ }^{-/-}-\mathrm{SGN}$ waren stumpfwinklig und flach. Sie ähnelten in ihrer Form den Schwänzen der $\mathrm{Cav} \beta_{2}{ }^{+/+}$-Frequenzabstimmkurven und lagen in ähnlichen Frequenzbereichen. Diese $\mathrm{Cav}_{v} \beta_{2}^{-/-}$-Frequenzabstimmkurven deuten auf eine fehlende oder erloschene ÄHZ-Funktion hin. Da den ÄHZ eine maximale Verstärkung der Hörsensitivität von 50 dB (Ryan und Dallos 1975; Møller 2006) zugeschrieben wird, kann ihr Fehlen den gemessenen Schwellenschwund von $70 \mathrm{~dB}$ nur zum Teil erklären.

Der der ÄHZ-Dysfunktion zugrundeliegende Mechanismus ist unklar und bedarf weiterer Untersuchungen. Da ÄHZ Cav1.3 besitzen, die altersabhängig an deren Entwicklung, Signalverarbeitung und Exozytose beteiligt sind (Michna et al. 2003; Shen et al. 2006; Knirsch et al. 2007; Kuhn et al. 2009), ist eine Einschränkung der Funktion in $\mathrm{Cav} \beta_{2}{ }^{-/-}$- $\mathrm{HZ}$ allerdings nicht unerwartet.

Anders als in $\mathrm{Ca}_{v} 1.3^{-/-}$- (Platzer et al. 2000; Glueckert et al. 2003) und $\mathrm{BK}^{-/-}$Mäusen (Rüttiger et al. 2004) zeigen $\mathrm{Cav}_{\vee} \mathrm{\beta}_{2}{ }^{-/}$-Cochleae keine ÄHZ-Degeneration. Glueckert (Glueckert et al. 2003) postuliert einen kleinen konstanten $\mathrm{Ca}^{2+}$ Einstrom in die Haarzellen, der notwendig ist, um die cochleäre Morphologie aufrecht zu erhalten. Wenn man dieser Hypothese folgt, werden in $\operatorname{Cav} \beta_{2}{ }^{--}$-ÄHZ möglicherweise ausreichend $\mathrm{Ca}^{2+}$-Kanäle exprimiert, um den für den Erhalt der ÄHZ mindestens erforderlichen $\mathrm{Ca}^{2+}$-Einstrom zu gewährleisten. Bis zu einem Alter von neun Wochen finden sich in allen Windungen intakte Reihen ÄHZ und IHZ und die Zellen erscheinen in immunhistochemischer Färbung bei visueller Inspektion normal. Funktionelle Veränderungen oder eine spätere Degeneration sind damit allerdings nicht ausgeschlossen.

Die mittlere CF der gefundenen $\mathrm{Ca}_{v} \beta_{2}{ }^{-/-}$-SGN lag bei $6 \mathrm{kHz}$, wohingegen sie für $\mathrm{Cav}_{2}{ }^{+/+}$-SGN bei $17,9 \mathrm{kHz}$ lag (Abbildung 3.1.2.3-5 Stimulusfrequenzen in Abhängigkeit vom Stimuluspegel). Unter Berücksichtigung des Hörfeldes von Mäusen zwischen 2,5 und $70 \mathrm{kHz}$ (Taberner und Liberman 2005) und den unterschiedlichen genetischen Hintergründen der Versuchstiere, wäre kein Unterschied zu erwarten ist. Der genetische Defekt der $\beta_{2}$-IHZ-Synapse sollte alle Bereiche entlang der Basilarmembran gleichermaßen betreffen. Für den Funktionsverlust der $\mathrm{A} H Z$ wurden neben abgeflachten Frequenzabstimmkurven auch in tiefere Frequenzbereiche verschobene Minima derselben beschrieben 
(Fettiplace und Hackney 2006). Dies könnte die Tatsache, dass die SGN der $\mathrm{Cav}_{2} \beta_{2}^{-/-}$-Mäuse tiefere $\mathrm{CF}$ aufweisen, erklären. Des Weiteren könnte sie zum einen durch die begrenzte Lautsprecherkapazität für hohe Frequenzen bedingt sein (Abbildung 3.1.2.3-1), zum anderen käme ein Lärm-induzierter Schaden als mögliche Ursache in Frage. Typischerweise betrifft dieser neben des mit der auslösenden Frequenz korrespondierenden tonotopischen Bereichs der Cochlea zunächst die hochfrequente Basis, wodurch SGN mit hohen CF seltener und mit möglicherweise erhöhter Schwelle gefunden werden (Wang et al. 2002).

Eine weitere mögliche Ursache eines Hochtonverlusts stellt eine Altersschwerhörigkeit dar. Inzuchtmausstämme wie $\mathrm{C} 57 \mathrm{Bl} / 6$ können bereits früh davon betroffen sein. In einem Alter von P40-70 ist sie als Ursache für das begrenzte CF-Spektrum der SGN allerdings fragwürdig. Es wird nicht davon ausgegangen, dass $\mathrm{Cav} \beta_{2}{ }^{-/-}$-Mäuse im Vergleich zu ihren Kontrollen einer frühzeitigen Alterung unterliegen.

Auch bei kongenital tauben weißen Katzen wurden SGN mit vergleichsweise tiefen CF gefunden (Ryugo et al. 1998). Bei ihnen zeigte sich allerdings neben weiteren morphologischen Auffälligkeiten ein Haarzell-Verlust auf einer Länge von $\sim 25 \%$ an der cochleären Basis mit korrespondierender SGN-Degeneration.

\subsubsection{Wieso erscheint der dynamische Bereich der Schallkodierung breit?}

Für die Messung der RLF und des PST wurde eine Stimulation mit der CF verwendet. Bei vielen $\mathrm{Cav}_{v} \beta_{2}{ }^{-/-}-\mathrm{SGN}$ konnte diese allerdings nicht mittels Frequenzabstimmung ermittelt werden, sondern musste abgeschätzt werden (s. Kapitel 2.6. Extrazelluläre Mikroelektroden-Ableitungen von einzelnen Hörnervenfasern). Zudem konnten die Stimulationspegel, die vermutlich nötig wären um die RLF der $\mathrm{Cav}_{v} \beta_{2}^{-/-}$-SGN komplett zu erfassen, nicht erreicht werden, sodass eine genaue Bestimmung des dynamischen Bereichs unmöglich ist. Um eine Aussage über mögliche Veränderungen der dynamischen Bereiche treffen zu können, müssten komplette RLF von SGN mit ähnlichen CF verglichen werden. Da kaum eine $\mathrm{Cav}_{2}{ }_{2}^{-/-}$-RLF eine Sättigung erreichte, konnte ein detaillierter Vergleich in dieser Studie nicht realisiert werden.

Die RLF schienen eher flach zu verlaufen, was für einen weiten dynamischen Bereich sprechen würde. Auch bei den $\mathrm{Cav}_{v} \beta_{2}{ }^{+/+}$-RLF fanden sich SGN mit flach verlaufender Sättigungskurve. Steile RLF werden vor allem im Bereich des besten 
Hörens erwartet. Ein steiler Verlauf ermöglicht eine feine Auflösung von Pegelunterschieden. Bei Mäusen, die darauf spezialisiert sind, Frequenzen bis $70 \mathrm{kHz}$ wahrzunehmen, werden dementsprechend steile RLF im Hochtonbereich erwartet. Eine andere Erklärung für flache RLF bieten die Charakteristika der Gruppe ISGN. Es ist möglich, dass hauptsächlich sie gefunden und vermessen wurden. Obwohl hier keine Korrelation zwischen SR und Schwelle der SGN gefunden wurde, ist ein Zusammenhang der anderen Parameter denkbar. Für SGN von Wüstenrennmäusen wurde eine negative Korrelation zwischen dynamischem Bereich eines SGN und seiner CF beschrieben (Ohlemiller et al. 1991). Bei Mäusen ist eine derartige Abhängigkeit bislang aber nicht beschrieben (Taberner und Liberman 2005).

\subsubsection{Wie kann die Reduktion der Aktionspotenzialraten erklärt werden?}

Eine eingeschränkte AP-Rate kann prinzipiell durch jede Störung im Bereich der Prä- und Postsynapse hervorgerufen werden. Auf beide können zudem efferente Einflüsse wirken. Einige Autoren beschreiben eine Expression von Cav1.3 in SGN (Chen et al. 2011). $\beta_{2}$-Protein wurde allerdings nur in geringem Maße nachgewiesen (Kuhn et al. 2009). Es wird daher davon ausgegangen, dass die Funktion der Postsynapse in $\operatorname{Cav} \beta_{2}{ }^{-/-}$-Cochleae nahezu ungestört ist und somit einen vernachlässigbaren Einfluss auf den Phänotyp hat. Auf präsynaptischer Seite hingegen wirken sich Veränderungen an ÄHZ und IHZ aus.

\subsubsection{Trotz reduzierter Zahl der Cav1.3 in der inneren Haarzellmembran ist eine Transmission möglich}

Die Exozytose synaptischer Vesikel aus IHZ ist $\mathrm{Ca}^{2+}$-abhängig. Die Anzahl von Cav1.3, ihre Funktion und korrekte Lokalisation an der Zellmembran ist daher entscheidend. Eine der den $\beta$-Untereinheiten zugeschriebenen Rollen ist der Transport der $\alpha_{1}$-Untereinheit an die Plasmamembran (Chien et al. 1995). Werden $\beta$-Untereinheiten gemeinsam mit $\alpha_{1}$-Untereinheiten in heterologen Zellsystemen exprimiert, lokalisieren beide an der Plasmamembran (Brice et al. 1997; Obermair et al. 2010).

Es gibt verschiedene Hypothesen, wie die $\beta$-Untereinheit die Präsenz der $\alpha_{1}$ Untereinheit an der Membran steigert. So könnte die $\beta$-Untereinheit die Translation bzw. Proteinfaltung oder posttranslationale Modifikationen im 
endoplasmatischen Retikulum ermöglichen, indem sie ein Retentionssignal auf der $\alpha_{1}$-Untereinheit abschirmt oder unterbricht (Bichet et al. 2000). Diese Hypothese ist umstritten ((Waithe et al. 2011) für N-Typ $\mathrm{Ca}^{2+}$-Kanäle). Sie könnte auch die Überlebenszeit der $\alpha_{1}$-Untereinheit erhöhen, indem sie sie vor Ubiquitinierung und Proteolyse schützt (Altier et al. 2011). Beiden Beobachtungen könnte eine, auf die Bindung der beiden Untereinheiten folgende, Konformationsänderung zugrunde liegen.

Die Funktion der $\beta$-Untereinheit als Chaperon, das die Membranständigkeit der $\alpha_{1}$-Untereinheit von Cav1- und Cav2-Kanälen drastisch erhöht, ist etabliert und konnte in verschiedenen Zellsystemen und in vivo nachgewiesen werden (PerezReyes et al. 1992; Chien et al. 1995; Gregg et al. 1996; Brice et al. 1997; Colecraft et al. 2002). Die Herunterregulierung der Expression der $\beta$-Untereinheit reduziert $\mathrm{Ca}^{2+}$-Ströme in neuronalen Zellen. Im Gegenzug erhöht die Überexpression der $\beta$-Untereinheit die Membranexpression der $\mathrm{Ca}^{2+}$-Kanäle (Wei et al. 1991; Obermair et al. 2010).

Ohne $\beta$-Untereinheit findet eine Membranlokalisierung der $\alpha_{1}$-Untereinheit nur in geringem Maße statt, die intrazelluläre $\alpha_{1}$-Proteinmenge ist dabei unverändert (Chien et al. 1995; Ravindran et al. 2008). Obwohl die $\alpha_{1}$-Untereinheit ohne eine $\beta$-Untereinheit in der Lage ist, die Membran zu erreichen und so einen $\mathrm{Ca}^{2+}$-Strom zu ermöglichen (Josephson und Varadi 1996; Kamp et al. 1996; Jones et al. 1998), spielt die $\beta$-Isoform wohl eine wichtige Rolle bei der exakten Lokalisierung des $\mathrm{Ca}^{2+}$-Kanals an der Zellmembran (Obermair u. a. 2010; S. K. Wei u. a. 2000). Eine Teilkompensation des Fehlens von $\beta_{2}$ durch andere Isoformen könnte, durch eine differente Lokalisierung der $\mathrm{Ca}^{2+}$-Kanäle, die Zelleigenschaften beeinflussen. Werden die Verteilung der Synapsen und die korrespondierenden Charakteristika der SGN entlang der Apex/Basis-Achse der IHZ bedacht, erscheint ein Einfluss denkbar.

Ausgehend von ihrer Aminosäure-Sequenz, sollten alle vier $\beta$-Untereinheiten im Zytosol lokalisiert sein. $\beta_{2 \mathrm{a}}$ und -e kommt eine besondere Bedeutung $\mathrm{zu}$ (Isoformen, die posttranslational modifiziert werden). Im Gegensatz $\mathrm{zu}$ den anderen $\beta$-Untereinheiten sind sie auch ohne co-exprimierte $\alpha_{1}$-Untereinheit an der Zellmembran lokalisiert (Chien et al. 1995; Chien et al. 1996; Chien et al. 1998; Gao et al. 1999; Takahashi et al. 2003). Maßgeblich scheint für $\beta_{2 a}$ die 
Palmitylierung zu sein. Für $\beta_{2 \mathrm{e}}$ scheint eine spezifische Sequenz im COOH-Ende entscheidend. Mit der Membranassoziation sind funktionelle Effekte verbunden, wie die Beeinflussung der Öffnungseigenschaften des Kanals (Findeisen und Minor 2009) und der Zugang für regulatorische Proteine.

Obwohl prinzipiell alle $\beta$-Untereinheiten die Plasmamembran-Expression der $\alpha_{1-}$ Untereinheit fördern und ihre Funktion regulieren können, übernehmen, abhängig von Zellart und $\alpha_{1}$-Untereinheit, unterschiedliche $\beta$-Untereinheiten diese Aufgabe. In Skelettmuskelzellen beispielsweise ist nur $\beta_{1}$ vorhanden und gewährleistet die Funktion der Cav1.1-Kanäle. Ein Austausch gegen $\beta_{2 a}$ führt zu vergleichbaren $\mathrm{Ca}^{2+}$-Strömen der Kanäle, kann aber keine vollständig normale Funktion der Zelle ermöglichen (Beurg et al. 1999).

In IHZ sind neben $\beta_{2}$ auch $\beta_{1}$ und $\beta_{3}$ vorhanden. Ihre Expression ist sehr gering und in $\operatorname{Cav} \beta_{2}{ }^{-/-}$-Mäuse nicht kompensatorisch erhöht (Neef et al. 2009). Obwohl der Transport der $\alpha_{1}$-Untereinheit maßgeblich von der co-exprimierten $\beta$-Untereinheit abhängig ist, könnte sich in $\mathrm{Ca}_{\mathrm{v}} \beta_{2}{ }^{-/-}-\mathrm{HZ}$ eine geringe Menge von $\mathrm{Ca}^{2+}$ Kanälen ohne $\beta$-Untereinheit korrekt an der Plasmamembran lokalisieren. Durch eine Teilkompensation mittels $\beta_{1}$ oder/und $\beta_{3}$ ist eine Restexpression an der Zellmembran ebenfalls erklärbar. Im Falle einer Kompensation ist davon auszugehen, dass $\beta_{1}$ oder $\beta_{3}$ eine geringere Effektivität als $\beta_{2}$ erreichen. Werden in Herzmuskelzellen verschiedene $\beta$-Untereinheiten exprimiert, zeigen $\beta_{2 a}$ und $\beta_{4}$ eine größere Effektivität den $\mathrm{Ca}^{2+}{ }^{2+}$ Strom (Colecraft et al. 2002) und den Transport (Chien et al. 1998) betreffend als $\beta_{1 b}$ und $\beta_{3}$. In Purkinje-Neuronen von Mäusen, die kein $\beta_{4}$ exprimieren, wurde gezeigt, dass $\alpha 1 \mathrm{~A}$ und $\alpha 1 \mathrm{~B}$ vermehrt mit den verbleibenden $\beta$-Untereinheiten 1-3 assoziieren, ohne dass sich die Menge deren mRNA signifikant verändert (Burgess et al. 1999). Dass lediglich $\mathrm{Ca}^{2+}-$ Kanäle an der Zelloberfläche erscheinen, die ohnehin mit einer der verbliebenen $\beta$ Untereinheit assoziiert sind, ist zweifelhaft, da nur in einigen IHZ ihre mRNA nachgewiesen wurde und z. B. der Phänotyp von $\mathrm{Cav}_{v} \beta_{3}{ }^{-/-}$-Mäusen sehr gering ausgeprägt ist (Kuhn et al. 2009).

Da die verwendeten $\mathrm{Cav}_{v} \beta_{2}^{-/-}$-Mäuse eine transgene, auf Rettung der Herzmuskelzellen zielende Expression von $\beta_{2}$ in sich tragen, ist eine partielle transgene Expression in IHZ als Ursache für den verbleibenden Strom und die nicht 
signifikant veränderten Öffnungseigenschaften nicht völlig auszuschließen. Der fehlende Nachweis von mRNA macht dies allerdings höchst unwahrscheinlich.

Mehrere Aspekte sprechen für vollständig konfigurierte Cav1.3:

\subsubsection{1. Öffnungswahrscheinlichkeit}

Für die Präsenz funktioneller $\alpha_{1} \mathrm{D} / \beta$-Komplexe an der Membran sprechen die nicht signifikant veränderten Öffnungseigenschaften. $\mathrm{Cav}_{v} \beta_{2}{ }^{-/-}-\mathrm{IHZ}$ weisen eine normale Öfnungswahrscheinlichkeit und spannungsabhängige Aktivierung auf (Neef et al. 2009). $\mathrm{Ca}^{2+}$-Kanäle ohne assoziierte $\beta$-Untereinheit öffnen sich weniger häufig und für eine kürzere Zeitspanne. Die Co-Expression aller $\beta$ Untereinheiten erhöht die Öffnungswahrscheinlichkeit des jeweiligen $\mathrm{Ca}^{2+}$-Kanals und verringert die Latenz bis zum ersten Öffnen (Colecraft et al. 2002; Dolphin 2003; Hullin et al. 2003; Herzig et al. 2007). Die Co-Expression einer $\beta$ Untereinheit bewirkt eine hyperpolarisierende Verschiebung der spannungsabhängigen Aktivierung (Gregg et al. 1996; Murakami et al. 2002; Weissgerber et al. 2006). Dadurch können geringere Depolarisationen eine Aktivierung hervorrufen.

\subsection{Grad der $\mathrm{Ca}^{2+}$-Strom-Reduktion}

Im Gegensatz zu $\alpha_{1} \mathrm{D}^{-/-}$-IHZ, die im Vergleich zu ihren Kontrollen eine $90 \%$-ige Reduktion ihres $\mathrm{Ca}^{2+}$-Stroms aufweisen (Brandt et al. 2003), zeigen $\mathrm{Cav}_{v} \beta_{2}{ }^{-/}$-IHZ nur eine 70 \%-ige Reduktion (Neef et al. 2009). Die $\beta$-Untereinheit spielt sowohl beim Transport innerhalb der Zelle, bei der korrekten Lokalisation an der Zellmembran als auch bei der Stabilisierung des Kanalkomplexes eine Rolle. Da nur ein geringer Prozentsatz von $\alpha_{1} \mathrm{D}$-Untereinheiten ohne assoziierte $\beta$-Untereinheit membranständig und somit funktionstüchtig ist (Chien et al. 1995), wird die These, inkomplette $\mathrm{Ca}^{2+}$-Kanäle würden den $\mathrm{Ca}^{2+}$-Strom in $\mathrm{Cav} \beta_{2}{ }^{-/-}$-IHZ aufrechterhalten, unwahrscheinlich.

\subsection{Spannungsabhängige Inaktivierung}

Für die meisten $\alpha_{1}$-Untereinheiten wurde gezeigt, dass eine assoziierte $\beta$ Untereinheit eine beschleunigte spannungsabhängige Inaktivierung (VDI) bewirkt. Davon auszunehmen sind $\beta_{2 \mathrm{a}}$ und $\mathrm{e}$, die diese verzögern (De Waard und Campbell 1995; Takahashi et al. 2003; He et al. 2007; Herzig et al. 2007). Dieser $\beta$-Isoform-abhängige Unterschied scheint in Cav1.3 zu fehlen. Im Gegensatz zu 
anderen $\mathrm{Ca}^{2+}$-Kanälen hat die Assoziation einer $\beta$-Untereinheit auf die VDI keine beschleunigende Wirkung. Cav1.3 scheinen eine von der Art der assoziierten $\beta$ Untereinheit unabhängig verzögerte VDI aufzuweisen. Der Austausch von $\beta_{2 a}$ gegen $\beta_{1 b}, \beta_{3}$ oder $\beta_{4}$ bewirkt in HEK-Zellen keine oder eine nur geringe Veränderung der VDI (Shen et al. 2006; Cui 2007; Tadross et al. 2010). Die in $\mathrm{Ca}_{v} \beta_{2}{ }^{-/-}$-IHZ gemessene unveränderte VDI deutet daher auf die Existenz vollständiger $\mathrm{Ca}^{2+}$-Kanäle in der Zellmembran hin, assoziiert mit einer in der Zelle vorhandenen $\beta$-Untereinheit.

\subsubsection{4. $\quad \mathrm{Ca}^{2+}$-abhängige Inaktivierung}

Ein negativer Rückkopplungsmechanismus, die $\mathrm{Ca}^{2+}$-abhängige Inaktivierung (CDI), wird durch die Interaktion von Calmodulin mit der $\alpha_{1}$-Untereinheit vermittelt (Lee et al. 1999; Peterson et al. 1999) und ebenfalls von der Bindung der $\beta$-Untereinheit beeinflusst (Findeisen und Minor 2009). Cav1.3 in IHZ zeigen verglichen mit denen anderer Zellen (beta-Zellen des Pankreas, Sinusknoten am Herzen) eine geringe CDI (Shen et al. 2006; Yang et al. 2006; Cui et al. 2007). Diese Eigenschaft könnte ihnen die Verarbeitung anhaltender akustischer Stimuli ermöglichen (Kollmar et al. 1997). Eine stärkere CDI könnte im Gegenzug eine deutliche Abnahme der Effektivität der IHZ-Synapse bei der Transmission andauernder Stimuli bedingen. Die vergleichsweise geringe CDI könnte durch die Bindung von $\mathrm{CaBP}$ an die $\alpha_{1} \mathrm{D}$-Untereinheit hervorgerufen werden (Yang et al. 2006). Diese soll durch Dislokation von Calmodulin regulatorisch wirksam sein (Cui et al. 2007). Für die Bindung ist eine assoziierte $\beta$-Untereinheit erforderlich (Findeisen und Minor 2009). In $\mathrm{Cav} \beta_{2}{ }^{-/-}$-IHZ ist sowohl die schnelle als auch die langsame Komponenten der CDI verändert und zwar in entgegen gesetzter Richtung. Das legt eine Ursache, die beide Komponenten beeinflussen kann, nahe. Da CaBP die Calmodulin-abhängige CDI beeinflussen (Cui et al. 2007) und auf Grund ihrer unterschiedlichen Bindungsstellen für $\mathrm{Ca}^{2+}$-Ionen regulatorische Eigenschaften besitzen können, stellen sie potenzielle Kandidaten dar. Die Bindung regulatorischer $\mathrm{CaBP}$ an $\mathrm{Ca}^{2+}$-Kanäle mit $\beta_{1}$ - oder $\beta_{3}$-statt $\beta_{2}$-Untereinheit könnte zu der oben beschriebenen veränderten CDI führen. Für CaBP4 zum Beispiel sind $\beta$-Isoform-spezifische Wirkungen beschrieben. Allerdings spielt CaBP4 an der Regulation der $\mathrm{Ca}^{2+}$-Kanäle von IHZ wohl nur eine untergeordnete Rolle. Eine Schlüsselrolle scheint hingegen CaBP2 inne zu haben (Schrauwen et al. 2012, Picher et al. 2017). Bereits geringe Abweichungen der 
CDI könnten sich deutlich auf die IHZ-Funktion auswirken. Die Sensitivität der IHZ wäre erniedrigt, was bei gleicher akustischer Stimulation zu einer reduzierten $\mathrm{Ca}^{2+}$-abhängigen Transmitterausschüttung führen würde (Grant und Fuchs 2008; Schrauwen et al. 2012).

Darüber hinaus sind Einflüsse anderer Reaktionspartner des Cav1.3, die sich je nach assoziierter $\beta$-Untereinheit unterschiedlich auswirken, denkbar. Interaktionen $\operatorname{der} \beta_{2}$-Untereinheit mit z. B. G-Proteinen, der RAS-Proteinfamilie, der $\mathrm{Ca}^{2+} / \mathrm{CaM}$ abhängigen Kinase II (CaMKII), MAP-Kinasen, Proteinkinase A, B, C und G oder Arachidonsäure wurden von zahlreichen Autoren beschrieben.

\subsubsection{Der unreife IHZ-Phänotyp kann sich auf die Aktivität auswirken}

Reife IHZ unterscheiden sich wesentlich von unreifen. In ihrer Entwicklung verlieren sie Efferenzen aus dem Hörnerven. Außerdem ändert sich die Kanalzusammensetzung ihrer Zellmembran. Elektrophysiologisch unterscheiden sie sich im Ausmaß ihrer $\mathrm{Ca}^{2+}$-Ströme sowie ihrer Aktivierungs- und Regenerationsgeschwindigkeit. Reife IHZ weisen deutlich niedrigere $\mathrm{Ca}^{2+}$-Ströme auf als unreife IHZ (Beutner und Moser 2001; Brandt et al. 2003). Die Aktivierung des $\mathrm{Ca}^{2+}$-Einstroms von adulten IHZ läuft schneller ab als die unreifer IHZ. Sie ist außerdem im hochfrequenten Bereich schneller.

Unreife IHZ sind reifen im Bezug auf die rasche Verarbeitung einkommender Stimuli und damit der präzisen Initiierung von Aktionspotenzialen sowie der Verarbeitung rasch aufeinander folgende Stimuli unterlegen. Sie zeigen allerdings deutlich höhere $\mathrm{Ca}^{2+}$-Ströme, die für die AP-Generierung entscheidend sind (Brandt et al. 2003). Da in $\mathrm{Cav} \beta_{2}{ }^{-/-}$-Mäusen die $\mathrm{Ca}^{2+}$-Ströme durch den Mangel an membranständigen $\mathrm{Ca}_{\vee} 1.3$ deutlich eingeschränkt sind, ist es höchst zweifelhaft, dass unreife $\mathrm{Cav}_{2} \beta_{2}^{-/-}$-IHZ gegenüber reifen erhöhte $\mathrm{Ca}^{2+}$-Ströme aufweisen. Inwieweit der unreife IHZ-Phänotyp physiologische Auswirklungen hat ist unklar. Es ist aber vorstellbar, dass die übrigen beschriebenen Befunde für einen Teil der AP-Ratenreduktion verantwortlich sind.

\subsubsection{Abschließende Beurteilung}

Die deutlich reduzierte Anzahl funktionstüchtiger $\mathrm{Cav} 1.3$ in $\mathrm{Cav} \beta 2^{-/-}-\mathrm{IHZ}$, deren im Vergleich zu Cav $\beta_{2}{ }^{+/+}$-IHZ veränderte Eigenschaften, der Defekt der ÄHZ und mögliche Auswirkungen der Entwicklungsstörung, können die profunde Schwer- 
hörigkeit erklären. Sie verdeutlichen die tragende Rolle der $\beta_{2}$-Untereinheit in einem fein abgestimmten komplexen System zahlreicher Reaktionspartner.

\subsection{Mauslinie $\mathrm{C} \times 26^{+/ \mathrm{S} 17 \mathrm{~F}}$}

$\mathrm{Cx} 26^{+/ \mathrm{S} 17 \mathrm{~F}}$-Mäuse weisen neben typischen Hauterscheinungen eines KITSyndroms eine hochgradige Schwerhörigkeit auf, die trotz einer bei den Kontrolltieren ebenfalls vorhandenen Hörminderung signifikant ist. Die erhöhten Schwellen der Kontrolltiere sind möglicherweise auf Lärm in den Tierställen oder eine stamm- bzw. altersabhängige Schwerhörigkeit zurückzuführen. Die Hörminderung der $\mathrm{Cx} 26^{+/ \mathrm{S} 17 \mathrm{~F}}$-Mäuse lässt sich nicht allein durch das Fehlen des cochleären Verstärkers erklären. Das EP der Cx26 ${ }^{+/ \mathrm{S} 17 \mathrm{~F}}$-Mäuse ist im Mittel um 30 \% vermindert. Zwischen ermittelten FAEP-Hörschwellen und EP besteht eine negative Korrelation. Vordergründig scheint eine gestörte Generierung des EPs, was eine Reduktion der in die Haarzellen gerichteten treibenden Kraft für $\mathrm{K}^{+}$Ionen bedeutet, ursächliche für die Schwerhörigkeit zu sein. Der zugrundeliegende Pathomechanismus ist aber komplexer.

\subsubsection{Wie führt Cx26 ${ }^{+/ S 17 F}$ zur Schwerhörigkeit?}

$\mathrm{Cx} 26^{-/-}$-Mäuse sterben während der Embryogenese. Wird Cx26 Cochleaspezifisch ausgeschaltet (Cx26 $6^{\mathrm{OtogCre}}$-Mäuse), lassen sich Rückschlüsse auf seine Funktion ziehen. Verglichen mit $\mathrm{Cx} 26^{+/ \mathrm{S} 17 \mathrm{~F}}$-Tieren fallen eine Taubheit, ein deutlich verringertes EP und eine reduzierte $\left[\mathrm{K}^{+}\right]$der Endolymphe auf. Im Gegensatz zu Cx26 ${ }^{\text {OtogCre }}$-Mäusen, denen Cx26 (Cohen-Salmon et al. 2002; Sun et al. 2009) und Cx30---Mäusen, denen Cx30 im Innenohr fehlt (Teubner et al. 2003), weisen $\mathrm{Cx} 26^{+/ \mathrm{S} 17 \mathrm{~F}}$-Mäuse nach Hörbeginn keine apoptotische Degeneration von cochleären Zellen auf (Schütz 2011). In Cx26 ${ }^{\text {OtogCre }}$-Mäusen scheint die Degeneration nach Hörbeginn von den Stützzellen um die ÄHZ oder den ÄHZ selbst auszugehen (Cohen-Salmon et al. 2002; Sun et al. 2009). Der Schluss liegt nahe, dass die Expression von einem Wildtyp-Cx26 Allel in $\mathrm{Cx} 26^{+/ \mathrm{S} 17 \mathrm{~F}}$, eventuell in Wechselwirkung mit Cx30, ausreicht, um eine Restfunktion der Cochlea aufrecht zu erhalten, die durch das vollständige Fehlen von Cx26 in Cx26 $6^{\text {OtogCre }}$ Mäusen nicht mehr gewährleistet ist. Der durch die Mutation entstehende Hörphänotyp könnte einem ähnlichen Pathomechanismus zugrunde liegen wie der Cx26 ${ }^{\text {OtogCre }}$-Phänotyp. Fehlendes Cx26 könnte zu einer Erhöhung der $\left[\mathrm{K}^{+}\right]$in der Corti-Lymphe führen. Die extrazelluläre $\left[\mathrm{K}^{+}\right]$hat offenbar einen direkten Einfluss 
auf die Funktion des Glutamat-Transporterproteins GLAST, das in Stützzellen um die IHZ exprimiert wird und eine Schlüsselrolle in der Entfernung des Transmitters aus der Extrazellularflüssigkeit trägt. Unter den beschriebenen Gegebenheiten, könnte der Transporter in reverser Weise funktionieren (Szatkowski et al. 1990), was zu einer Kumulation von extrazellulärem Glutamat führt, was wiederum einen inhibitorischen Effekt auf die Bildung von Glutathion haben kann. Eine Störung der interzellulären Kopplung kann also zu einer Kumulation von Glutamat, damit $\mathrm{zu}$ oxidativem Stress und so zum Tod von cochleären Stützzellen führen (Murphy et al. 1989; Tan et al. 1998).

$\mathrm{Cx} 30^{-/-}$-Mäuse leiden an einer hochgradigen Schwerhörigkeit und, anders als Cx26 $6^{\text {OtogCre }}$-Mäuse, vor allem unter einem Verlust von ÄHZ und IHZ sowie wohl sekundär von SGN (Sun et al. 2009). Cx30-/-Mäuse generieren weder vor noch nach Hörbeginn ein EP, während die $\left[\mathrm{K}^{+}\right]$in der Endolymphe erst nach Hörbeginn drastisch sinkt. Die Menge der gebildeten Endolymphe und die initiale $\mathrm{K}^{+}$Sekretion durch die Stria vascularis erscheinen normgerecht. Ein möglicher Pathomechanismus ist die Kumulation von $\mathrm{K}^{+}$-Ionen in der Corti-Lymphe, die über eine chronische Depolarisation die Apoptose der Haarzellen vermittelt. Die Latenz kann variieren und hängt vermutlich von der $\left[\mathrm{K}^{+}\right] \mathrm{ab}$. Wird bedacht, dass $\mathrm{K}^{+}$aus den Haarzellen und der Corti-Lymphe über die Stützzellen abtransportiert wird, erscheint eine primäre Schädigung dieser Strukturen bei behinderten Transportwegen naheliegend.

Ein weiteres Mausmodell, das die Mutation R75W im Cx26-Gen trägt, die auf dominant-negative Weise die Expression des Wildtyp-Cx26 inhibieren soll, zeigt eine Taubheit, missgestaltete Stützzellen mit Deformation des Cortischen Tunnels und eine Degeneration von ÄHZ und IHZ (Kudo et al. 2003). Die EP-Messung offenbart einen wesentlichen Unterschied zu den bislang beschriebenen Phänotypen. Es ist nur um $10 \%$ reduziert. Die Autoren vermuten den oben beschriebenen Pathomechanismus mit erhöhter $\left[\mathrm{K}^{+}\right]$in der Corti-Lymphe statt einer gestörten Endolymph-Homöostase. Keines der beschriebenen Mausmodelle zeigt morphologische Veränderungen der Stria vascularis oder des Lig. spirale. Auch stellt sich die Reissner Membran in histologischen Untersuchungen intakt und unverändert dar. Sie lässt indirekt Rückschlüsse auf die Produktion der Endolymphe zu (Vetter et al. 1996; Delpire et al. 1999). 
Die aufgeführten Befunde lassen die Hypothese zu, funktionelles Cx26 sei vor allem für die $\mathrm{K}^{+}$-Sekretion in die Endolymphe und den Abtransport aus der CortiLymphe verantwortlich, Cx30 für die Generierung des EPs. Die Menge an produzierter Endolymphe beeinflussen sie allenfalls marginal.

Da in adulten $\mathrm{Cx} 26^{+/ \mathrm{S} 17 \mathrm{~F}}$-Mäusen kein Untergang cochleärer Zellen zu finden ist, tritt dieser entweder mit verlängerter Latenz oder gar nicht ein. Eine erhöhte $\left[\mathrm{K}^{+}\right]$ in der Corti-Lymphe könnte dennoch vorhanden sein und, wenn auch nicht zur Apoptose, zu einer Dysfunktion der Zellen führen. In dieser Arbeit wurde die $\left[\mathrm{K}^{+}\right]$ in der Endolymphe weder vor noch nach Hörbeginn gemessen. Daher kann keine Aussage über die diesbezüglichen Auswirkungen der Mutation Cx26S17F getroffen werden. $\mathrm{Zu}$ erwarten wäre eine reduzierte $\left[\mathrm{K}^{+}\right]$bei vor Hörbeginn nur leicht dezimiertem EP.

Eine Erklärung für Pathologien, die sich erst nach Hörbeginn manifestieren, liefert die Beobachtung, dass cochleäre Stützzellen erst drei Tage postnatal mit gap junctions bestückt sind und diese einem progredienten Reifungsprozess unterliegen (Zhang et al. 2005). Ein anderer Ansatz stellt die erst nach Hörbeginn mögliche Stimulus-abhängige Aktivierung des Cortischen Organs in den Vordergrund. Diese Theorie würde erklären, warum die sensitivsten Regionen entlang der Basilarmembran als erste der Degeneration unterliegen (Sun et al. 2009).

\subsubsection{Welchen Effekt hat die Mutation Cx26S17F auf zellulärer Ebene?}

In HeLa-Zellen und Oozyten wurde gezeigt, dass Cx26S17F-Kanäle zwar produziert und zur Zellmembran transportiert werden, ihre Funktion und Permeabilität aber gestört ist. Untersuchungen an Halbkanälen (Connexonen) mit unterschiedlichen Punktmutationen in Cx26, die zu einem KIT- oder KITähnlichen Syndrom führen, zeigen Veränderungen der Kanal-Ströme (Lee et al. 2009). Es wird angenommen, dass der N-Terminus des Proteins eine Art Stöpsel für den Kanal bildet. In der Röntgenkristallographie kann gezeigt werden, dass eine Deletion der 2.-7. Aminosäure zu einer verringerten Dichte der in der Pore des Kanals lokalisierten Struktur führt. Ob der Stöpsel aber zu einem Verschluss oder zu einer Stabilisierung des Offen-Zustands des Kanals beiträgt, ist nicht hinreichend geklärt (Oshima et al. 2008; Oshima et al. 2011). Weiter wird angenommen, dass dieser durch hydrophobe Wechselwirkungen zwischen Trp3 und Met34 gebildet wird und durch Konformationsänderungen spannungs- 
abhängig den Kanal verschließen kann. Durch eine Veränderung der Wechselwirkungen zwischen den Aminosäureresten können Mutationen im NTerminus des Proteins zu veränderten Öffnungswahrscheinlichkeiten und -eigenschaften führen.

Die Mehrzahl der KIT-auslösenden Mutationen weist eine deutlich erhöhte Halbkanalaktivität auf. Dabei korreliert eine erhöhte Aktivität mit gehäuftem Zelltod. Cx26S17F hingegen ruft eine biochemische und elektrische Entkopplung hervor. Untersuchte Halbkanäle weisen eine deutlich eingeschränkte Aktivität auf. Obwohl sie sehr ähnliche Symptome auslösen, spielt die Lokalisation der Mutationen somit eine entscheidende Rolle für ihre Auswirkung auf die Halbkanaleigenschaften (Lee et al. 2009).

\subsubsection{Wirkt sich die Mutation sekundär aus?}

Zahlreiche Mutationen im GJB2-Gen, die sowohl für Transmembran- als auch extrazelluläre Domänen des Proteins kodieren, hemmen die Ionen-Permeabilität und damit elektrische interzelluläre Kopplung. Andere Mutationen im GJB2-Gen wie V84L, V95M und A88S oder die Mutation T5M im GJB6-Gen führen zu einer unveränderten Ionen-Permeabilität der Kanalproteine. Sie stören den biochemischen interzellulären Transport von größeren Molekülen, z. B. von Signalmolekülen wie $\mathrm{IP}_{3}$, ATP, cAMP, cGMP oder von Metaboliten (Beltramello et al. 2005; Zhang et al. 2005; Zhao 2005). Da Signalmoleküle gewöhnlich eine sehr geringe Lebens- bzw. Wirkdauer haben, kann eine Störung der Signalkaskade große Auswirkungen nach sich ziehen. Die cochleären Stütz- und Sinneszellen haben keine direkte Verbindung zu Blutgefäßen. Ihre Nährstoffversorgung und der Abtransport von Metaboliten sind nur interzellulär über gap junctions möglich. Da Cx26-Kanäle im Gegensatz zu denen anderer Connexine permeabel für Anionen sind, scheinen sie maßgeblich an der interzelluäre Signalverarbeitung und Nährstoffversorgung beteiligt $\mathrm{zu}$ sein. Eine Mutation könnte darüber eine gravierende Schädigung der Zellen bis hin zum Zelltod hervorrufen (Zhao 2005). Neben der biochemischen und elektrischen Entkopplung cochleärer Zellen sind sekundäre Effekte möglich.

Eine Abnahme des EPs wird auch bei Furosemid-induziertem Hörverlust beschrieben (Ikeda und Morizono 1989). Furosemid hemmt den Na-K-ClCotransporter. Teilweise wird das EP durch das $\mathrm{Na}^{+}$-Diffusionspotenzial über der 
basolateralen Membran der Marginalzellen gebildet. Die Reduktion des EPs wird offenbar über einen Anstieg der intrazellulären $\left[\mathrm{Ca}^{2+}\right]$ in den Marginalzellen der Stria vascularis vermittelt (Mori et al. 2009). Vier potenzielle Mechanismen werden diskutiert: Furosemid könnte direkt intrazelluläre $\mathrm{Ca}^{2+}$-Pumpen inhibieren oder membranständige $\mathrm{Ca}^{2+}$-Kanäle aktivieren. Die intrazelluläre $\left[\mathrm{Cl}^{-}\right]$könnte durch eine Hemmung des Na-K-Cl-Cotransporters (NKCC1) in der basolateralen Membran gesenkt werden, was in einer Freisetzung von $\mathrm{Ca}^{2+}$ aus intrazellulären Speichern resultierte. Es könnte die Produktion von ATP inhibieren, was wiederum zu einer Hemmung der endoplasmatischen $\mathrm{Ca}^{2+}$-Pumpen führen würde. Bei Presbyakusis und Medikamenten-induziertem Hörverlust wird der Verlust des EPs als Ursache kontrovers diskutiert. Nur in einigen der entsprechenden Mausmodelle wurde eine Reduktion des Potenzials gefunden (Ohlemiller et al. 2006). Ein erhaltenes EP, trotz drastisch reduzierter Expression mehrerer IonenTransporter der Stria vascularis (Yang et al. 2013), liegt vermutlich im speziellen Verhältnis der Transporter zueinander begründet (potenzielle Kandidaten sind im Speziellen der NKCC1 und die $\alpha_{2}-\mathrm{Na}-\mathrm{K}-\mathrm{ATPase}$ ) (Diaz et al. 2007; Xiong et al. 2011). Der Presbyakusis und dem Medikamenten-induzierten Hörverlust ist außerdem gemeinsam, dass sie im Gegensatz zur Cx26S17F-bedingten Schwerhörigkeit mit einem progredienten Rückgang der Stria vascularis einhergehen.

Eine direkte Auswirkung der Mutation Cx26S17F auf den $\mathrm{Na}^{+}$- und $\mathrm{Ca}^{2+}$-Haushalt der Marginalzellen, dem fein aufeinander abgestimmten Verhältnis ihrer IonenTransporter, der Stria vascularis insgesamt und der Endolymphe erscheint unwahrscheinlich. Ein indirekter sekundärer Einfluss kann hingegen nicht ausgeschlossen werden.

\subsubsection{Kann die Dysfunktion von Cx26S17F teilkompensiert werden?}

Cx26 und -30 sind neben anderen die vorherrschenden Connexine in der Cochlea. Connexone variieren abhängig von ihrer Zusammensetzung (homomer: aus sechs gleichen, heteromer: aus unterschiedlichen Connexinen aufgebaut) in ihren Eigenschaften. Einer Hypothese nach ist die Bildung heteromerer Cx26/Cx30-Kanäle auf die besonderen Bedürfnisse spezialisierter Gewebe angepasst und essenziell für die Aufrechterhaltung von Homöostase und interzellulären Signalkaskaden im Innenohr (Yum et al. 2007; Sun et al. 2009). Die heteromere Anordnung beider in der Cochlea scheint einzigartig zu sein. Dies könnte erklären, warum $\mathrm{Cx}-$ 
Mutationen hauptsächlich nichtsyndromale Schwerhörigkeiten induzieren (Sun et al. 2009). Homomere gap junctions, aufgebaut aus Cx26 oder -30, weisen eine hohe Permeabilität für $\mathrm{K}^{+}$-Ionen auf und zeigen vor allem für größere Moleküle abweichende Permeabilitäten. Die immense Auswirkung des Fehlens oder der Dysfunktion eines der beiden Connexine spricht daher für eine heteromere Anordnung. Eine Kompensation durch das jeweils andere noch vorhandene Connexin würde einen milden Phänotyp erwarten lassen.

$\mathrm{Ob}$ eine Kompensation durch andere in der Cochlea vorhandene Connexine erfolgt, ist unklar. In Cx30-defizienten Mäusen konnte keine Mehrexpression von Cx26 ermittelt werden (Teubner et al. 2003). Immunfluoreszenzanalysen zeigen keine Auffälligkeiten in Expression und Lokalisation von Cx26 und Cx30 in $\mathrm{Cx} 26^{+/ \mathrm{S} 17 \mathrm{~F}}$-Cochleae und deuten auf eine Co-Lokalisation beider Proteine hin (Schütz 2011). Auch dies macht das Vorhandensein heteromerer Kanäle wahrscheinlich (Ahmad et al. 2001; Forge et al. 2003). Immunblots decken allerdings eine reduzierte Expression auf (Schütz 2011). Aufgrund dieser und vorheriger Ergebnisse (Richard et al. 2002; Lee et al. 2009) wird angenommen, dass das mutierte Protein zwar in der Zellmembran gefunden wird, dort aber keine Funktionalität aufweist. Es liegt nahe, dass neben funktionellen Cx26/Cx30Kanälen insuffiziente Cx26S17F/Cx30- oder Cx26S17F/Cx26-Kanäle gebildet werden. Ob die Expression von Cx26S17F dabei die der anderen Kanäle im Sinne eines trans-dominanten Effekts beeinflusst, bleibt ungeklärt. Da unter der Expression der Mutation S17F in vitro keine funktionellen gap junction-Kanäle gebildet werden, könnte der Phänotyp durch eine sekundäre Inhibition des Wildtyp-Cx im Sinne eines dominant-negativen Effekts mitbedingt sein. Auch die Interaktion der Kanäle mit anderen Proteinen könnte durch die Mutation gestört sein. Es ist unwahrscheinlich, dass die Mutation lediglich eine verringerte Cx26-Expression hervorbringt. Auch diese würde die Funktion der Cochlea zwar einschränken, vermutlich aber einen schwächeren Phänotyp nach sich ziehen (vergleiche Cx30T5M-Mutation in (Schütz et al. 2010)).

\subsubsection{Wie wirkt sich der genetische Maushintergrund aus?}

Der Hörphänotyp ist in Cx26/S17F-Tieren mit 129/Sv-Hintergrund stärker ausgeprägt als in Tieren mit C57B1/6-Hintergrund. Die Hautanomalien hingegen treten im C57Bl/6-Hintergrund deutlicher hervor. Unterschiede in der Ausprägung 
phänotypischer Merkmale zwischen genetisch verschiedenen Mausinzuchtstämmen sind bekannt (Champy et al. 2008). Grundlegende biochemische, hämatologische und metabolische Differenzen wurden bereits beschrieben und charakterisiert. Sie entstehen maßgeblich durch den Einfluss von ModifikatorGenen. Dabei handelt es sich um Gene bzw. Genloci, die unabhängig vom gewünschten mutierten Gen im Genpool vorliegen. Die Genloci beeinflussen phänotypische Variationen in quantitativer, nicht aber qualitativer Weise. Dies geschieht wahrscheinlich durch das Zusammenspiel mehrerer dieser Gene, wobei jedes einzelne einen geringen Effekt haben dürfte. Zwischen den verschiedenen Mausinzuchtstämmen kommen sie in unterschiedlicher Verteilung vor. Neben Modifikator-Genen haben umwelt- und entwicklungsbedingte Faktoren einen Einfluss (Montagutelli 2000; Johnson et al. 2006).

\subsubsection{Abschließende Beurteilung}

Der Hörphänotyp der $\mathrm{Cx} 26^{+/ \mathrm{S} 17 \mathrm{~F}}$-Mäuse äußerte sich in einer hochgradigen Schwerhörigkeit und einem korrelierend reduzierten EP. Neben der Reduktion der in die Haarzellen gerichteten treibenden Kraft für $\mathrm{K}^{+}$-Ionen kann die erhöhte $\left[\mathrm{K}^{+}\right]$ in der Corti-Lymphe eine Dysfunktion der Haarzellen hervorrufen. Dies bietet eine plausible Erklärung für das Fehlen von DPOAE in einigen der untersuchten Tiere. Eine andere Erklärung hierfür bietet der alters- oder lärmbedingte Verlust der ÄHZ-Funktion. Eine Störung der intracochleären Homöostase anderer Ionen sowie der Nährstoffversorgung von Haar- und Stützzellen ist naheliegend. Weitere sekundäre Effekte können nicht ausgeschlossen werden, scheinen aber gering zu sein, da sich keine morphologischen Pathologien finden. 


\section{Zusammenfassung}

In dieser Arbeit wurde die Hörfunktion zweier Mausmutanten charakterisiert, in denen der präsynaptische $\mathrm{Ca}^{2+}$-Einstrom $\left(\mathrm{Cav}_{v} \beta_{2}\right)$ in innere Haarzellen bzw. der cochleäre Kaliumkreislauf (Cx26) durch gezielte Mutagenese gestört wurde. Es wurden systemphysiologische Methoden etabliert und angewandt, die Einblicke in die Rolle der $\mathrm{Ca}^{2+}$-Kanaluntereinheit $\mathrm{Cav} \beta_{2}$ in der Schallkodierung ermöglichen. $\mathrm{Cav}_{v} \beta_{2}$ ist dabei, vermutlich durch die positive Regulation der Zahl synaptischer $\mathrm{Ca}^{2+}$-Kanäle, essenziell für synaptische Transmission an der Haarzellsynapse und hat darüber hinaus eine wichtige Rolle in den äußeren Haarzellen, die jedoch nicht weiter untersucht wurde. Messungen der frühen akustisch evozierten Potenziale zeigten eine profunde Schwerhörigkeit der $\operatorname{Cav} \beta_{2}{ }^{-/-}$-Tiere. Distorsionsprodukte otoakustischer Emissionen fehlten weitgehend. Extrazelluläre MikroelektrodenAbleitungen von einzelnen Hörnervenfasern wiesen verringerte Aktivitäten auf, die nur durch hohe Reizpegel evoziert werden konnten. So resultierte hier eine Reduktion der Zahl präsynaptischer $\mathrm{Ca}^{2+}$-Kanäle an der inneren Haarzellsynapse in einer deutlich eingeschränkten Aktionspotenzialrate der Postsynapse. Spontanaktivitätsraten, dynamische Bereiche und Schwellen zeigten eine geringere Streuung. Eine Degeneration der Spiralganglionneurone war immunhistochemisch nicht nachweisbar. Maßgeblich für diese Veränderungen scheint die Anzahl der Cav1.3 und das damit verbundene Ausmaß des $\mathrm{Ca}^{2+}$-Einstroms in die Haarzellen zu sein. Grundsätzlich ist zudem eine marginale Wirkung pathologisch vorhandener Efferenzen denkbar. Eine Auswirkung der Messbedingungen auf die Messergebnisse in Form einer Anhebung der Schwelle durch ein akutes akustisches Trauma erscheint aufgrund der reduzierten Exozytosefähigkeit der inneren Haarzellen unwahrscheinlich.

Die Untersuchung der Auswirkung der, das humane KIT-Syndrom bedingenden, Punktmutation S17F im GJB2-Gen auf die Funktion der Cochlea wies auf die Senkung des endocochleären Potenzials als wichtigen Pathomechanismus Connexin26-bedingter Schwerhörigkeiten hin. Verminderte endocochleäre Potenziale korrelierten mit erhöhten Hörschwellen der frühen akustisch evozierten Potenziale. Die negative Korrelation beider Befunde legt einen kausalen Zusammenhang nahe. Die interzellulären Transportwege innerhalb der Cochlea scheinen durch die Mutation gestört. Dies bewirkt wahrscheinlich eine Reduktion 
der in die Haarzellen gerichteten treibenden Kraft für $\mathrm{K}^{+}$-Ionen, eine Reduktion der $\left[\mathrm{K}^{+}\right]$in der Endolymphe und eine Erhöhung der $\left[\mathrm{K}^{+}\right]$in der Corti-Lymphe. Diese Veränderungen können die Dysfunktion der inneren und äußeren Haarzellen erklären. 


\section{Anhang}

\subsection{Klassifikation von auditorischen Neuronentypen}

Abbildung 6.1-1 zeigt PST von unterschiedlichen auditorischen Neuronen. Anhand ihrer charakteristischen Entladungsmuster können sie klassifiziert werden. $\mathrm{Cav} \mathrm{B}_{2}{ }^{+/+}$-Neurone sind in schwarz, $\mathrm{Cav} \mathrm{B}_{2}{ }^{-1}$-Neurone in hellgrau bzw. rot (Chopper; für die leichtere Unterscheidung) dargestellt.
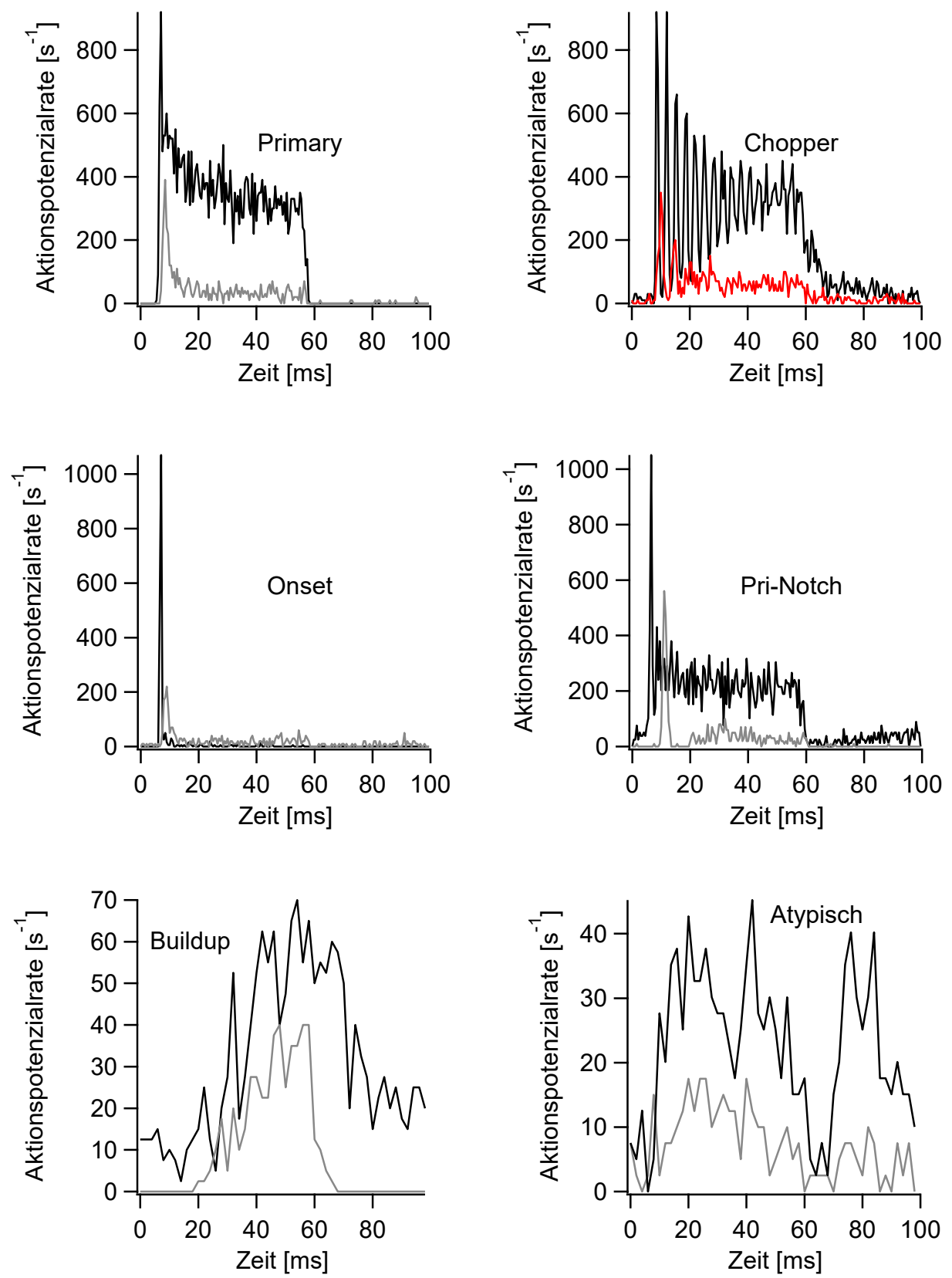

Abbildung 6.1-1 Klassifikation auditorischer Neurone

Beispiele charakteristischer PST von $\mathrm{Cav}_{v} \beta_{2}^{+/+}$- und $\mathrm{Cav} \beta_{2}{ }^{-/-}$-Mäusen. 
Die gewählten $\mathrm{Cav}_{v} \mathrm{\beta}_{2}{ }^{+/+}$-Beispiele sind repräsentativ. Um einen Vergleich zu ermöglichen, wurden von den $\operatorname{Cav} \beta_{2}^{-/-}$-PST möglichst ähnliche Beispiele ausgewählt. Abbildung 6.1-2 bietet eine Übersicht, in welcher Tiefe die unterschiedliche auditorische Nervenfasern gefunden wurden. Aufgrund der geringen AP-Raten war die Klassifizierung der Neuronentypen, besonders aus dem Nucleus cochlearis, in $\mathrm{Cav}_{2} \beta_{2}^{-/-}$-Daten erschwert. Hinzu kommt, dass der typische Gipfel zu Beginn der Antwort (onset) häufig fehlte. Markante Charakteristika wie Einkerbungen oder das Choppen sind unzureichend deutlich ausgeprägt. Daher kamen die von Godfrey (Godfrey et al. 1975a; Godfrey et al. 1975b) und Taberner und Liberman (Taberner und Liberman 2005) beschriebenen Definitionen in leicht modifizierter Weise zur Anwendung (Tabelle 6.1-1 Charakteristika von auditorischen Neuronen).

\section{Neuronentyp Charakteristika}

Chopper Anfangsgipfel, irreguläre Adaptation an die Plateau-Antwort mit mehreren Spitzen in ähnlichem zeitlichem Abstand voneinander. Die meisten anderen $\mathrm{Cav}_{v} \beta_{2}{ }^{-/}$-Beispiele zeigten weniger deutlich ausgeprägte Entladungsmuster.

Primary Anfangsgipfel, exponentielle Adaptation an die Plateau-Rate. Wie von Taberner und Liberman 2005 diskutiert, wird angenommen, dass die meisten Fasern, wenn sie im Bereich des Hörnerven lokalisiert sind (d. h. eher tief im posteroventralen Nucleus cochlear als im anteroventralen Nucleus cochlear) SGN darstellen. Neurone mit entsprechendem Entladungsmuster, die in einer Elektrodentiefe von $>1000 \mu \mathrm{m}$ gefunden wurden, wurden als SGN klassifiziert. Der Einschluss von Antworten einiger Nukleus cochlearis-Neurone kann nicht völlig ausgeschlossen werden.

Onset Anfangsgipfel gefolgt von einem scharfen Abfall der AP-Rate und einer Adaptation an ein sehr geringes Plateau-Niveau. Die Maximalraten der $\mathrm{Cav} \beta_{2}{ }^{-/-}$-SGN bleiben unter denen der $\mathrm{Cav} \beta_{2}{ }^{+/+}$SGN und beginnen mit verlängerter Latenz. Die Raten des Plateaus weisen eine geringere Diskrepanz auf.

Pri-Notch Anfangsgipfel mit anschließendem Abfall der AP-Rate und darauffolgender exponentieller Adaptation (ähnlich den PrimaryLike-Fasern).

Buildup Anfangsgipfel fehlt, die AP-Rate steigert sich bis zum Ende des Stimulus

Tabelle 6.1-1 Charakteristika von auditorischen Neuronen 
Es wurden, vorwiegend im Nucleus cochlearis, viele Fasern gefunden, die keine der oben genannten Kriterien erfüllen und damit keiner der Kategorien zugeordnet werden konnten. Dies liegt hauptsächlich daran, dass der Anfangsgipfel fehlt. Diese Fasern wurden als atypisch bezeichnet und fanden keine weitere Berücksichtigung.
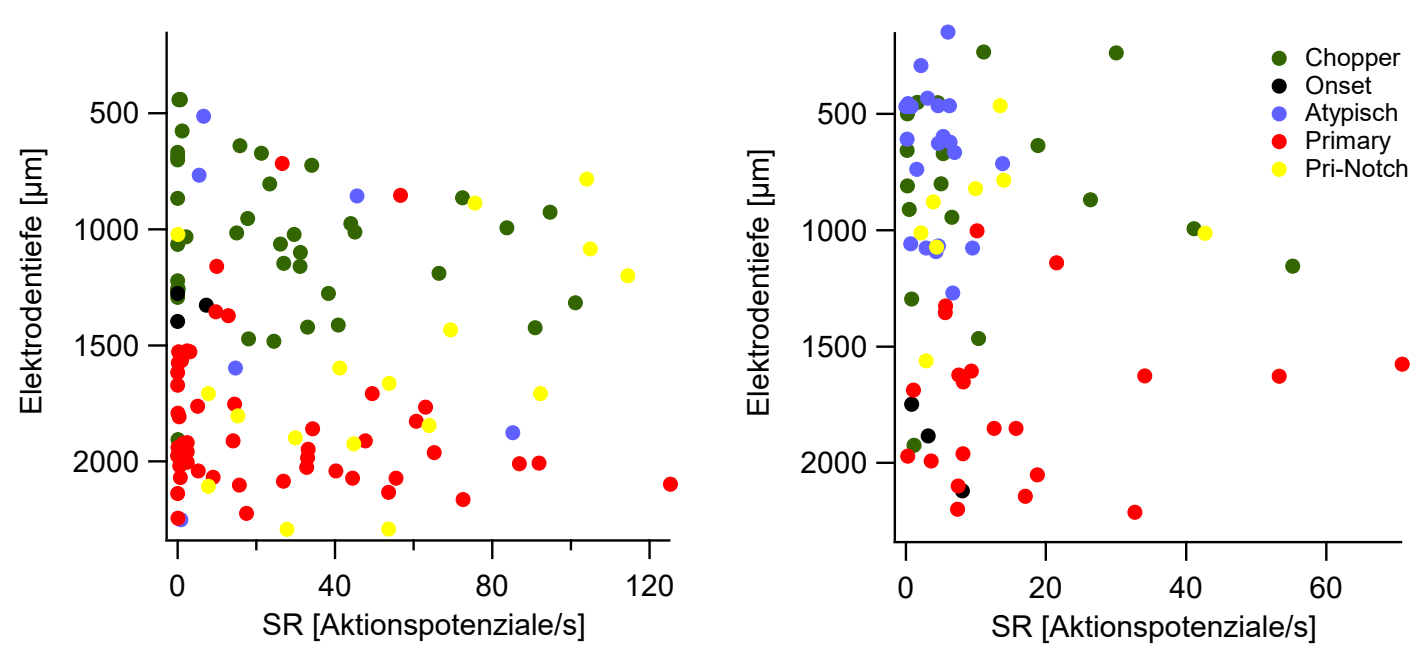

Abbildung 6.1-2 Spontanaktivitätsraten in Abhängigkeit von der Elektrodentiefe

Verteilung von Spontanaktivitätsraten und entsprechender Elektrodenposition bei Messung. Die Tiefe der Elektrode wird ab etwa $200 \mu \mathrm{m}$ oberhalb der Nucleus cochlearis-Oberfläche gemessen. Unterschiedliche Neuronentypen sind farblich gekennzeichnet. $\mathrm{Cav} \beta_{2}{ }^{+/ /}$links, $\mathrm{Cav} \beta_{2}{ }^{-/ /}$rechts. 


\section{Literaturverzeichnis}

Ahmad S, Martin PE, Evans WH (2001): Assembly of gap junction channels: mechanism, effects of calmodulin antagonists and identification of connexin oligomerization determinants. Eur J Biochem 268, 4544-4552

Altier C, Garcia-Caballero A, Simms B, You H, Chen L, Walcher J, Tedford HW, Hermosilla T, Zamponi GW (2011): The Cav $\beta$ subunit prevents RFP2-mediated ubiquitination and proteasomal degradation of L-type channels. Nat Neurosci $\underline{14}$, $173-180$

Alvarez-Leefmans FJ, Delpire E (Hrsg.): Physiology and pathology of chloride transporters and channels in the nervous system: from molecules to diseases. Academic Press, San Diego 2009

Atkinson PJ, Wise AK, Flynn BO, Nayagam BA, Hume CR, O’Leary SJ, Shepherd RK, Richardson RT (2012): Neurotrophin gene therapy for sustained neural preservation after deafness. PLoS ONE $\underline{7}$, e52338

Ball SL, Powers PA, Shin HS, Morgans CW, Peachey NS, Gregg RG (2002): Role of the beta(2) subunit of voltage-dependent calcium channels in the retinal outer plexiform layer. Invest Ophthalmol Vis Sci $\underline{43}, 1595-1603$

Béguin P, Nagashima K, Gonoi T, Shibasaki T, Takahashi K, Kashima Y, Ozaki N, Geering K, Iwanaga T, Seino S (2001): Regulation of Ca2+ channel expression at the cell surface by the small G-protein kir/Gem. Nature $\underline{411}, 701-706$

Beltramello M, Piazza V, Bukauskas FF, Pozzan T, Mammano F (2005): Impaired permeability to Ins $(1,4,5) \mathrm{P} 3$ in a mutant connexin underlies recessive hereditary deafness. Nat Cell Biol $\underline{7}, 63-69$

Berglund AM, Ryugo DK (1987): Hair cell innervation by spiral ganglion neurons in the mouse. J Comp Neurol 255, 560-570

Bess FH, Dodd-Murphy J, Parker RA (1998): Children with minimal sensorineural hearing loss: prevalence, educational performance, and functional status. Ear Hear 19, 339354

Beurg M, Sukhareva M, Ahern CA, Conklin MW, Perez-Reyes E, Powers PA, Gregg RG, Coronado R (1999): Differential regulation of skeletal muscle L-type Ca2+ current and excitation-contraction coupling by the dihydropyridine receptor beta subunit. Biophys J $\underline{76}, 1744-1756$

Beurg M, Fettiplace R, Nam JH, Ricci AJ (2009): Localization of inner hair cell mechanotransducer channels using high-speed calcium imaging. Nat Neurosci $\underline{12}$, $553-558$

Beutner D, Moser T (2001): The presynaptic function of mouse cochlear inner hair cells during development of hearing. J Neurosci 21, 4593-4599 
Biacabe B, Chevallier JM, Avan P, Bonfils P (2001): Functional anatomy of auditory brainstem nuclei: application to the anatomical basis of brainstem auditory evoked potentials. Auris Nasus Larynx $\underline{28}, 85-94$

Bichet D, Cornet V, Geib S, Carlier E, Volsen S, Hoshi T, Mori Y, de Waard M (2000): The I-II loop of the Ca2+ channel alpha1 subunit contains an endoplasmic reticulum retention signal antagonized by the beta subunit. Neuron $\underline{25}, 177-190$

Birkenhäger R, Aschendorff A, Schipper J, Laszig R (2007): Nicht-syndromale hereditäre Schwerhörigkeiten. Laryngorhinootologie $\underline{86}, 299-313$

Bosher SK (1979): The nature of the negative endocochlear potentials produced by anoxia and ethacrynic acid in the rat and guinea-pig. J Physiol 293, 329-345

Brandt A, Striessnig J, Moser T (2003): CaV1.3 channels are essential for development and presynaptic activity of cochlear inner hair cells. J Neurosci $\underline{23}, 10832-10840$

Brandt A, Khimich D, Moser T (2005): Few CaV1.3 channels regulate the exocytosis of a synaptic vesicle at the hair cell ribbon synapse. J Neurosci $25,11577-11585$

Brice NL, Berrow NS, Campbell V, Page KM, Brickley K, Tedder I, Dolphin AC (1997): Importance of the different beta subunits in the membrane expression of the alpha1A and alpha2 calcium channel subunits: studies using a depolarizationsensitive alpha1 A antibody. Eur J Neurosci $\underline{9}$, 749-759

Brownell WE, Bader CR, Bertrand D, de Ribaupierre Y (1985): Evoked mechanical responses of isolated cochlear outer hair cells. Science 227, 194-196

Burgess DL, Biddlecome GH, McDonough SI, Diaz ME, Zilinski CA, Bean BP, Campbell KP, Noebels JL (1999): Beta subunit reshuffling modifies N- and P/Q-type Ca2+ channel subunit compositions in lethargic mouse brain. Mol Cell Neurosci 13, 293311

Cantí C, Bogdanov Y, Dolphin AC (2000): Interaction between G proteins and accessory subunits in the regulation of $1 \mathrm{~B}$ calcium channels in Xenopus oocytes. J Physiol (Lond) $\underline{527}$, 419-432

Champy MF, Selloum M, Zeitler V, Caradec C, Jung B, Rousseau S, Pouilly L, Sorg T, Auwerx J (2008): Genetic background determines metabolic phenotypes in the mouse. Mamm Genome 19, 318-331

Chapochnikov NM, Takago H, Huang CH, Pangršič T, Khimich D, Neef J, Auge E, Göttfert F, Hell SW, Wichmann C et al. (2014): Uniquantal release through a dynamic fusion pore is a candidate mechanism of hair cell exocytosis. Neuron $\underline{83}$, 1389-1403

Chen WC, Xue HZ, Hsu YL, Liu Q, Patel S, Davis RL (2011): Complex distribution patterns of voltage-gated calcium channel $\alpha$-subunits in the spiral ganglion. Hear Res $\underline{278}, 52-68$

Chen Z, Kujawa SG, Sewell WF (2010): Functional roles of high-affinity glutamate transporters in cochlear afferent synaptic transmission in the mouse. J Neurophysiol $\underline{103}, 2581-2586$ 
Chien AJ, Zhao X, Shirokov RE, Puri TS, Chang CF, Sun D, Rios E, Hosey MM (1995): Roles of a membrane-localized beta subunit in the formation and targeting of functional L-type Ca2+ channels. J Biol Chem 270, 30036-30044

Chien AJ, Carr KM, Shirokov RE, Rios E, Hosey MM (1996): Identification of palmitoylation sites within the L-type calcium channel beta2a subunit and effects on channel function. J Biol Chem 271, 26465-26468

Chien AJ, Gao T, Perez-Reyes E, Hosey MM (1998): Membrane targeting of L-type calcium channels. Role of palmitoylation in the subcellular localization of the beta2a subunit. J Biol Chem $\underline{273}$, 23590-23597

Cohen-Salmon M, Ott T, Michel V, Hardelin JP, Perfettini I, Eybalin M, Wu T, Marcus DC, Wangemann P, Willecke K, Petit C (2002): Targeted ablation of connexin26 in the inner ear epithelial gap junction network causes hearing impairment and cell death. Curr Biol 12, 1106-1111

Colecraft HM, Alseikhan B, Takahashi SX, Chaudhuri D, Mittman S, Yegnasubramanian V, Alvania RS, Johns DC, Marbán E, Yue DT (2002): Novel functional properties of $\mathrm{Ca}(2+)$ channel beta subunits revealed by their expression in adult rat heart cells. J Physiol (Lond) $\underline{541}, 435-452$

Cui G, Meyer AC, Calin-Jageman I, Neef J, Haeseleer F, Moser T, Lee A (2007): Ca2+binding proteins tune $\mathrm{Ca} 2+$-feedback to Cav1.3 channels in mouse auditory hair cells. J Physiol (Lond) $\underline{585}$, 791-803

Davis H (1953): Acoustic trauma in the guinea pig. J Acoust Soc Am 25, 1180-1189

De Waard M, Campbell KP (1995): Subunit regulation of the neuronal alpha 1A Ca2+ channel expressed in Xenopus oocytes. J Physiol (Lond) 485 ( Pt 3), 619-634

Delpire E, Lu J, England R, Dull C, Thorne T (1999): Deafness and imbalance associated with inactivation of the secretory Na-K-2Cl co-transporter. Nat Genet $\underline{22}, 192-195$

Delprat B, Irving S. http://www.cochlea.eu/en/cochlea/cochlear-fluids; abgerufen am 20.03.2017

Diaz RC, Vazquez AE, Dou H, Wei D, Cardell EL, Lingrel J, Shull GE, Doyle KJ, Yamoah EN (2007): Conservation of hearing by simultaneous mutation of $\mathrm{Na}, \mathrm{K}-$ ATPase and NKCC1. J Assoc Res Otolaryngol $\underline{8}$, 422-434

Dolphin AC (2003): Beta subunits of voltage-gated calcium channels. J Bioenerg Biomembr 35, 599-620

Dou H, Vazquez AE, Namkung Y, Chu H, Cardell EL, Nie L, Parson S, Shin HS, Yamoah EN (2004): Null mutation of alpha1D Ca2+ channel gene results in deafness but no vestibular defect in mice. J Assoc Res Otolaryngol ㅁ, 215-226

Ertel EA, Campbell KP, Harpold MM, Hofmann F, Mori Y, Perez-Reyes E, Schwartz A, Snutch TP, Tanabe T, Birnbaumer L et al. (2000): Nomenclature of voltage-gated calcium channels. Neuron $\underline{25}, 533-535$ 
Fettiplace R, Hackney CM (2006): The sensory and motor roles of auditory hair cells. Nat Rev Neurosci 7, 19-29

Findeisen F, Minor DL Jr (2009): Disruption of the IS6-AID linker affects voltage-gated calcium channel inactivation and facilitation. J Gen Physiol 133, 327-343

Forge A, Becker D, Casalotti S, Edwards J, Marziano N, Nevill G (2003): Gap junctions in the inner ear: comparison of distribution patterns in different vertebrates and assessement of connexin composition in mammals. J Comp Neurol 467, 207-231

Frank T, Khimich D, Neef A, Moser T (2009): Mechanisms contributing to synaptic Ca2+ signals and their heterogeneity in hair cells. Proceedings of the National Academy of Sciences 106, 4483-4488

Froud KE, Wong ACY, Cederholm JME, Klugmann M, Sandow SL, Julien JP, Ryan AF, Housley GD (2015): Type II spiral ganglion afferent neurons drive medial olivocochlear reflex suppression of the cochlear amplifier. Nat Commun $\underline{6}, 7115$

Fukui H, Raphael Y (2013): Gene therapy for the inner ear. Hear Res 297, 99-105

Furness DN, Lawton DM (2003): Comparative distribution of glutamate transporters and receptors in relation to afferent innervation density in the mammalian cochlea. $\mathrm{J}$ Neurosci 23, 11296-11304

Furman AC, Kujawa SG, Liberman MC (2013): Noise-induced cochlear neuropathy is selective for fibers with low spontaneous rates. J Neurophysiol 110, 577-586

von Gablenz P, Holube I (2015): Prävalenz von Schwerhörigkeit im Nordwesten Deutschlands. Ergebnisse einer epidemiologischen Untersuchung zum Hörstatus (HÖRSTAT). HNO $\underline{63}, 195-214$

Gabriel HD, Jung D, Bützler C, Temme A, Traub O, Winterhager E, Willecke K (1998): Transplacental uptake of glucose is decreased in embryonic lethal connexin26deficient mice. J Cell Biol 140, 1453-1461

Gao T, Chien AJ, Hosey MM (1999): Complexes of the alpha1C and beta subunits generate the necessary signal for membrane targeting of class C L-type calcium channels. J Biol Chem 274, 2137-2144

Gerido DA, White TW (2004): Connexin disorders of the ear, skin, and lens. Biochim Biophys Acta 1662, 159-170

Gillespie LN, Shepherd RK (2005): Clinical application of neurotrophic factors: the potential for primary auditory neuron protection. Eur J Neurosci 22, 2123-2133

Gilliam A, Williams ML (2002): Fatal septicemia in an infant with keratitis, ichthyosis, and deafness (KID) syndrome. Pediatr Dermatol 19, 232-236

Glowatzki E, Fuchs PA (2002): Transmitter release at the hair cell ribbon synapse. Nat Neurosci $\underline{5}, 147-154$ 
Glueckert R, Wietzorrek G, Kammen-Jolly K, Scholtz A, Stephan K, Striessnig J, SchrottFischer A (2003): Role of class D L-type Ca2+ channels for cochlear morphology. Hear Res $\underline{178}, 95-105$

Godfrey DA, Kiang NY, Norris BE (1975a): Single unit activity in the dorsal cochlear nucleus of the cat. J Comp Neurol 162, 269-284

Godfrey DA, Kiang NY, Norris BE (1975b): Single unit activity in the posteroventral cochlear nucleus of the cat. J Comp Neurol 162, 247-268

Gonzalez-Gutierrez G, Miranda-Laferte E, Neely A, Hidalgo P (2007): The Src homology 3 domain of the beta-subunit of voltage-gated calcium channels promotes endocytosis via dynamin interaction. J Biol Chem $\underline{282}$, 2156-2162

Goodenough DA (1976): In vitro formation of gap junction vesicles. J Cell Biol $\underline{68}, 220$ 231

Goodenough DA, Paul DL (2009): Gap junctions. Cold Spring Harb Perspect Biol 1 , a002576

Goutman JD, Glowatzki E (2007): Time course and calcium dependence of transmitter release at a single ribbon synapse. Proc Natl Acad Sci USA 104, 16341-16346

Goutman JD, Elgoyhen AB, Gómez-Casati ME (2015): Cochlear hair cells: The soundsensing machines. FEBS Lett $\underline{589}$, 3354-3361

Grant L, Fuchs P (2008): Calcium- and calmodulin-dependent inactivation of calcium channels in inner hair cells of the rat cochlea. J Neurophysiol 99, 2183-2193

Grant L, Yi E, Glowatzki E (2010): Two modes of release shape the postsynaptic response at the inner hair cell ribbon synapse. J Neurosci 30, 4210-4220

Graydon CW, Cho S, Li GL, Kachar B, von Gersdorff H (2011): Sharp $\mathrm{Ca}^{2+}$ nanodomains beneath the ribbon promote highly synchronous multivesicular release at hair cell synapses. J Neurosci $\underline{31}$, 16637-16650

Green LM, LaBue M, Lazarus JP, Jennings JC (1996): Reduced cell-cell communication in experimentally induced autoimmune thyroid disease. Endocrinology 137, 28232832

Gregg RG, Messing A, Strube C, Beurg M, Moss R, Behan M, Sukhareva M, Haynes S, Powell JA, Coronado R, Powers PA (1996): Absence of the beta subunit (cchb1) of the skeletal muscle dihydropyridine receptor alters expression of the alpha 1 subunit and eliminates excitation-contraction coupling. Proc Natl Acad Sci USA $\underline{93}, 13961-13966$

Gregory FD, Pangrsic T, Calin-Jageman IE, Moser T, Lee A (2013): Harmonin enhances voltage-dependent facilitation of Cav1.3 channels and synchronous exocytosis in mouse inner hair cells. J Physiol (Lond) 591, 3253-3269

Gross M, Finckh-Krämer U, Spormann-Lagodzinski M (2000): Angeborene Erkrankungen des Hörvermögens bei Kindern Teil 1: Erworbene Hörstörungen. HNO $\underline{48}$, 879886 
Gurgel RK, Jackler RK, Dobie RA, Popelka GR (2012): A new standardized format for reporting hearing outcome in clinical trials. Otolaryngol Head Neck Surg 147, 803807

Hanlon MR, Berrow NS, Dolphin AC, Wallace BA (1999): Modelling of a voltagedependent $\mathrm{Ca} 2+$ channel beta subunit as a basis for understanding its functional properties. FEBS Lett $\underline{445}, 366-370$

Hardie NA, Shepherd RK (1999): Sensorineural hearing loss during development: morphological and physiological response of the cochlea and auditory brainstem. Hear Res $\underline{128}, 147-165$

Harris AL (2007): Connexin channel permeability to cytoplasmic molecules. Prog Biophys Mol Biol 94, 120-143

Harris DM, Dallos P (1979): Forward masking of auditory nerve fiber responses. J Neurophysiol $\underline{42}, 1083-1107$

He LL, Zhang Y, Chen YH, Yamada Y, Yang J (2007): Functional modularity of the betasubunit of voltage-gated Ca2+ channels. Biophys J $\underline{93}, 834-845$

Heger D, Holube I. (2010): Wie viele Menschen sind schwerhörig? Zeitschrift für Audiologie (Audiological Acoustics). 49. 61-70

Hequembourg S, Liberman MC (2001): Spiral ligament pathology: a major aspect of agerelated cochlear degeneration in C57BL/6 mice. J Assoc Res Otolaryngol 2, 118 129

Herzig S, Khan IFY, Gründemann D, Matthes J, Ludwig A, Michels G, Hoppe UC, Chaudhuri D, Schwartz A, Yue DT, Hullin R (2007): Mechanism of Ca(v)1.2 channel modulation by the amino terminus of cardiac beta2-subunits. FASEB J $\underline{21}$, $1527-1538$

Hirose K, Liberman MC (2003): Lateral wall histopathology and endocochlear potential in the noise-damaged mouse cochlea. J Assoc Res Otolaryngol 4, 339-352

Hofmann F, Lacinová L, Klugbauer N (1999): Voltage-dependent calcium channels: from structure to function. Rev Physiol Biochem Pharmacol 139, 33-87

Hullin R, Khan IFY, Wirtz S, Mohacsi P, Varadi G, Schwartz A, Herzig S (2003): Cardiac L-type calcium channel beta-subunits expressed in human heart have differential effects on single channel characteristics. J Biol Chem 278, 21623-21630

Ikeda K, Morizono T (1989): Effect of albumin-bound furosemide on the endocochlear potential of the chinchilla. Alleviation of furosemide-induced ototoxicity. Arch Otolaryngol Head Neck Surg 115, 500-502

Issa NP, Hudspeth AJ (1994): Clustering of $\mathrm{Ca} 2+$ channels and $\mathrm{Ca}(2+)$-activated $\mathrm{K}+$ channels at fluorescently labeled presynaptic active zones of hair cells. Proc Natl Acad Sci USA $\underline{91}, 7578-7582$

Jagger DJ, Forge A (2015): Connexins and gap junctions in the inner ear--it's not just about $\mathrm{K}^{+}$recycling. Cell Tissue Res $\underline{360}$, 633-644 
Jewett DL, Williston JS (1971): Auditory-evoked far fields averaged from scalp of humans. Brain $\underline{94}$, 681-696

Jing Z, Rutherford MA, Takago H, Frank T, Fejtova A, Khimich D, Moser T, Strenzke N (2013): Disruption of the presynaptic cytomatrix protein bassoon degrades ribbon anchorage, multiquantal release, and sound encoding at the hair cell afferent synapse. J Neurosci $\underline{33}$, 4456-4467

Johnson KR, Zheng QY, Noben-Trauth K (2006): Strain background effects and genetic modifiers of hearing in mice. Brain Res 1091, 79-88

Joiner MA, Lee A (2015): Voltage-gated CaV1 channels in disorders of vision and hearing. Curr Mol Pharmacol $\underline{8}, 143-148$

Jones LP, Wei SK, Yue DT (1998): Mechanism of auxiliary subunit modulation of neuronal alpha1E calcium channels. J Gen Physiol 112, 125-143

Josephson IR, Varadi G (1996): The beta subunit increases Ca2+ currents and gating charge movements of human cardiac L-type Ca2+ channels. Biophys J $\underline{70}, 1285-$ 1293

Jung S, Maritzen T, Wichmann C, Jing Z, Neef A, Revelo NH, Al-Moyed H, Meese S, Wojcik SM, Panou I et al. (2015a): Disruption of adaptor protein $2 \mu$ (AP-2 $\mu$ ) in cochlear hair cells impairs vesicle reloading of synaptic release sites and hearing. EMBO J $\underline{34}, 2686-2702$

Jung S, Oshima-Takago T, Chakrabarti R, Wong AB, Jing Z, Yamanbaeva G, Picher MM, Wojcik SM, Göttfert F, Predoehl F et al. (2015b): Rab3-interacting molecules $2 \alpha$ and $2 \beta$ promote the abundance of voltage-gated $\mathrm{CaV} 1.3 \mathrm{Ca} 2+$ channels at hair cell active zones. Proc Natl Acad Sci USA $\underline{112}$, E3141-3149

Kamp TJ, Pérez-García MT, Marban E (1996): Enhancement of ionic current and charge movement by coexpression of calcium channel beta 1A subunit with alpha 1C subunit in a human embryonic kidney cell line. J Physiol (Lond) 492 ( Pt 1), 89-96

Kemperman MH, Hoefsloot LH, Cremers CWRJ (2002): Hearing loss and connexin 26. J R Soc Med 95, 171-177

Khimich D, Nouvian R, Pujol R, Tom Dieck S, Egner A, Gundelfinger ED, Moser T (2005): Hair cell synaptic ribbons are essential for synchronous auditory signalling. Nature 434, 889-894

Kim SH, Kim BG, Kim JY, Roh KJ, Suh MJ, Jung J, Moon IS, Moon SK, Choi JY (2015): Electrogenic transport and $\mathrm{K}(+)$ ion channel expression by the human endolymphatic sac epithelium. Sci Rep $\underline{5}, 18110$

Knirsch M, Brandt N, Braig C, Kuhn S, Hirt B, Münkner S, Knipper M, Engel J (2007): Persistence of $\mathrm{Ca}(\mathrm{v}) 1.3 \mathrm{Ca} 2+$ channels in mature outer hair cells supports outer hair cell afferent signaling. J Neurosci 27, 6442-6451

Kollmar R, Fak J, Montgomery LG, Hudspeth AJ (1997): Hair cell-specific splicing of mRNA for the alpha1D subunit of voltage-gated Ca2+ channels in the chicken's cochlea. Proc Natl Acad Sci USA 94, 14889-14893 
Komune S, Huangfu M, Snow JB (1983): Mechanism of the production of the negative endocochlear DC potential in the guinea pig. Otolaryngol Head Neck Surg $\underline{91}$, 427434

Kudo T, Kure S, Ikeda K, Xia AP, Katori Y, Suzuki M, Kojima K, Ichinohe A, Suzuki Y, Aoki Y et al. (2003): Transgenic expression of a dominant-negative connexin26 causes degeneration of the organ of Corti and non-syndromic deafness. Hum Mol Genet $\underline{12}$, 995-1004

Kuhn S, Knirsch M, Rüttiger L, Kasperek S, Winter H, Freichel M, Flockerzi V, Knipper M, Engel J (2009): Ba2+ currents in inner and outer hair cells of mice lacking the voltage-dependent $\mathrm{Ca} 2+$ channel subunits beta3 or beta4. Channels (Austin) $\underline{3}$, 366-376

Kujawa SG, Liberman MC (2009): Adding insult to injury: cochlear nerve degeneration after „temporary“ noise-induced hearing loss. J Neurosci $\underline{29}$, 14077-14085

Kujawa SG, Liberman MC (2015): Synaptopathy in the noise-exposed and aging cochlea: Primary neural degeneration in acquired sensorineural hearing loss. Hear Res $\underline{330}$, 191-199

Le TN, Straatman LV, Lea J, Westerberg B (2017): Current insights in noise-induced hearing loss: a literature review of the underlying mechanism, pathophysiology, asymmetry, and management options. J Otolaryngol Head Neck Surg $\underline{46}$

Lee A, Wong ST, Gallagher D, Li B, Storm DR, Scheuer T, Catterall WA (1999): $\mathrm{Ca} 2+/$ calmodulin binds to and modulates P/Q-type calcium channels. Nature $\underline{399}$, $155-159$

Lee JR, Derosa AM, White TW (2009): Connexin mutations causing skin disease and deafness increase hemichannel activity and cell death when expressed in Xenopus oocytes. J Invest Dermatol $\underline{129}, 870-878$

Leitlinie Periphere Hörstörungen im Kindesalter. http://www.awmf.org/leitlinien/detail/ 11/049-010.html; abgerufen am 15.03.2017

Liberman LD, Wang H, Liberman MC (2011): Opposing gradients of ribbon size and AMPA receptor expression underlie sensitivity differences among cochlearnerve/hair-cell synapses. J Neurosci $\underline{31}$, 801-808

Liberman MC (1978): Auditory-nerve response from cats raised in a low-noise chamber. J Acoust Soc Am $\underline{63}, 442-455$

Liberman MC (2017): Noise-induced and age-related hearing loss: new perspectives and potential therapies. F1000Res $\underline{6}, 927$

Liberman MC, Dodds LW (1987): Acute ultrastructural changes in acoustic trauma: serialsection reconstruction of stereocilia and cuticular plates. Hear Res $\underline{26}, 45-64$

Ludolph A, Pickenhain L, Reichert H, Spitzer M. http://www.spektrum.de/lexikon/neurowissenschaft/cerebrospinalfluessigkeit/2007; abgerufen am 22.03.2017 
Maison SF, Usubuchi H, Liberman MC (2013): Efferent feedback minimizes cochlear neuropathy from moderate noise exposure. J Neurosci $\underline{33}, 5542-5552$

Marcus DC, Wu T, Wangemann P, Kofuji P (2002): KCNJ10 (Kir4.1) potassium channel knockout abolishes endocochlear potential. Am J Physiol Cell Physiol 282, C403407

Matsubara A, Laake JH, Davanger S, Usami S, Ottersen OP (1996): Organization of AMPA receptor subunits at a glutamate synapse: a quantitative immunogold analysis of hair cell synapses in the rat organ of Corti. J Neurosci $\underline{16}, 4457-4467$

Matthews G, Sterling P (2008): Evidence that vesicles undergo compound fusion on the synaptic ribbon. J Neurosci $\underline{28}, 5403-5411$

Matthews G, Fuchs P (2010): The diverse roles of ribbon synapses in sensory neurotransmission. Nat Rev Neurosci $\underline{11}, 812-822$

Meir A, Bell DC, Stephens GJ, Page KM, Dolphin AC (2000): Calcium channel beta subunit promotes voltage-dependent modulation of alpha 1 B by $\mathrm{G}$ beta gamma. Biophys J $\underline{79}, 731-746$

Melichar I, Syka J (1987): Electrophysiological measurements of the stria vascularis potentials in vivo. Hear Res $\underline{25}, 35-43$

Merchan-Perez A, Liberman MC (1996): Ultrastructural differences among afferent synapses on cochlear hair cells: correlations with spontaneous discharge rate. J Comp Neurol 371, 208-221

Meyer AC, Frank T, Khimich D, Hoch G, Riedel D, Chapochnikov NM, Yarin YM, Harke B, Hell SW, Egner A et al. (2009): Tuning of synapse number, structure and function in the cochlea. Nat Neurosci $\underline{12}, 444-453$

Michna M, Knirsch M, Hoda JC, Muenkner S, Langer P, Platzer J, Striessnig J, Engel J (2003): Cav1.3 (alpha1D) Ca2+ currents in neonatal outer hair cells of mice. J Physiol (Lond) 553, 747-758

Minor DL Jr, Findeisen F (2010): Progress in the structural understanding of voltage-gated calcium channel $(\mathrm{CaV})$ function and modulation. Channels (Austin) $\underline{4}, 459-474$

Møller AR: Hearing: anatomy, physiology, and disorders of the auditory system. 2. Auflage; Elsevier, Burlington 2006

Montagutelli X (2000): Effect of the genetic background on the phenotype of mouse mutations. J Am Soc Nephrol 11 Suppl 16, S101-105

Mori Y, Watanabe M, Inui T, Nimura Y, Araki M, Miyamoto M, Takenaka H, Kubota T (2009): $\mathrm{Ca}(2+)$ regulation of endocochlear potential in marginal cells. J Physiol Sci $\underline{59}, 355-365$

Moser T, Beutner D (2000): Kinetics of exocytosis and endocytosis at the cochlear inner hair cell afferent synapse of the mouse. Proc Natl Acad Sci USA 97, 883-888 
Moser T, Brandt A, Lysakowski A (2006): Hair cell ribbon synapses. Cell and Tissue Research $\underline{326}, 347-359$

Murakami M, Fleischmann B, de Felipe C, Freichel M, Trost C, Ludwig A, Wissenbach U, Schwegler H, Hofmann F, Hescheler J et al. (2002): Pain perception in mice lacking the beta3 subunit of voltage-activated calcium channels. J Biol Chem $\underline{277}$, 40342-40351

Murphy TH, Miyamoto M, Sastre A, Schnaar RL, Coyle JT (1989): Glutamate toxicity in a neuronal cell line involves inhibition of cystine transport leading to oxidative stress. Neuron $\underline{2}, 1547-1558$

Neef J, Gehrt A, Bulankina AV, Meyer AC, Riedel D, Gregg RG, Strenzke N, Moser T (2009): The $\mathrm{Ca} 2+$ channel subunit beta2 regulates $\mathrm{Ca} 2+$ channel abundance and function in inner hair cells and is required for hearing. J Neurosci $\underline{29}, 10730-10740$

Neef J, Jung S, Wong AB, Reuter K, Pangrsic T, Chakrabarti R, Kügler S, Lenz C, Nouvian R, Boumil RM et al. (2014): Modes and regulation of endocytic membrane retrieval in mouse auditory hair cells. J Neurosci $\underline{34}$, 705-716

Neely A, Wei X, Olcese R, Birnbaumer L, Stefani E (1993): Potentiation by the beta subunit of the ratio of the ionic current to the charge movement in the cardiac calcium channel. Science $\underline{262}, 575-578$

Nin F, Hibino H, Doi K, Suzuki T, Hisa Y, Kurachi Y (2008): The endocochlear potential depends on two $\mathrm{K}+$ diffusion potentials and an electrical barrier in the stria vascularis of the inner ear. Proc Natl Acad Sci U S A $\underline{105}$, 1751-1756

Nordmann AS, Bohne BA, Harding GW (2000): Histopathological differences between temporary and permanent threshold shift. Hear Res $\underline{139}, 13-30$

Nouvian R, Beutner D, Parsons TD, Moser T (2006): Structure and Function of the Hair Cell Ribbon Synapse. Journal of Membrane Biology 209, 153-165

Nouvian R, Neef J, Bulankina AV, Reisinger E, Pangršič T, Frank T, Sikorra S, Brose N, Binz T, Moser T (2011): Exocytosis at the hair cell ribbon synapse apparently operates without neuronal SNARE proteins. Nat Neurosci 14, 411-413

Obermair GJ, Schlick B, Di Biase V, Subramanyam P, Gebhart M, Baumgartner S, Flucher BE (2010): Reciprocal interactions regulate targeting of calcium channel beta subunits and membrane expression of alphal subunits in cultured hippocampal neurons. J Biol Chem 285, 5776-5791

Offner FF, Dallos P, Cheatham MA (1987): Positive endocochlear potential: mechanism of production by marginal cells of stria vascularis. Hear Res 29, 117-124

Ohlemiller KK, Echteler SM, Siegel JH (1991): Factors that influence rate-versus-intensity relations in single cochlear nerve fibers of the gerbil. J Acoust Soc Am 90, 274-287

Ohlemiller KK, Siegel JH (1994): Cochlear basal and apical differences reflected in the effects of cooling on responses of single auditory nerve fibers. Hear Res $\underline{80}, 174$ 190 
Ohlemiller KK, Siegel JH (1998): Temporal aspects of the effects of cooling on responses of single auditory nerve fibers. Hear Res $\underline{123}, 78-86$

Ohlemiller KK, Lett JM, Gagnon PM (2006): Cellular correlates of age-related endocochlear potential reduction in a mouse model. Hear Res $\underline{220}, 10-26$

Ohn TL, Rutherford MA, Jing S, Duque-Afonso CJ, Hoch G, Picher MM, Scharinger A, Strenzke N, Moser T (2016): Hair cells use active zones with different voltage dependence of $\mathrm{Ca} 2+$ influx to decompose sounds into complementary neural codes. Proc Natl Acad Sci USA $\underline{113}, 4716-4725$

Oshima A, Tani K, Hiroaki Y, Fujiyoshi Y, Sosinsky GE (2008): Projection structure of a $\mathrm{N}$-terminal deletion mutant of connexin 26 channel with decreased central pore density. Cell Commun Adhes $\underline{15}, 85-93$

Oshima A, Tani K, Toloue MM, Hiroaki Y, Smock A, Inukai S, Cone A, Nicholson BJ, Sosinsky GE, Fujiyoshi Y (2011): Asymmetric configurations and N-terminal rearrangements in connexin26 gap junction channels. J Mol Biol $\underline{405}, 724-735$

Ottersen OP, Takumi Y, Matsubara A, Landsend AS, Laake JH, Usami S (1998): Molecular organization of a type of peripheral glutamate synapse: the afferent synapses of hair cells in the inner ear. Prog Neurobiol 54, 127-148

Pangršič T, Lasarow L, Reuter K, Takago H, Schwander M, Riedel D, Frank T, Tarantino LM, Bailey JS, Strenzke N et al. (2010): Hearing requires otoferlin-dependent efficient replenishment of synaptic vesicles in hair cells. Nat Neurosci. $\underline{13}, 869-876$

Pangršič T, Reisinger E, Moser T (2012): Otoferlin: a multi-C2 domain protein essential for hearing. Trends Neurosci $\underline{35}, 671-680$

Perez-Reyes E, Castellano A, Kim HS, Bertrand P, Baggstrom E, Lacerda AE, Wei XY, Birnbaumer L (1992): Cloning and expression of a cardiac/brain beta subunit of the L-type calcium channel. J Biol Chem $\underline{267}, 1792-1797$

Peterson BZ, DeMaria CD, Adelman JP, Yue DT (1999): Calmodulin is the Ca2+ sensor for $\mathrm{Ca} 2+$-dependent inactivation of L-type calcium channels. Neuron $\underline{22}, 549-558$

Picher MM, Gehrt A, Meese S, Ivanovic A, Predoehl F, Jung S, Schrauwen I, Dragonetti AG, Colombo R, van Camp G et al. (2017): Ca2+-binding protein 2 inhibits Ca2+channel inactivation in mouse inner hair cells. Proc Natl Acad Sci USA $\underline{114}$, 17171726

Platzer J, Engel J, Schrott-Fischer A, Stephan K, Bova S, Chen H, Zheng H, Striessnig J (2000): Congenital deafness and sinoatrial node dysfunction in mice lacking class D L-type Ca2+ channels. Cell 102, 89-97

Puel JL, Ruel J, Gervais d'Aldin C, Pujol R (1998): Excitotoxicity and repair of cochlear synapses after noise-trauma induced hearing loss. Neuroreport $\underline{9}, 2109-2114$

Rabbitt RD, Brownell WE (2011): Efferent modulation of hair cell function. Curr Opin Otolaryngol Head Neck Surg $\underline{19}, 376-381$ 
Ravindran A, Lao QZ, Harry JB, Abrahimi P, Kobrinsky E, Soldatov NM (2008): Calmodulin-dependent gating of $\mathrm{Ca}(\mathrm{v}) 1.2$ calcium channels in the absence of $\mathrm{Ca}(\mathrm{v})$ beta subunits. Proc Natl Acad Sci USA $\underline{105}, 8154-8159$

Regus-Leidig H, Ott C, Löhner M, Atorf J, Fuchs M, Sedmak T, Kremers J, Fejtová A, Gundelfinger ED, Brandstätter JH (2013): Identification and immunocytochemical characterization of Piccolino, a novel Piccolo splice variant selectively expressed at sensory ribbon synapses of the eye and ear. PLoS ONE $\underline{8}$, e70373

Reijntjes DOJ, Pyott SJ (2016): The afferent signaling complex: regulation of type I spiral ganglion neuron responses in the auditory periphery. Hear Res $\underline{336}, 1-16$

Richard G, Rouan F, Willoughby CE, Brown N, Chung P, Ryynänen M, Jabs EW, Bale SJ, DiGiovanna JJ, Uitto J, Russell L (2002): Missense mutations in GJB2 encoding connexin-26 cause the ectodermal dysplasia keratitis-ichthyosis-deafness syndrome. Am J Hum Genet $\underline{70}$, 1341-1348

Roberts WM, Jacobs RA, Hudspeth AJ (1990): Colocalization of ion channels involved in frequency selectivity and synaptic transmission at presynaptic active zones of hair cells. J Neurosci $\underline{10}, 3664-3684$

Robertson D (1983): Functional significance of dendritic swelling after loud sounds in the guinea pig cochlea. Hear Res $\underline{9}, 263-278$

Robertson D, Paki B (2002): Role of L-type Ca2+ channels in transmitter release from mammalian inner hair cells. II. Single-neuron activity. J Neurophysiol $\underline{87}, 2734$ 2740

Rosenberg E, Spray DC, Reid LM (1992): Transcriptional and posttranscriptional control of connexin mRNAs in periportal and pericentral rat hepatocytes. Eur J Cell Biol $\underline{59}, 21-26$

Roux I, Safieddine S, Nouvian R, Grati M, Simmler MC, Bahloul A, Perfettini I, Le Gall M, Rostaing P, Hamard G et al. (2006): Otoferlin, defective in a human deafness form, is essential for exocytosis at the auditory ribbon synapse. Cell $\underline{127}, 277-289$

Ruel J, Wang J, Rebillard G, Eybalin M, Lloyd R, Pujol R, Puel JL (2007): Physiology, pharmacology and plasticity at the inner hair cell synaptic complex. Hear Res $\underline{227}$, $19-27$

Ruel J, Emery S, Nouvian R, Bersot T, Amilhon B, van Rybroek JM, Rebillard G, Lenoir M, Eybalin M, Delprat B et al. (2008a): Impairment of SLC17A8 encoding vesicular glutamate transporter-3, VGLUT3, underlies nonsyndromic deafness DFNA25 and inner hair cell dysfunction in null mice. Am J Hum Genet $\underline{83}$, 278292

Ruel J, Chabbert C, Nouvian R, Bendris R, Eybalin M, Leger CL, Bourien J, Mersel M, Puel JL (2008b): Salicylate enables cochlear arachidonic-acid-sensitive NMDA receptor responses. J Neurosci $\underline{28}, 7313-7323$ 
Rutherford MA, Moser T: The ribbon synapse between type I spiral ganglion neurons and inner hair cells. In: Dabdoub A, Fritsch B, Popper AN, Fay RR (Hrsg.): "The Primary Auditory Neurons of the Mammilian Cochlea" der Serie "Springer Handbook of Auditory Research". Springer, New York 2016, 117-156

Rutherford MA, Chapochnikov NM, Moser T (2012): Spike encoding of neurotransmitter release timing by spiral ganglion neurons of the cochlea. J Neurosci $\underline{32}, 4773-4789$

Rüttiger L, Sausbier M, Zimmermann U, Winter H, Braig C, Engel J, Knirsch M, Arntz C, Langer P, Hirt B et al. (2004): Deletion of the Ca2+-activated potassium (BK) alpha-subunit but not the BKbetal-subunit leads to progressive hearing loss. Proc Natl Acad Sci USA 101, 12922-12927

Ryan A, Dallos P (1975): Effect of absence of cochlear outer hair cells on behavioural auditory threshold. Nature 253, 44-46

Ryugo DK, Rosenbaum BT, Kim PJ, Niparko JK, Saada AA (1998): Single unit recordings in the auditory nerve of congenitally deaf white cats: morphological correlates in the cochlea and cochlear nucleus. J Comp Neurol 397, 532-548

Salt AN. http://oto2.wustl.edu/cochlea/intro3.htm; abgerufen am 20.03.2017

Salt AN, Melichar I, Thalmann R (1987): Mechanisms of endocochlear potential generation by stria vascularis. Laryngoscope $97,984-991$

Salvi RJ, Wang J, Ding D (2000): Auditory plasticity and hyperactivity following cochlear damage. Hear Res 147, 261-274

Schmitz F, Königstorfer A, Südhof TC (2000): RIBEYE, a component of synaptic ribbons: a protein's journey through evolution provides insight into synaptic ribbon function. Neuron $\underline{28}, 857-872$

Schrauwen I, Helfmann S, Inagaki A, Predoehl F, Tabatabaiefar MA, Picher MM, Sommen M, Zazo Seco C, Oostrik J, Kremer H et al. (2012): A mutation in CABP2, expressed in cochlear hair cells, causes autosomal-recessive hearing impairment. Am J Hum Genet 91, 636-645

Schütz M: Charakterisierung von Cx30 und Cx26 Punktmutationen in der Maus, die im Menschen zu syndromischer und nicht-syndromischer Taubheit führen. PhDThesis. Bonn 2011

Schütz M, Scimemi P, Majumder P, de Siati RD, Crispino G, Rodriguez L, Bortolozzi M, Santarelli R, Seydel A, Sonntag S et al. (2010): The human deafness-associated connexin $30 \mathrm{~T} 5 \mathrm{M}$ mutation causes mild hearing loss and reduces biochemical coupling among cochlear non-sensory cells in knock-in mice. Hum Mol Genet $\underline{19}$, 4759-4773

Seal RP, Akil O, Yi E, Weber CM, Grant L, Yoo J, Clause A, Kandler K, Noebels JL, Glowatzki E et al. (2008): Sensorineural deafness and seizures in mice lacking vesicular glutamate transporter 3. Neuron 57, 263-275 
Shen Y, Yu D, Hiel H, Liao P, Yue DT, Fuchs PA, Soong TW (2006): Alternative splicing of the $\mathrm{Ca}(\mathrm{v}) 1.3$ channel IQ domain, a molecular switch for $\mathrm{Ca} 2+$-dependent inactivation within auditory hair cells. J Neurosci 26, 10690-10699

Shen Z, Marcus DC, Sunose H, Chiba T, Wangemann P (1997): I(sK) Channel in strial marginal cells. Voltage-dependence, ion-selectivity, inhibition by $293 \mathrm{~B}$ and sensitivity to clofilium. Aud Neurosci $\underline{3}, 215-230$

Shepherd RK, Hardie NA (2001): Deafness-induced changes in the auditory pathway: implications for cochlear implants. Audiol Neurootol $\underline{6}$, 305-318

Silbernagl S, Klinke R (Hrsg.): Lehrbuch der Physiologie. 4. Auflage; Thieme, Stuttgart 2003

Söhl G, Willecke K (2004): Gap junctions and the connexin protein family. Cardiovasc Res $\underline{62}, 228-232$

Söhl G, Odermatt B, Maxeiner S, Degen J, Willecke K (2004): New insights into the expression and function of neural connexins with transgenic mouse mutants. Brain Res Brain Res Rev 47, 245-259

Stankovic K, Rio C, Xia A, Sugawara M, Adams JC, Liberman MC, Corfas G (2004): Survival of adult spiral ganglion neurons requires erbB receptor signaling in the inner ear. J Neurosci 24, 8651-8661

Strenzke N, Chanda S, Kopp-Scheinpflug C, Khimich D, Reim K, Bulankina AV, Neef A, Wolf F, Brose N, Xu-Friedman MA, Moser T (2009): Complexin-I is required for high-fidelity transmission at the endbulb of Held auditory synapse. J Neurosci 29 , 7991-8004

Sugawara M, Corfas G, Liberman MC (2005): Influence of supporting cells on neuronal degeneration after hair cell loss. J Assoc Res Otolaryngol $\underline{6}$, 136-147

Sun J, Ahmad S, Chen S, Tang W, Zhang Y, Chen P, Lin X (2005): Cochlear gap junctions coassembled from $\mathrm{Cx} 26$ and 30 show faster intercellular $\mathrm{Ca} 2+$ signaling than homomeric counterparts. Am J Physiol, Cell Physiol 288, C613-623

Sun Y, Tang W, Chang Q, Wang Y, Kong W, Lin X (2009): Connexin30 null and conditional connexin26 null mice display distinct pattern and time course of cellular degeneration in the cochlea. J Comp Neurol 516, 569-579

Szatkowski M, Barbour B, Attwell D (1990): Non-vesicular release of glutamate from glial cells by reversed electrogenic glutamate uptake. Nature $\underline{348}, 443-446$

Taberner AM, Liberman MC (2005): Response properties of single auditory nerve fibers in the mouse. J Neurophysiol 93, 557-569

Tadross MR, Ben Johny M, Yue DT (2010): Molecular endpoints of Ca2+/calmodulin- and voltage-dependent inactivation of $\mathrm{Ca}(\mathrm{v}) 1.3$ channels. J Gen Physiol $\underline{135}, 197-215$

Takahashi SX, Mittman S, Colecraft HM (2003): Distinctive modulatory effects of five human auxiliary beta2 subunit splice variants on L-type calcium channel gating. Biophys J $\underline{84}, 3007-3021$ 
Takeuchi S, Ando M, Kozakura K, Saito H, Irimajiri A (1995): Ion channels in basolateral membrane of marginal cells dissociated from gerbil stria vascularis. Hear Res $\underline{83}$, $89-100$

Takeuchi S, Ando M (1999): Voltage-dependent outward K(+) current in intermediate cell of stria vascularis of gerbil cochlea. Am J Physiol 277, C91-99

Takeuchi S, Ando M, Kakigi A (2000): Mechanism generating endocochlear potential: role played by intermediate cells in stria vascularis. Biophys J $\underline{79}, 2572-2582$

Tan S, Sagara Y, Liu Y, Maher P, Schubert D (1998): The regulation of reactive oxygen species production during programmed cell death. J Cell Biol 141, 1423-1432

Teubner B, Michel V, Pesch J, Lautermann J, Cohen-Salmon M, Söhl G, Jahnke K, Winterhager E, Herberhold C, Hardelin JP et al. (2003): Connexin30 (Gjb6)deficiency causes severe hearing impairment and lack of endocochlear potential. Hum Mol Genet 12, 13-21

Titeux M, Mendonça V, Décha A, Moreira E, Magina S, Maia A, Lacaze-Buzy L, Mejía JE, Torrão L, Carvalho F et al. (2009): Keratitis-ichthyosis-deafness syndrome caused by GJB2 maternal mosaicism. J Invest Dermatol 129, 776-779

Traynelis SF, Wollmuth LP, McBain CJ, Menniti FS, Vance KM, Ogden KK, Hansen KB, Yuan H, Myers SJ, Dingledine R (2010): Glutamate receptor ion channels: structure, regulation, and function. Pharmacol Rev $\underline{62}, 405-496$

van Camp G, Smith R. http://hereditaryhearingloss.org/; abgerufen am 15.03.2017

van Petegem F, Clark KA, Chatelain FC, Minor DL Jr (2004): Structure of a complex between a voltage-gated calcium channel beta-subunit and an alpha-subunit domain. Nature $\underline{429}, 671-675$

Vetter DE, Mann JR, Wangemann P, Liu J, McLaughlin KJ, Lesage F, Marcus DC, Lazdunski M, Heinemann SF, Barhanin J (1996): Inner ear defects induced by null mutation of the isk gene. Neuron $\underline{17}, 1251-1264$

Vogl C, Cooper BH, Neef J, Wojcik SM, Reim K, Reisinger E, Brose N, Rhee JS, Moser T, Wichmann C (2015): Unconventional molecular regulation of synaptic vesicle replenishment in cochlear inner hair cells. J Cell Sci 128, 638-644

von Bekesy G (1952): Resting potentials inside the cochlear partition of the guinea pig. Nature $\underline{169}, 241-242$

Waithe D, Ferron L, Page KM, Chaggar K, Dolphin AC (2011): Beta-subunits promote the expression of $\mathrm{Ca}(\mathrm{V}) 2.2$ channels by reducing their proteasomal degradation. J Biol Chem 286, 9598-9611

Walker EA, Holte L, McCreery RW, Spratford M, Page T, Moeller MP (2015): The influence of hearing aid use on outcomes of children with mild hearing loss. J Speech Lang Hear Res $\underline{58}, 1611-1625$

Walsh EJ, McGee J (1987): Postnatal development of auditory nerve and cochlear nucleus neuronal responses in kittens. Hear Res $\underline{28}, 97-116$ 
Wan G, Gómez-Casati ME, Gigliello AR, Liberman MC, Corfas G (2014): Neurotrophin-3 regulates ribbon synapse density in the cochlea and induces synapse regeneration after acoustic trauma. Elife $\underline{3}$

Wang Y, Hirose K, Liberman MC (2002): Dynamics of noise-induced cellular injury and repair in the mouse cochlea. J Assoc Res Otolaryngol $\underline{3}, 248-268$

Wangemann P (2002): $\mathrm{K}(+)$ cycling and its regulation in the cochlea and the vestibular labyrinth. Audiol Neurootol $\underline{7}, 199-205$

Wangemann P (2006): Supporting sensory transduction: cochlear fluid homeostasis and the endocochlear potential. The Journal of Physiology $\underline{576}, 11-21$

Webster M, Webster DB (1981): Spiral ganglion neuron loss following organ of Corti loss: a quantitative study. Brain Res $\underline{212}, 17-30$

Wei XY, Perez-Reyes E, Lacerda AE, Schuster G, Brown AM, Birnbaumer L (1991): Heterologous regulation of the cardiac $\mathrm{Ca} 2+$ channel alpha 1 subunit by skeletal muscle beta and gamma subunits. Implications for the structure of cardiac L-type Ca2+ channels. J Biol Chem 266, 21943-21947

Weissgerber P, Held B, Bloch W, Kaestner L, Chien KR, Fleischmann BK, Lipp P, Flockerzi V, Freichel M (2006): Reduced cardiac L-type Ca2+ current in $\mathrm{Ca}(\mathrm{V})$ beta2-/- embryos impairs cardiac development and contraction with secondary defects in vascular maturation. Circ Res $\underline{99}$, 749-757

White JA, Burgess BJ, Hall RD, Nadol JB (2000): Pattern of degeneration of the spiral ganglion cell and its processes in the C57BL/6J mouse. Hear Res $\underline{141}, 12-18$

WHO. http://www.who.int/pbd/deafness/estimates/en/; abgerufen am 15.03.2017

Wise AK, Tu T, Atkinson PJ, Flynn BO, Sgro BE, Hume C, O’Leary SJ, Shepherd RK, Richardson RT (2011): The effect of deafness duration on neurotrophin gene therapy for spiral ganglion neuron protection. Hear Res $\underline{278}$, 69-76

Wong AB, Jing Z, Rutherford MA, Frank T, Strenzke N, Moser T (2013): Current maturation of inner hair cell synaptic $\mathrm{Ca} 2+$ influx and auditory nerve spontaneous activity around hearing onset in mice. J Neurosci $\underline{33}$, 10661-10666

Wong AB, Rutherford MA, Gabrielaitis M, Pangrsic T, Göttfert F, Frank T, Michanski S, Hell S, Wolf F, Wichmann C, Moser T (2014): Developmental refinement of hair cell synapses tightens the coupling of Ca2+ influx to exocytosis. EMBO J 33, 247264

Xiong H, Chu H, Zhou X, Huang X, Cui Y, Zhou L, Chen J, Li J, Wang Y, Chen Q, Li Z (2011): Simultaneously reduced NKCC1 and Na,K-ATPase expression in murine cochlear lateral wall contribute to conservation of endocochlear potential following a sensorineural hearing loss. Neurosci Lett $\underline{488}, 204-209$

Yang H, Xiong H, Huang Q, Pang J, Zheng X, Chen L, Yu R, Zheng Y (2013): Compromised potassium recycling in the cochlea contributes to conservation of endocochlear potential in a mouse model of age-related hearing loss. Neurosci Lett $\underline{555}, 97-101$ 
Yang PS, Alseikhan BA, Hiel H, Grant L, Mori MX, Yang W, Fuchs PA, Yue DT (2006): Switching of $\mathrm{Ca} 2+$-dependent inactivation of $\mathrm{Ca}(\mathrm{v}) 1.3$ channels by calcium binding proteins of auditory hair cells. J Neurosci 26, 10677-10689

Yin Y, Liberman LD, Maison SF, Liberman MC (2014): Olivocochlear innervation maintains the normal modiolar-pillar and habenular-cuticular gradients in cochlear synaptic morphology. J Assoc Res Otolaryngol 15, 571-583

Yu Q, Chang Q, Liu X, Wang Y, Li H, Gong S, Ye K, Lin X (2013): Protection of spiral ganglion neurons from degeneration using small-molecule TrkB receptor agonists. J Neurosci $\underline{33}$, 13042-13052

Yum SW, Zhang J, Valiunas V, Kanaporis G, Brink PR, White TW, Scherer SS (2007): Human connexin 26 and connexin30 form functional heteromeric and heterotypic channels. Am J Physiol, Cell Physiol 293, C1032-1048

Zampini V, Johnson SL, Franz C, Lawrence ND, Münkner S, Engel J, Knipper M, Magistretti J, Masetto S, Marcotti W (2010): Elementary properties of CaV1.3 $\mathrm{Ca}(2+)$ channels expressed in mouse cochlear inner hair cells. J Physiol (Lond) $\underline{588}, 187-199$

Zanazzi G, Matthews G (2009): The molecular architecture of ribbon presynaptic terminals. Mol Neurobiol 39, 130-148

Zettl UK, Lehmitz R, Mix E (Hrsg.): Klinische Liquordiagnostik. 2. Auflage. Walter de Gruyter, Berlin 2005

Zhang Y, Tang W, Ahmad S, Sipp JA, Chen P, Lin X (2005): Gap junction-mediated intercellular biochemical coupling in cochlear supporting cells is required for normal cochlear functions. Proc Natl Acad Sci USA 102, 15201-15206

Zhao HB (2005): Connexin26 is responsible for anionic molecule permeability in the cochlea for intercellular signalling and metabolic communications. Eur J Neurosci $\underline{21}, 1859-1868$

Zhao HB, Yu N (2006): Distinct and gradient distributions of connexin26 and connexin30 in the cochlear sensory epithelium of guinea pigs. J Comp Neurol $\underline{499}, 506-518$

Zheng J, Shen W, He DZ, Long KB, Madison LD, Dallos P (2000): Prestin is the motor protein of cochlear outer hair cells. Nature $\underline{405}, 149-155$

Zidanic M, Brownell WE (1990): Fine structure of the intracochlear potential field. I. The silent current. Biophys J $\underline{57}, 1253-1268$

Zilberstein Y, Liberman MC, Corfas G (2012): Inner hair cells are not required for survival of spiral ganglion neurons in the adult cochlea. J Neurosci $\underline{32}$, 405-410 


\section{Danksagung}

Danken möchte ich Tobias Moser für die Überlassung des Themas und die geduldige Ausbildung im wissenschaftlichen Arbeiten mit viel persönlichem Engagement. Nicola Strenzke danke ich für die Vorbereitung und Vermittlung der technischen und methodischen Grundlagen sowie die sehr individuelle Begleitung des Promotionsprojektes und meiner anschließenden beruflichen Entwicklung.

Gerhard Hoch bin ich dankbar für die Schaffung und Betreuung der technischen Infrastruktur für die komplexen Versuchsanordnungen. Jakob Neef danke ich für die sehr kollegiale und hilfsbereite Zusammenarbeit. Melanie Schütz möchte ich für die gemeinsame Arbeit am Mausmodell danken. Allen Mitarbeitern des Innenohrlabors danke ich für die immer konstruktive Atmosphäre und gute Zusammenarbeit. 